University of New Orleans

ScholarWorks@UNO

University of New Orleans Theses and

Dissertations

Dissertations and Theses

$5-22-2006$

\title{
A Comparison of Body Composition between Eumenorrheic and Amenorrheic Adolescent Cross-Country Runners
}

Marc Bonis

University of New Orleans

Follow this and additional works at: https://scholarworks.uno.edu/td

\section{Recommended Citation}

Bonis, Marc, "A Comparison of Body Composition between Eumenorrheic and Amenorrheic Adolescent Cross-Country Runners" (2006). University of New Orleans Theses and Dissertations. 380.

https://scholarworks.uno.edu/td/380

This Dissertation is protected by copyright and/or related rights. It has been brought to you by ScholarWorks@UNO with permission from the rights-holder(s). You are free to use this Dissertation in any way that is permitted by the copyright and related rights legislation that applies to your use. For other uses you need to obtain permission from the rights-holder(s) directly, unless additional rights are indicated by a Creative Commons license in the record and/ or on the work itself.

This Dissertation has been accepted for inclusion in University of New Orleans Theses and Dissertations by an authorized administrator of ScholarWorks@UNO. For more information, please contact scholarworks@uno.edu. 


\title{
A COMPARISON OF BODY COMPOSITION BETWEEN EUMENORRHEIC AND AMENORRHEIC ADOLESCENT CROSS-COUNTRY RUNNERS
}

\author{
A Dissertation \\ Submitted to the Graduate Faculty of the \\ University of New Orleans \\ in partial fulfillment of the \\ requirements for the degree of \\ Doctor of Philosophy \\ in \\ Curriculum and Instruction \\ and \\ Human Performance and Health Promotion
}

by

Marc P. Bonis

B.S., Loyola University of New Orleans, 1968

M.B.A., Tulane University, 1980

M.A., University of New Orleans, 2002

May 2006 
(C) Copyright, 2006, Marc P. Bonis 


\section{Acknowledgements}

My two major advisors, Dr. J. Mark Loftin and Dr. Richard Speaker have freely and graciously provided their expertise, recommendations, direction, support, time and energy to which I am greatly indebted.

The other members of my doctoral committee, Dr. Bobby Eason, Dr. Roger DeSanti, and Dr. Anthony Kontos have been sources of constructive comments, suggestions, and assistance. I truly appreciate their input.

The administration, cross-country coaching staff, parents, and student-athletes from Mount Carmel Academy have been very accommodating and enthusiastic regarding the research. I am thankful for their cooperation.

Finally, my wife, Darlene, and sons, Lance and Mark, have been constant sources of encouragement and have been extremely patient. Their understanding and cooperation has helped bring this study to a reality. 
List of Tables .......................................................................................... vii

List of Figures...................................................................................................... viii

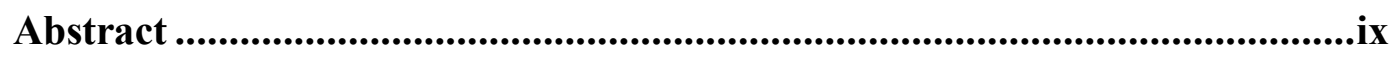

Chapter 1: Introduction.........................................................................1

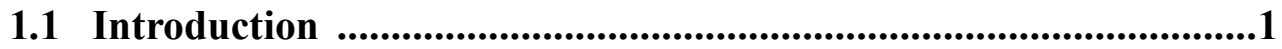

1.2 Research Question ......................................................................5

1.3 Purpose .......................................................................................6

1.4 Theoretical Framework .............................................................6

1.5 Statement of Problem .................................................................7

1.6 Research Questions...................................................................7

1.7 Method of Investigation ...............................................................8

1.8 Need for the Study $\quad$................................................................................8

1.9 Limitations .....................................................................................9

1.10 Delimitations ..................................................................................9

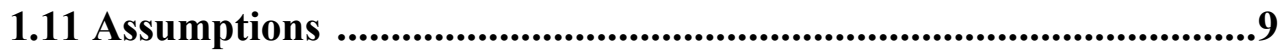

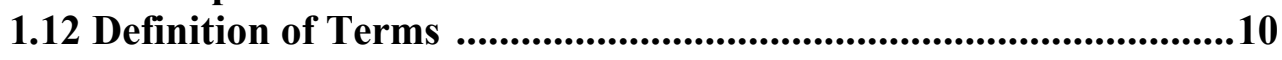

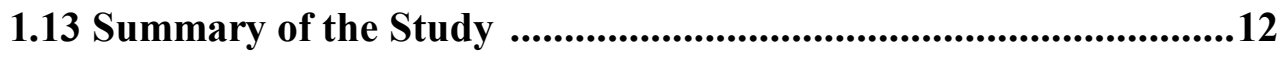

Chapter 2: Review of Literature ..............................................................13

2.1 Bone Development ...............................................................13

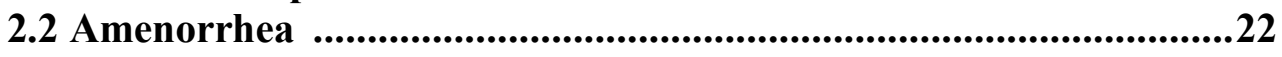

Chapter 3: Methodology .........................................................................................34

3.1 Participants .....................................................................................34

3.2 Instrumentation ....................................................................................35

3.3 Procedures for Conducting the Study ............................................36

3.4 Data Analysis Procedure ..............................................................37

3.5 Research Issues ..........................................................................40

Chapter 4: Results ..............................................................................................42

4.1 Overview ......................................................................................42

4.2 Participant Data .............................................................................44

4.3 Bone Mineral Density \& Body Composition.....................................47

4.4 Performance \& Training Volume .......................................................61 


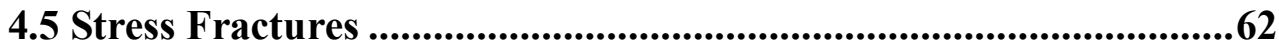

4.6 Nutritional Supplementation..............................................................63

4.7 Predictor Variables for BMD ........................................................63

4.8 Results by Research Questions.............................................................67

4.8.1 Does Exercise-Associated Amenorrhea Affect Performance in Adolescent Cross-Country Runners? ...................................67

4.8.2 Is Bone Mineral Density Affected by Exercise-Associated Amenorrhea in Adolescent Cross-Country Runners? ..........68

4.8.3 Is Body Composition Affected by Exercise-Associated Amenorrhea in Adolescent Cross-Country Runners? ..........68

4.8.4 Is Bodyweight Affected by Exercise-Associated Amenorrhea in Adolescent Cross-Country Runners? ..................................68

4.8.5 Is Bone Mineral Density Affected by Cross-Country Running in Adolescent Cross-Country Runners? .................................69

4.8.6 Is the Incidence of Stress Fractures Greater in Amenorrheic Adolescent Cross-Country Runners than in Eumenorrheic Adolescent Cross-Country Runners? ....................................69

4.8.7 Is There Less Nutritional Supplementation by Amenorrheic Adolescent Cross-Country Runners than by Eumenorrheic Adolescent Cross-Country Runners? ....................................69

4.8.8 Is Bodyweight the Best Predictor of Bone Mineral Density in Adolescent Cross-Country Runners? ......................................70

4.9 Summary ..................................................................................................70

Chapter 5: Discussion ...............................................................................................72

5.1 Overview ...........................................................................................72

5.2 Purpose of Study ....................................................................................72

5.3 Summary of the Findings .......................................................................73

5.4 Discussion of the Findings ......................................................................74

5.5 Recommendations for Future Research ........................................90

5.6 Implications ...............................................................................................92

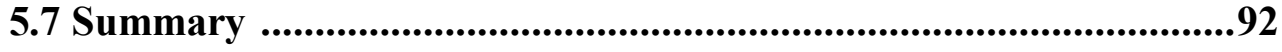

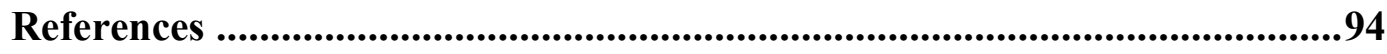

Appendices .....................................................................................................103

Appendix A - Data Questionnaire ............................................................103

Appendix B - Raw Data ..............................................................................105

Appendix C - Detailed Results of Paired t-tests ......................................112

Appendix D - Detailed Results of Multivariate Analyses ......................116 
Appendix E - Human Subjects Approval..............................................125

Appendix F - Informed Consent Form..............................................127

Appendix G - Child's Assent Form ...................................................132

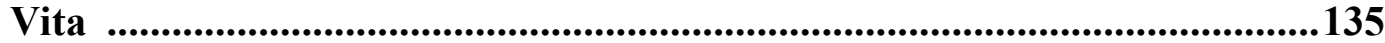




\section{List of Tables}

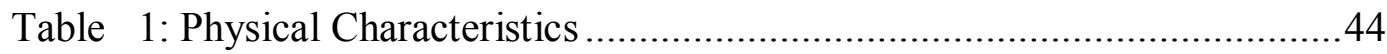

Table 2: Physical Characteristics - Preseason vs. Post-Season by Subgroup ......46

Table 3: Preseason Body Composition Associations .........................................48

Table 4: Post-Season Body Composition Associations ….................................48

Table 5: BMD Associations Among Body Composition Components ...............49

Table 6: BMD Subgroup Associations Among Body Composition

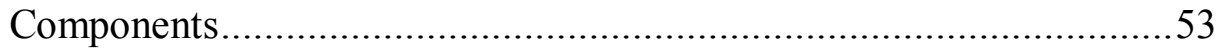

Table 7: Menstrual Dysfunction Associations .................................................54

Table 8: Summary of Multivariate Analysis of Significant Subgroup

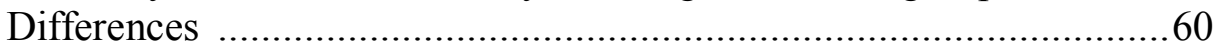

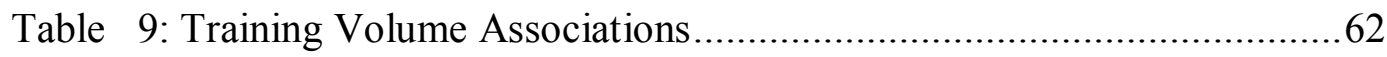

Table 10: Coefficients of Determination of Predictor Variables............................64

Table 11: Physical Characteristics and Training Regimens by Subgroup of Adult and Adolescent Cross-Country Runners .................................79

Table 12: Overall Seasonal Changes of Body Composition Components...........113

Table 13: Seasonal Changes of Body Composition Components by Subgroup.. 114

Table 14: Paired t-test Results of Variables, Overall and by Subgroup...............115

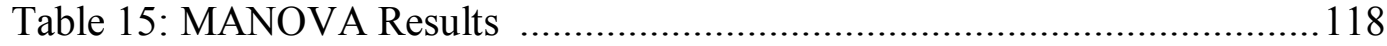

Table 16: ANOVA Results .........................................................................119

Table 17: MANCOVA Results - Controlled for Skeletal Maturity ...................121

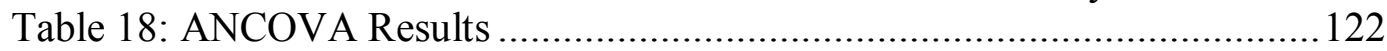

Table 19: MANCOVA Results - Controlled for Skeletal Maturity \&

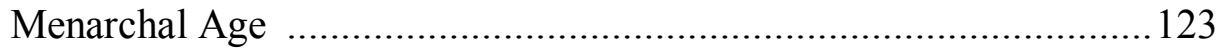

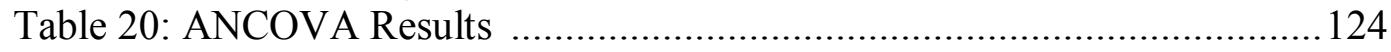




\section{List of Figures}

Figure 1: Scatterplot of Overall Post-Season BMD vs. Post-Season

Bodyweight ......................................................................... 51

Figure 2: Scatterplot of Overall Post-Season BMD vs. Post-Season Lean

Tissue .........................................................................................51

Figure 3: Scatterplot of Overall Post-Season BMD vs. Post-Season Fat

Tissue ...................................................................................52

Figure 4: Scatterplot of Overall Post-Season BMD vs. Post-Season Body

Mass Index ...................................................................................52

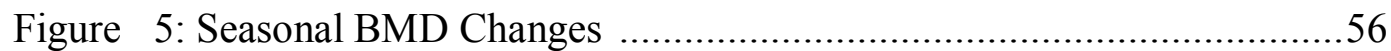

Figure 6: Seasonal BMD z-score Changes .................................................57

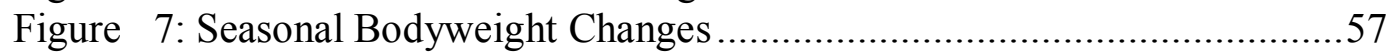

Figure 8: Seasonal Fat Tissue Changes .....................................................58

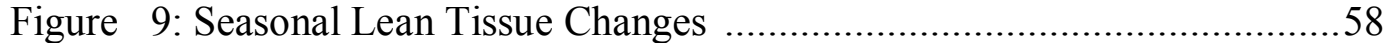

Figure 10: Predictor Variable - Bodyweight ..............................................65

Figure 11: Predictor Variable - Bodyweight - Amenorrheic Subgroup ..............66

Figure 12: Predictor Variable - Lean Tissue - Eumenorrheic Subgroup .............67 


\begin{abstract}
Purpose: The purpose of the study was to examine the relationship and comparisons of athletic amenorrhea and bone mineral density in adolescent, cross-country runners. Subjects: Twentyeight female adolescent cross-country runners (Mean Age $\pm \mathrm{SD}=15.0 \pm 1.3$ years); consisting of seventeen eumenorrheics \& eleven amenorrheics. Design: The design consisted of a six-month longitudinal design in which the subjects were measured before and after cross-country season for height, weight, and lean tissue (LT), body fat (BF), bone mineral content (BMC), and bone mineral density (BMD) using whole-body scan densitiometry with a Lunar Dual-energy X-ray Absorptiometer (DXA). Run performance, weekly training volumes, menstrual dysfunction, menarchal age, nutritional information, and stress fractures were reported by the subjects.

Statistical analyses consisted of Pearson product-moment and partial correlations to examine the associations of the variables, paired t-tests to measure seasonal body composition changes, multivariate analysis (MANOVA \& MANCOVA) to investigate the subgroup differences of variables, and simple linear regression to determine the best body composition predictor variable for BMD. Results: The eumenorrheic subgroup's BMD was significantly greater than the amenorrheic subgroup's BMD $\left(\mathrm{F}(1,54)=16.22, \mathrm{p}<.05\right.$, partial $\left.\eta^{2}=.231\right)$. The eumenorrheic subgroup's bodyweight $\left(\mathrm{F}(1,54)=7.65, \mathrm{p}<.05\right.$, partial $\left.\eta^{2}=.124\right), \mathrm{BF}(\mathrm{F}(1,54)=8.56, \mathrm{p}<.05$, partial $\left.\eta^{2}=.137\right)$, and $\mathrm{BMC}\left(\mathrm{F}(1,54)=8.52, \mathrm{p}<.05\right.$, partial $\left.\eta^{2}=.136\right)$ were significantly greater than the amenorrheic subgroup. There was also a significant seasonal increase in BMD $(\mathrm{t}(27)=-$ $4.01, \mathrm{p}<.05)$ for the overall group. Bodyweight was the body composition component that best predicted $\mathrm{BMD}\left(\mathrm{F}(1,26)=46.434, \mathrm{p}<.05, \mathrm{R}^{2}=.641\right)$. There were no significant subgroup differences with respect to run performance, stress fractures, and nutritional supplementation. Conclusions: Athletic amenorrhea was highly associated with lower levels of BMD in adolescent, cross-country runners. Athletic amenorrhea was also highly associated with lower levels of bodyweight, BF, and BMC in adolescent cross-country runners. Finally, cross-country running was highly associated with increased BMD in adolescent athletes. Implications: The long-term implication of the study is that subjects with lower levels of BMD may be at a greater risk of osteoporosis. Recommendations: Educate and instruct runners to utilize proper training methods so the healthful benefits of cross-country running, as well as improved performance, are obtained.
\end{abstract}




\section{Chapter I}

\section{Introduction}

\subsection{Introduction}

Osteoporosis is a worldwide public health problem because it increases the risk of bone fracture. It is characterized by a significant reduction of bone mass and structural deterioration of bone tissue, leading to an increased susceptibility to fractures, especially of the hip, spine and wrist, although any bone can be affected. In the United States, 10 million individuals have been diagnosed with the disease and almost 34 million more Americans are estimated to have low bone mass, placing them at risk of osteoporosis. Of the 10 million Americans diagnosed with osteoporosis, 8 million are women and 2 million are men. The disease is responsible for more than 1.5 million fractures annually, including 300,000 hip fractures, 700,000 vertebral fractures, 250,000 wrist fractures, and 300,000 fractures at other sites. The estimated national direct expenditures in hospitals and nursing homes for osteoporotic hip fractures were $\$ 18$ billion dollars in 2002, and the costs are rising. Osteoporosis is often called a "silent disease" because bone loss occurs without symptoms. People may not know that they have the disease until their bones become so weak that a sudden strain, bump or fall causes a bone to fracture or a vertebra to collapse. While the disease primarily occurs later in life, it can occur during growth (Peck, Riggs, \& Bell, 2004). Because most available treatments of osteoporosis do not significantly restore previously lost bone (Drinkwater, Nelson, Chestnut, Bremner, \& Shainholtz, 1984), there is a growing emphasis on osteoporosis prevention. At present there are two approaches to reducing the risk of osteoporosis: increasing peak bone mass at skeletal maturity and reducing the rate of bone loss after menopause. The first 
approach, attaining a maximal bone mass at skeletal maturity, is considered the better approach of the two (Hallberg, 2004; Newton-John \& Morgan, 1970), and sports participation is one method to this approach.

One of the advantages of sport participation is that physical activity promotes strong bones and reduces the long-term risk of osteoporosis (Beck \& Snow, 2003; Botwinick, et al., 1989); but for female athletes who suffer from athletic or exerciseassociated amenorrhea (EAA), increased physical activity actually puts them at greater risk of osteoporosis later in life (Drinkwater, 1984; Drinkwater, Breumner, \& Chestnut, 1990; Dueck, Matt, Manore, \& Skinner, 1996). Interestingly, increased physical activity is normally associated with increased bone density (Beck \& Snow, 2003). The fact that physical activity has been shown to inhibit and even reverse some bone loss in postmenopausal women would seem to indicate that increased physical activity would exert a protective effect against bone loss in the female athletes in question (Gutin \& Kasper, 1992; Vainionpaa, 2004). However, the frequency, duration, and intensity of training levels for female athletes may be the key to this confounding problem.

The increased popularity of female athletics in the last two to three decades has brought high performance expectations and demanding training levels to women's competitive sports. Today, competitive female athletes train as hard as their male counterparts. However, female athletes have greater physiological issues compared to male athletes such as menstrual dysfunction, reproductive disorders, and musculoskeletal differences (Bungum \& Vincent, 1997; Dueck, Matt, Manore, \& Skinner, 1996). Because of these physiological differences, women are more at risk than male athletes to develop health problems from the same intense training levels of exercise duration, frequency, 
and intensity (Loucks, 1985). Although most female athletes meet these training demands without harm or incidence, some female athletes, especially those associated with weightrelated or image-related sports, experience negative consequences, such as irregular menses or the complete cessation of menstrual function. If energy intake does not meet the demands of intense training requirements, a significant energy deficit will result. It has been suggested that the cessation of menstruation is an adaptation by the body to compensate for the large metabolic demands that are not met by inadequate energy intakes, especially when energy demands are high (Warren, 1983). The specific circumstances that initiate the onset and reversal of athletic menstrual dysfunction remain unclear. The underlying mechanisms are not known, and it has not been determined whether amenorrhea is a single entity or a combination of several metabolic and hormonal abnormalities producing a common syndrome. It is clear, however, that the female athlete who is undergoing intensive training is at a much greater risk for developing menstrual dysfunction than her sedentary counterpart (Bullen, Skrinar, Beitins, VonMering, Turnball, \& McArthur, 1985).

Female cross-country runners fall into a group potentially prone to primary and secondary amenorrhea (Cobb, et al., 2003). Amenorrhea is a condition caused by the female body reacting to an intense physical stress by putting the reproductive functions second to survival. This condition is known as exercise-associated amenorrhea and it has been related to higher injury rates and lower bone density in female athletes (Drinkwater, 1984). The high volume of physical training associated with competition may inhibit the neuroendocrine system, particularly the hypothalamic-pituitary-ovarian axis (Loucks, Mortola, Girton, \& Yen, 1989). Amenorrheic athletes typically display reduced levels of 
estradiol and progesterone and have hormonal profiles more similar to postmenopausal women than to those of their age-matched counterparts (Loucks \& Horvath, 1984). The reduced levels of estrogen associated with amenorrhea may prevent the formation of adequate bone density (Drinkwater, 1992). Although the precise mechanism by which estrogen affects bone mineralization is unknown, numerous studies have shown that low estrogen levels, such as those observed after surgery or natural menopause, are associated with low levels of skeletal bone density (Dhuper, Warren, Brooks-Gunn \& Fox, 1990). Many physicians prescribe hormone therapy or place amenorrheic athletes on oral contraceptives in order to treat the hypoestrogenemia associated with amenorrhea and to reduce the risk of developing poor bone density (Highet, 1989). Unfortunately, many female athletes associate oral contraceptive use with performance-hindering side effects such as nausea, fatigue, and weight increase and, consequently, avoid seeking appropriate medical attention for their menstrual dysfunction. However, prolonged periods of low estrogen levels increase the risk of stress fractures and the development of osteoporosis later in life.

The prevalence of this problem in female athletes who compete in image- or sizerelated sports is dramatic (Wolman, Faulmann, Clark, Hesp, \& Harries, 1991). Image- or size-related sports, such as figure skating, gymnastics, and cross-country running, require athletes to possess a certain aesthetic body image or lean body type. It is an issue that must be of concern to female athletes. Although this problem has been researched considerably using collegiate and post-collegiate athletes (Loucks, 1985; Rencken, Chestnut, \& Drinkwater, 1996; Risser, Lee, \& Leblanc, 1990), there has been relatively little research in this area directed toward high school female athletes. In fifty-five studies 
cited in a literary review by Gutin and Kasper (1992) investigating the relationship of vigorous exercise to bone mineral density (BMD), none of the subjects were less than 18 years old. There have, however, been a few studies that investigated related topics of female adolescents. Torstveit \& Sundgot-Borgen (2005) studied the incidence of the female athlete triad on both the senior and junior level of female athletes on the 2002 national Norwegian teams consisting of sixty-six different sports or events; however, the research design consisted solely of a questionnaire mailed to the athletes. They concluded that elite athletes competing in lean or low body weight sports were more at risk than elite athletes competing in sports that are not associated with leanness or low body weight. Dhuper, Warren, Brooks-Gunn and Fox (1990) investigated the association between bone mineral density and estrogen levels of forty-three female subjects between the ages of 13-20 years. Twenty-eight of the subjects were dancers, fifteen were not physically active. Estrogen levels were obtained by a score based on physiological events and bone mineral density was measured using dual photon absorptiometry. They concluded that bone mass in the active adolescent is affected by the absence of estrogen exposure. Their research design did not investigate the changes of bone mineral density of the subjects over a period of time. The proposed study was designed to measure the changes of bone mineral density of female high school cross-country runners before and after a cross-country season.

\subsection{Research Question}

Is there a difference in bone mineral density between amenorrheic and eumenorrheic (normally menstruating) high school cross-country runners? 


\subsection{Purpose of the Study}

The purpose of the study was to examine the relationship of athletic amenorrhea and bone mineral density in adolescent cross-country runners.

\subsection{Theoretical Framework}

It has been theorized that female athletes may be at a greater risk of osteoporosis later in life if they are affected by amenorrhea (Modlesky \& Lewis, 2002). The seminal study regarding this area of research was conducted by Drinkwater (1984) which was the catalyst for numerous studies to examine the association between amenorrheic athletes and lower levels of bone mineral density as compared to their eumenorrheic counterparts (Drinkwater, 1992; Drinkwater, Bruemner, \& Chestnut, 1990; Drinkwater, Nelson, Chestnut, Bruemner, \& Shainholtz, 1984; Drinkwater, Nelson, Ott, \& Chestnut, 1986; Nattiv, Agostini, Drinkwater, \& Yeager, 1994). Some of these studies concluded that lower levels of bone mineral density were strongly associated with menstrual dysfunction which causes reduced levels of estrogen, a trigger for bone growth (Drinkwater, 1984 \& 1992; Nattiv, Agostini, Drinkwater, \& Yeager, 1994; Williams et al., 1995). This is a special concern for female athletes that participate in sports that are weight- or sizesensitive, such as figure-skating, gymnastics, or cross-country running, because the incidence of athletic amenorrhea is considerably greater for them than for female athletes that participate in other sports (Wolman, Faulmann, Clark, Hesp, \& Harries, 1991). This research was used as the theoretical framework for the current study. 


\subsection{Statement of the Problem}

The problem is if an insufficient level of bone mineral density is attained during the adolescent period of growth, there may be an increased risk of osteoporosis later in life (Modlesky \& Lewis, 2002). While training, the menstrual cycle of female athletes can be disrupted or can cease to function in association with intense training and/or disordered eating (Nattiv, Agostini, Drinkwater, \& Yeager, 1994). This can result in the reduction or cessation in the manufacture of estrogen, an important trigger mechanism for the development of bone growth (Williams et al., 1995). While this situation is a cause for concern for any female athlete, it is of special concern for the adolescent, female athlete who is undergoing rapid bone growth (Beck, et al., 2003).

\subsection{Research Questions}

1. Does exercise-associated amenorrhea affect performance in adolescent crosscountry runners?

2. Is bone mineral density affected by exercise-associated amenorrhea in adolescent cross-country runners?

3. Is body composition affected by exercise-associated amenorrhea in adolescent cross-country runners?

4. Is body weight affected by exercise-associated amenorrhea in adolescent crosscountry runners?

5. Is bone mineral density affected by cross-country running in adolescents?

6. Is the incidence of stress fractures greater in amenorrheic, adolescent cross-country runners than in eumenorrheic, adolescent cross-country runners? 
7. Is there less nutritional supplementation by amenorrheic, adolescent crosscountry runners than by eumenorrheic, adolescent cross-country runners?

8. Is bodyweight the best predictor of BMD in female, adolescent cross-country runners?

\subsection{Method of Investigation}

The method of investigation consisted of a six-month longitudinal study of body composition changes of female, adolescent cross-country runners before and after the competitive high school, cross-country season using descriptive, associative, and parametric inferential statistical procedures.

\subsection{Need for the Study}

While there have been numerous studies that demonstrated a high association between amenorrheic athletes and lower levels of bone mineral density as compared to their eumenorrheic counterparts (Drinkwater, 1984 \& 1992; Drinkwater, Bruemner, \& Chestnut, 1990; Drinkwater, Nelson, Chestnut, Bruemner, \& Shainholtz, 1984;

Drinkwater, Nelson, Ott, \& Chestnut, 1986; Nattiv, Agostini, Drinkwater, \& Yeager, 1994), the generalizability of these findings is limited because the data gathered from these studies were from adult cross-country runners. Similar research using female, adolescent athletes as subjects has been negligible at best. By including the findings of the current research that examined bone growth of adolescent cross-country runners, generalizability can be expanded. Furthermore, a better understanding of adolescent bone 
growth may reduce the risk of osteoporosis later in life and encourage women to incorporate this type of physical activity into their lifestyle.

\subsection{Limitations}

Involved in the study are certain limitations that could affect the outcome of the results. The limitations were as follows:

Sample size - The sample population was small (28 runners)

Convenience sample - The sample population was one of convenience; therefore, the sample may not be representative of adolescent athletes.

No sedentary adolescent control group was used because this was a pre- and poststudy of amenorrheic and eumenorrheic cross-country runners.

\subsection{Delimitations}

The study was delimited to female, adolescent cross-country runners.

\subsection{Assumptions}

Because little research has been conducted on adolescent, female athletes in relation to bone mineral density, the prevalence of amenorrhea in adolescent female athletes was assumed to be the same as adult female athletes.

Because the athletes were from the same cross-country program, it was assumed that the training regimen for the participants was the same. 


\subsection{Definition of Terms}

Adolescent - A person from the onset of puberty to adulthood (12-18 years).

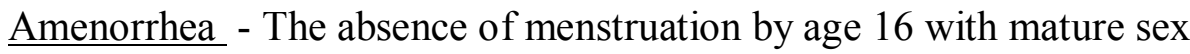

characteristics (primary amenorrhea), and by the cessation of menstrual function for 3 or more months without menopause (secondary amenorrhea) (Drinkwater, Bruemner, \& Chesnut, 1990).

$\underline{B F}$ - Body Fat - A body composition term indicating the amount of fat in a body, expressed in kilograms.

$\underline{B M C}$ - Bone Mineral Content - A body composition term indicating the amount of bone in a body, expressed in grams or kilograms.

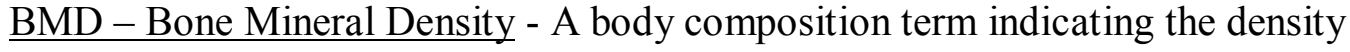
of bone in a body, expressed in grams per square centimeter.

BMDlegs - A body composition term indicating the density of bone in the legs, expressed in grams per square centimeter.

BMDpelvis - A body composition term indicating the density of bone in the pelvis, expressed in grams per square centimeter.

BMDspine - A body composition term indicating the density of bone in the spine, expressed in grams per square centimeter.

$\underline{B M I}$ - Body Mass Index - A body composition term defined as body weight (kilograms) divided by height (meters) squared.

Disordered eating - an eating pattern that does not provide a nutritionallybalanced diet. Disordered eating can range from eating patterns that do not provide required nutrients to an eating disorder, such as anorexia nervosa. 
EAA - Exercise Associated Amenorrhea. Amenorrhea associated with intense training, rapid weight loss, and disordered eating patterns.

Eumenorrhea - Normal menstruation with no more than 2 periods missed annually (Drinkwater, Bruemner, \& Chesnut, 1990).

GnRH - Gonadotropin Releasing Hormone. A hormone that stimulates leutinizing hormone (LH) to pulse and to begin menstruation.

HCG - Human Chorionic Gonadotropin. A hormone found in urine that indicates pregnancy.

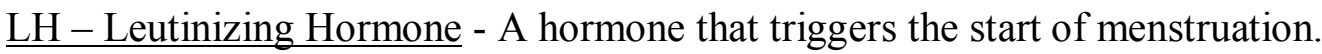

LT - Lean Tissue - A body composition term indicating bodyweight less body fat (BF) less bone mineral content (BMC), expressed in kilograms.

Maturational Status - \% of predicted adult stature (Bayer \& Bayley, 1976).

Menarche - Age in years when menstruation first begins.

Osteoporosis - A bone disease that impairs the structural integrity of the bone as a result of bone loss; greater than 2.5 standard deviations below the BMD age norm.

$\underline{\text { Stress Fracture }-A ~ c o m m o n ~ i n j u r y ~ o f ~ t h e ~ l o w e r ~ e x t r e m i t i e s ~ m o s t ~ o f t e n ~ a s s o c i a t e d ~}$ with running, jumping, or repetitive stress.

Z-Score - A measurement that specifies the location of a single value in reference to the mean distribution. The z-score's unit of measurement is standard deviation and its polarity specifies whether the value is above $(+)$ or below (-) the mean distribution. $\%$ BF - Body Fat Percentage. Amount of body fat divided by total body weight, expressed as a percent. 


\subsection{Summary of the Study}

The study examined the body composition changes of twenty-eight female, adolescent cross-country runners over a six-month period (during the season and after the season) using a device called a DXA (Dual energy X-ray Absorptiometry) whole body densitometer. Data collection occurred on campus and required two visits to the laboratory, during and after the participants' competitive season, lasting approximately 60 minutes each. A questionnaire was used to assess the participant's competitive performance history, nutritional supplementation, maturational status, menarchal age, and menstrual history. The independent variables that were measured were age, run performance, menstrual history, menarchal age, maturational status, incidence of injury, nutritional supplementation, weight, height, body fat, lean tissue, bone mineral content, and bone mineral density. 


\section{Chapter II}

\section{Review of Literature}

The section includes a review of two distinct topics, bone development and amenorrhea, that are related to the study.

\subsection{Bone Development}

The numerous health benefits of regular exercise are dependent on the type, intensity and volume of activity (Barbeau, Gutin, \& Litaker, 1999; Suominen, 1993)). One of the benefits of physical activity in adults is an increase in bone mineral density (BMD) and bone mineral content (BMC). There is strong evidence from cross-sectional and prospective studies (Almarwaey, Jones, \& Tolfrey, 2003; Nelson, Fisher, Dilmanian, Dallal, \& Evans, 1991) that moderate levels of weight-bearing physical activity are positively related to increased BMC.

The relationship is less clear with children. However, findings from the Iowa Bone Development Study (Janz, et al., 2001) indicate that there are significant associations between physical activity and bone measures during early childhood, well ahead of the onset of peak bone mass. Starting at a prepubertal age, long-term ordinary physical activities like recreational out-of-school sport activities can provide osteogenic benefits (Vicente-Rodriquez, et al., 2004). A three-year longitudinal study of prepubescent soccer players, playing at least three hours per week in a recreational soccer league, demonstrated a greater acquisition of bone mineral content (BMC) and bone mineral density (BMD) than a matched control group of physically active boys who did not participate in any kind of sport other than compulsory primary school activities in the physical education program and occasional children games. Furthermore, exercise during 
skeletal growth generates a greater osteogenic effect than exercise during skeletal maturity (Turner and Robling, 2003). The biological mechanisms for this phenomenon are not fully understood, but are probably related to the fact that there are a greater amount of active osteoblasts on the surface of the bone during growth than there are on the same surface after skeletal maturity.

A more compelling reason for children and adolescents to engage in exercise is that periosteal expansion occurs predominantly during growth, and consequently, the childhood and adolescent years provide a window of opportunity to significantly enhance periosteal growth. Periosteal growth determines the breadth of a bone and improves its bending and torsional strength. Furthermore, bone resorption from the periosteal surface is extremely rare in the adult. Usually, it is the trabecular, endocortical, and Haversian bone surfaces that undergo remodeling. Therefore, the periosteal breadth should remain intact well into old age. According to Beck, et al. (2003), exercise interventions for bone have only recently targeted pediatric populations, and research data for this cohort are few. Of those that exist, however, results indicate that vigorous weight-bearing activities that overload the skeleton in prepubescent children increase hip and spine BMC and BMD (Fuchs, Bauer, \& Snow, 2001). This would suggest that intervention strategies to increase physical activity in children and adolescents could contribute to optimal bone development. The interest in intervention strategies of regular exercise on bone development during the peak growth period of adolescence stems in part from the observations that adult athletes involved in high-load activities have very high bone mass, yet the adult skeleton typically demonstrates a limited response to exercise intervention (Karlsson, et al., 2000; Khan, et al., 2000). These observations suggest that the enhanced 
bone mass in adult athletes is the result of genetic factors and/or early initiation of training. Considering that approximately ninety percent of total bone mineral content (BMC) is accumulated by the end of adolescence, coupled with the continual change in the size and shape of the immature skeleton, the peak growth period appears to be the optimal time for altering the mass, geometry, and microarchitecture of bone (Modlesky, et al., 2002).

Additional research also suggests that greater gains in bone development may be linked to the level of skeletal maturity when exercise is initiated (Kannus, et al., 1995). The degree of difference in BMC of the dominant humerus versus the non-dominant humerus of tennis players who began training before menarche is significantly greater than players who initiated training after menarche. The importance of these observations depend upon whether the BMC and BMD gains attributed to physical activity are maintained throughout the life cycle so that the risk of osteoporosis is reduced later in life. For example, female gymnasts who have been retired for greater than ten years have higher hip, lumbar spine, and total BMD than age-, height-, and weight-matched controls. These findings may suggest a long-term residual effect of physical activity on BMD; however, compared to current gymnasts their BMD was lower (Kirchner, Lewis, \& O'Connor, 1996). One possible conclusion that can be made from these findings is that the older gymnasts never attained the BMD of the current gymnasts; another is that some of the BMD gains of the older gymnasts have diminished over time. The fact that the older gymnasts on average began training at 11.9 years old as compared to the current gymnasts who began training on average at 6.2 years old supports the findings of Kannus, et al. (1995) that there is a connection between bone development and when training 
commences. On the other hand, findings by Karlsson, et al. (2000) support the idea that bone gains are lost when physical activity ceases. Their findings demonstrate a steady decline in the difference of BMD levels between the legs and arms of soccer players after physical activity ceases. The BMD of the legs of active soccer players was $11.6 \%$ greater than the BMD in their arms. After thirty-five years of retirement there was no difference between the two sites, and the fracture history for the retired soccer players was no different than the controls. However, that may not be the case for athletes who continue physical activity. Research to determine whether chronic running by women master runners influenced age-related bone loss, found that there was no significant bone loss over a five year period regardless of menstrual or hormone replacement treatment status (Hawkins, Schroeder, Dreyer, Underwood, \& Wiswell, 2003). Longitudinal studies tracking changes in $\mathrm{BMC}$ and $\mathrm{BMD}$ of retired athletes may provide additional understanding about the permanence of bone gains likely achieved, in large part, during growth. The increased interest in the dynamics of bone acquisition is based on the growing recognition that high peak bone mass may be the most effective deterrent against osteoporosis.

The impact nature of physical activity also appears to affect BMD (Creighton, et al., 2000). In a study of forty-one female athletes (mean age $=20.7$ years) investigating the impact nature of exercise as related to BMD found that female athletes of high impact sports, such as volleyball and basketball, had significantly greater BMD than females athletes of medium impact sports, such as soccer and track. The athletes from medium impact sports had greater BMD than athletes of non-impact sports, such as swimming, who, in turn, had greater BMD than non-exercisers. Exercise has the potential to improve 
bone strength by not only increasing BMD, but also by altering the geometric properties of bone, such as, bone shape and size (Beck, et al., 2003). Athletes who predominately load their dominant limb exhibit improved geometric parameters, such as, increased diaphyseal diameters, cortical wall thickness, and BMD in that limb as compared to their non-dominant limb. Dynamic loading creates hydrostatic pressure gradients within the fluid-filled lacunar-canalicular network of bone. As the pressure gradients are equalized by the movement of extracellular fluid from regions of high pressure to regions of low pressure, shear stresses are generated on the plasma membranes of osteocytes and osteoblasts. These cells are highly sensitive to fluid shear stresses and respond by initiating a cascade of cellular events, including elevation of intracellular calcium, expression of growth factors, and bone matrix protein production. High-impact exercise that produces large rates of deformation of the bone matrix drives the extracellular fluid through the lacunar-canalicular network system better than low- or moderate-intensity exercise. In addition, loading applied at a higher frequency rate (cycles per second) stimulates osteogenesis more effectively; and regimens that incorporate sufficient periods of rest between these vigorous skeletal-loading sessions further enhance the osteogenic effect (Marieb, 1998).

Most physical activity studies of children and adolescents have focused on bone mineral content or bone mineral density as a surrogate measure of bone strength. These are clinically valid measures in the context of osteoporosis. However, Carbon, Sambrook, and Deakin (1990) found considerable overlap in the BMD of subjects with stress fractures and subjects that were fracture-free. These findings suggest that other factors besides bone mineral status, such as, bone geometry, biomechanical, and material 
properties may play a role in determining bone strength and functional competency. Research by Turner and Robling (2003) also supports the importance of nonmineral bone properties. The study consisted of sixteen-weeks of mechanical loading on the ulnae of adult female rats. The ulnae were then broken in axial compression using a materialstesting machine. Results revealed increases of only $5.4 \%$ in BMD and $6.9 \%$ in BMC during the study, but mechanical testing revealed a $64 \%$ increase in the amount of force necessary for bone failure and a $94 \%$ increase in energy absorbed by the bone before failure. The reason that a small amount of new bone resulted in such dramatic changes in bone strength was because the new bone formation was localized in the medial and lateral periosteal surfaces where mechanical stresses were greatest. Consequently, only modest increases in new bone formation produced a large increase in bone strength by placing bone in the areas of the greatest biomechanical demands. The influence of exercise on these nonmineral properties of bone has not been extensively investigated in children and adolescents mostly due to technological limitations in measuring these parameters accurately with minimal health risk. Studies using computer tomography expose children to undesirable levels of radiation; and studies using DXA have limited accuracy and reliability in measuring internal dimensions and biomechanical properties. DXA is also incapable of providing 3-D analysis of long-bone geometry due to its uni-planar nature. However, Duncan, et al. (2002), using a new approach, combined magnetic resonance imaging (MRI) with biomechanical analysis to study the cross-sectional areas, volumes, and moments of inertia of the femurs of elite, adolescent female athletes. The researchers found running, a weight-bearing exercise, was associated with more favorable geometric and biomechanical bone strength characteristics than swimming and cycling, both weight 
supported activities. Differences suggest skeletal adaptations to the specific mechanicalloading patterns inherent in the sports. Cullen, Smith, and Akhter (2000) noted that increased load increases bone cell activity until the new bone structure is sufficient to meet the new demand. Once adaptation is complete, cell activity returns to preload levels and the new bone structure is maintained. They concluded that bone formation on periosteal and endocortical surfaces were elevated after six weeks of loading. After eighteen weeks of loading periosteal adaptation seemed complete with no resorption observed. The studies illustrate the importance of non-mineral properties as well as mineral properties of bone development when assessing the relationship between skeletal adaptation and mechanical loading.

A complicating factor of bone development is that different exercise regimens affect bone development in different ways, even though they have similar functional effects. For example, young mice were randomly divided into three groups and subjected to either one of two types of loading: high-intensity, short-duration loading or lowintensity, high-duration loading. The third group was used as a control and not subjected to any loading. The high-intensity group improved most along the trabecular area of the bone, while the low-intensity group improved most in the cross-sectional, cortical area of the bone. Regardless of these differences, the breaking strength of the femurs for both exercise groups was $64 \%$ greater than the non-exercise control group (Gordon, Perl, \& Levi, 1989). Not all research demonstrates BMD differences between participants of weight-bearing and non-weight bearing exercise. Block, et al. (1989) found that the variable most associated with BMD was the intensity of training. The study consisted of fifty-nine male Caucasians (mean age $=21.6 \pm 1.8$ years), twenty nationally ranked water 
polo players, nineteen athletes engaged in weight training programs and twenty nonexercisers. While both exercise groups had significantly greater BMDs than the nonexercise control group, the BMDs were not significantly different between the water polo player group and the group participating in weight-training programs. This finding seems to contradict other studies that indicate weight-bearing exercise to be more effective than non-weight-bearing exercise in building bone density. However, most of the elite caliber of swimmers tested had previously participated in resistance training and additional aerobic exercise as components of their conditioning. Subsequent studies of participants in less strenuous, non-weight-bearing programs who have little or no experience in weight-bearing activities are needed to confirm this finding. There is also strong evidence that moderate levels of weight-bearing physical activity are positively related to increased BMC (Almarwaey, Jones, \& Tolfrey, 2003; Nelson, Fisher, Dilmanian, Dallal, \& Evans, 1991).

Research demonstrating that tennis players have greater BMD in their dominant arms supports the concept of bone specificity, that bone response to exercise is locally controlled (Maughan, Abel, Watson, \& Weir, 1986). Furthermore, a study conducted by Nevill, Burrows, Holder, Bird, and Simpson (2003) supports previous findings (Margulies, Simkin, \& Leichter, 1986) that endurance running has a positive osteogenic effect on bone in lower-body skeletal sites and also supports the theory that bone mass acquisition obeys a principle of specificity. Data revealed a positive association between calcium intake and bone mineral content (BMC) at the legs site, but a negative association at other sites. This suggests that calcium intake was diverted to the legs, where mechanical loading was occurring, at the expense of other sites. Research 
conducted by Procter, Adams, Shaffrath, and Van Loan (2002) also yielded findings that supported the theory of specificity. Upper limb BMD followed use patterns in both gymnasts and controls, demonstrating that the forces imposed on the arms with gymnastics training enhanced BMD and resulted in no bilateral differences. These findings illustrate the association between gymnastics training and increased BMD, suggesting that the high BMD values observed in gymnasts are due primarily to the activity itself rather than selection bias. To further support the concept of bone specificity, Risser, Lee, \& Leblanc (1990) found in a study of volleyball and basketball players, whose sports placed stress on the heel, had greater calcaneus and lumbar BMD than their controls (Botwinick, et al., 1989).

Body composition and bone development of adolescents are influenced by maturation levels as well as physical activity and inactivity levels (Zacharias, Rand \& Wurtman, 1976). Therefore, maturation levels must also be considered when examining the complex relationship between body composition, bone development, and physical activity in youth (Beunen et al., 1994). In addition to maturation levels, genetic factors contribute to peak bone mass. Twin studies using a horizontal comparison design demonstrate a positive relationship between peak bone mass and siblings (Pocock, et al., 1987; Smith, Nancy, Won Kang, Christian, \& Johnston, 1973). A similar motherdaughter study employing a vertical relationship design concluded genetic factors contribute to bone development (Lutz, 1986). The skeleton is continuously subjected to hormonal influences as well as mechanical forces. It is speculated that the hormonal loop is the major determinant of whether and when bone remodeling will occur in response to 
changing blood calcium levels, while mechanical stress or loading determines where remodeling will occur (Marieb, 1998).

Peak bone mass is also related to nutrition. Calcium intake may be an important determinant of peak bone mass in young adults. A difference of BMC and fracture rate in two populations under thirty years old with different calcium intakes, suggests the importance of calcium intake in early bone growth (Matkovic, Kostial, Simonivic, Bradarec, \& Nordin, 1977). Adolescence may be a critical period when inadequate calcium intake is detrimental to skeletal maturation. Turn-of-the-century research indicated children who consumed milk grew taller than control subjects without milk supplementation (Leighton and Clark, 1929; Orr, 1928). Unfortunately, bone density assessment was not available at the time.

Understanding the associations that exist between body composition, bone development, and physical activity in adolescents is the key to understanding the human growth process (Morrow \& Freedson, 1994). Consideration of the behavioral context of their physical activities, such as, the sports in which they participate and their methods of physical and mental conditioning, is a major, contributing factor to their immediate and long-term health and well-being.

\subsection{Amenorrhea}

Amenorrhea is defined, respectively, as the absence of menstruation by age 16 with mature sex characteristics (primary amenorrhea), and by the cessation of menstrual function for 3 or more months without menopause (secondary amenorrhea). It is a 
condition caused by the female body reacting to an intense physical stress by placing the reproductive functions secondary to survival.

Traditionally, amenorrhea in the female cross-country runner is associated with rapid weight reduction, low body fat, and/or vigorous training. This condition is known as exercise-associated amenorrhea (EAA) and it has also been linked with higher injury rates and lower bone density in adult female athletes (Mean Age $\pm \mathrm{SD}=24.3 \pm 2.1 \mathrm{yrs}$ ) (Loucks, 1985). Wolman, et al. (1991), researching EAA, studied 226 elite female athletes. The incidence of amenorrhea was $71 \%$ in gymnasts, $46 \%$ in lightweight rowers and $45 \%$ in runners. The incidence of amenorrhea in the general female population is $2 \%$ to 5\% (Wells, 1991). Research suggests that female athletes who participate in the sports that were studied by Wolman and associates have a higher prevalence of amenorrhea than non-athletes.

Although the potential to stimulate bone growth through mechanical loading during the pubertal period is associated with marked increases in serum estrogen (Lee and Lanyon, 2004); mechanical loading does not enhance bone growth in amenorrheic athletes, such as gymnasts, ballet dancers, and long distance runners. Also, these athletes possess a BMD lower than age-matched eumenorrheic athletes from the same respective sports (Warren, Brooks-Gunn, Hamilton, Warren, \& Hamilton, 1986). In states of relative estrogen deficiency, the bone's adaptive response to mechanical loading fails to maintain an appropriate bone mass and architecture (Whalen and Carter, 1988). Consequently, amenorrheic runners have significantly lower bone density than eumenorrheic runners (Drinkwater, 1984; Risser, et al., 1990), and are more susceptible to short-term injury, such as stress fractures, and, long-term, are at greater risk of osteoporosis (Johnson, 
Weiss, \& Wheeler, 1994; Modleskey \& Lewis, 2002). In addition, decreased bone mass from prolonged amenorrhea has another serious implication, irreversible bone loss. Follow-up research of the amenorrheic runners by Drinkwater, Nilson, Ott, and Chestnut (1986) indicated that those runners that resumed regular menses never attained the levels of bone density of regularly menstruating athletes.

While low percentages of body fat, weight loss, excessive training and poor nutrition habits may be contributing factors that influence amenorrhea, findings by Nattiv, et al. (1994) suggest that inadequate caloric intake is the primary factor. Reproductive function depends on energy availability. When energy intake is sufficient, GnRH (gonadotropin releasing hormone) stimulates another hormone, LH (leutinizing hormone), to "pulse." This starts the menstrual cycle. When the signal from GnRH is disrupted, the LH pulse frequency decreases, becomes ineffective, and menstruation does not occur. Without the menstrual cycle, there is no cycling of the hormones responsible for stimulating bone deposition. Contrary to these findings, research by Cobb, et al. (2003) indicate that oligo/amenorrhea of female runners was not associated with calorie restriction, rather the findings suggest a reduction of dietary fat intake to be the factor associated with the condition. Furthermore, the research also indicated lower body fat and higher menarchal age to be other factors associated with amenorrhea. Though dietary fat, independent of total energy intake, has previously been shown to influence the menstrual cycle in non-athletic women (Jones, Judd, Taylor, Campbell, and Nair, 1987; Merzenich, Boeing, Wahrendorf, 1993), this association has not previously been demonstrated in female athletes. 
Because excessive training has traditionally been noted as the key component influencing amenorrhea, Williams, et al. (1995) conducted a study to determine whether the typical decrease in LH pulse frequency observed in amenorrheic athletes was due to the effects of exercise itself, or to a deficit in energy when training volume was suddenly increased. In the study, four normally menstruating women (Mean Age \pm SD $=28.2 \pm 1.3$ yrs) completed three different 8-day treatments. The first treatment consisted of a protocol that provided adequate calories to maintain weight with no exercise, the second treatment included a protocol consisting of adequate calories to maintain weight with short-term training at $75 \%$ of $\mathrm{VO} 2 \mathrm{max}$, and the last treatment contained a protocol of caloric restriction ( $60 \%$ of requirement to maintain body weight) with short-term training at $75 \%$ of VO2max. For control purposes, LH pulse tests were done at the end of each protocol and were timed to coincide with the 8th day of the menstrual cycle. LH pulse frequency was significantly lower when calories were restricted during short-term training. Under these conditions, an approximate $5 \mathrm{lb}$. weight loss was experienced. LH pulse frequency was not different between the two conditions where caloric intake was sufficient to maintain body weight. This implies the LH pulse response is sensitive to caloric restriction lasting as little as 8 days. Therefore, when training load is increased, caloric intake should be increased accordingly to prevent the condition of calorie restriction and the decrease in $\mathrm{LH}$ pulse that can follow. The fact that a loss as small as 5 lbs is associated with changes in the hormonal profile suggests that an athlete's susceptibility to amenorrhea is related more to the availability of short-term energy (i.e. food intake) than to energy stores (i.e. body fat). Weight loss due to caloric restriction may predispose an athlete to suppressed LH pulsatility and amenorrhea, which will 
eventually take its toll on the bone health of the athlete (McMurray, Procter, \& Wilson, 1991). Because bone density reaches its maximum in the beginning of the third decade of the human life cycle (early twenties), adolescent amenorrheic athletes don't accumulate bone mass during their peak bone growth period like other adolescents, and increase the risk of low bone mineral density and osteoporosis long before they reach menopause. This creates a true dilemma for the female cross-country runner.

Loucks, Verdun, and Heath (1998) investigated two proposed leutinizing hormone reaction theories, a calorie-balanced low energy state and a calorie-restricted low energy state. LH pulse data was measured in nine regularly menstruating women (average age 21 ) after 4 days of intense treadmill exercise ( $70 \%$ of aerobic capacity) under calorie-balanced and calorie-restricted conditions. Both conditions introduced a state of low energy availability. In the calorie-balanced condition, the low energy state was caused by exercise; and in the calorie-restricted condition, the low energy state was caused by a reduction in caloric intake. LH pulse testing coincided with Day 8, 9, or 10 of the menstrual cycle for all treatments. Subjects lost an average of $3.7 \mathrm{lbs}$ during the calorie-restricted treatment and none under the calorie-balanced condition. The caloriebalanced condition reduced LH pulse frequency by $10 \%$; however, the calorie-restricted condition reduced LH pulse frequency by a much greater extent, $25 \%$. The subjects said that they were satisfied with the amount of food they were given to eat for the calorierestricted segment of the study and found it difficult to consume all of the food that they were required to eat for the calorie-balanced portion of the study. This may suggest that the amount of food desired at meals is more habit than anything else. Therefore, even though the body may require additional food for energy, the cross-country runner has no 
desire to increase her eating. The results from this study imply that low energy availability due to restricting caloric intake has more impact on disturbing LH pulsatility than the same degree of low energy availability caused by exercising alone. This is important because it yields a guideline for how to minimize the amenorrheic effect. Female cross-country runners should turn to increasing energy expenditure rather than decreasing energy intake when looking to lose weight and the amount of calories consumed should be regulated according to need as required to fuel and re-fuel the body. Additionally, LH pulsatility can be restored by resuming a calorie-balanced diet following a calorie-restricted diet (Loucks \& Verdun, 1998). Eight regularly menstruating females (Mean Age $\pm \mathrm{SD}=21.3 \pm 1.8$ yrs.) were intentionally taken through a 5-day period of low energy availability (combination of diet restriction and exercise) in order to disrupt the LH pulse response. On the sixth day of treatment, subjects were aggressively overfed with 15 meals for a total of 4,100 kcal. LH testing was performed in both the low energy and overfed states. The 5-day low energy availability treatment led to a mean weight loss of approximately $5.24 \mathrm{lbs}$, a significant reduction in circulating glucose, and a suppression of LH pulse frequency of 57\%. Twenty-four hours of aggressive re-feeding restored levels of circulating glucose, but did not restore LH pulse frequency to normal levels. While the consequences of low energy availability are quick to develop, the factors responsible for restoring normal LH pulsatility seem to be far less responsive to re-feeding intervention. It takes more than one day to reverse the effects of energy restriction. Exactly how long has yet to be determined. However, a case study by Dueck, et al. (1996) demonstrates the positive effects of treating athletic amenorrhea by increasing energy input and reducing training levels. A 19-year-old runner underwent a 
15-week diet and training intervention. She began menstruating at the age of 12 , but had lost close to $20 \mathrm{lbs}$ over 3 months during her freshman year at college and had been amenorrheic for 14 consecutive months leading up to the intervention. Six months before the treatment, she began to complain of chronic fatigue, poor performance, and a high frequency of illness and injury. The dietary component of the intervention consisted of adding one 11-oz serving of nutritionally balanced sports nutrition shake to her daily diet. The training component of the intervention consisted of eliminating one day of training from her schedule, bringing the athlete's program from seven days/week to six. Prior to the intervention, this runner was deficient in her caloric intake by about $155 \mathrm{kcal} / \mathrm{day}$, or $1,085 \mathrm{kcal} /$ week. At the end of 15 weeks, she gained $6 \mathrm{lbs}$ and her percent body fat was restored from $8.2 \%$ to $14.4 \%$. Her LH levels increased to match those of her normally menstruating teammates'. Her serum cortisol, which was $70 \%$ above the expected limit at the onset of the intervention, fell significantly to only $21 \%$ above the normal range. (Note: Cortisol is a substance the body produces in response to both physical and emotional stress.) This runner's performance improved during the season. She went on to set more personal records than during any prior season, breaking two school records and qualifying for Nationals in several events. She resumed normal menstruation three months later and displayed normal function for two consecutive months. In retrospect, it became apparent that in addition to being caloric deficit, the athlete was also overtraining. Rest days are an important part of recovery following intense training sessions, but with a seven day-a-week schedule no allowance was made. Here, the caloric deficit the runner was experiencing would have led her to continue losing weight at a rate of 
approximately 1 pound every three weeks with no regard given to the diet requirements of this athlete prior to intervention.

Energy availability is the key (Wolinsky, 1994). Even though this particular athlete's body fat percentage increased with the intervention, there are plenty of females with low body fat who retain their monthly cycle. The case study (Dueck, et al., 1996) discussed is an extreme example but it does show how easy it is to rectify this health problem once it is diagnosed (Smith, 1984). It also illustrates the consequences of pursuing such a training plan as was being used. In conclusion, with regard to current data, every indication is that there is no "set" level of body fat that is applicable to all athletes for normal menstrual function (Stark, Peckham, \& Maynihan, 1989).

There does, however, seem to be a consistent link between energy balance, body mass, and bone density in young women (Zanker, Cooke, Truscott, Oldroyd, \& Jacobs, 2004). A short-term ( $<2$ yrs.) prospective study of changes in BMD in young women with eating disorders suggest that trabecular and cortical bone loss accelerate when BMI falls below a "threshold" in the range of 16-17 kg/m squared (Hotta, Shibasaki, Sato, \& Demura, 1998). This threshold is characterized by reduced serum levels of bone formation markers and an elevated urinary excretion of bone resorption markers. Also, research by Drinkwater, Bruemner, and Chestnut (1990) suggests an interaction between body weight, bone density, and menstrual history. According to Drinkwater, et al. (1990) normal estrogen levels seem to override any negative effect of decreased body weight; however, as menstrual irregularities increase in severity, body weight becomes a more important factor. Dhuper, Warren, Brooks-Gunn, and Fox (1990) also found an interdependence between body weight and estrogen exposure on bone density. These 
findings are consistent with research (Wolman, et al., 1991) that indicates that EAA is especially prevalent in size- and weight-sensitive sports like gymnastics, figure-skating, ballet, and long distance running. This does not seem to be the case in sports not sensitive to size or image. Research (Meyer, et al., 2004) investigating the menstrual history of athletes participating in winter sports that were not related to weight or image did not find an association to BMD. While the bone mineral density (BMD) of forty female, Olympic-level athletes who participated in intense winter sports, such as speed skating, snowboarding, and freestyle skiing, was significantly greater than a control group of twenty-one, healthy females of similar age and body mass index (BMI), menstrual history was not associated with BMD in the athletic group. Athletes with a history of oligoand/or amenorrhea had similar BMD than their eumenorrheic counterparts and significantly greater BMD than the control group subjects.

In many cases amenorrhea is not only associated with body weight (Dhuper, et al., 1990; Drinkwater, et al., 1990), it is also associated with menarchal age (Cobb, et al, 2003; Dhuper, et al., 1990). According to Cobb, et al. (2003), the likelihood of amenorrhea more than doubles $(2.45: 1)$ for every year menarchal age increases. Dhuper, et al. (1990) investigating the hormonal effects on bone density in adolescents found the group with the lowest estrogen levels to be oligo/amenorrheic (25\%). This group displayed the lowest bone density, the lowest body weight, and the highest menarchal age than two other eumenorrheic groups which were grouped by medium and high estrogen levels. There are a variety of factors related to menarche. It is hypothesized that menarche consists of two different types of factors, biological and social/environmental (Malina, 1985). The biological factors consist of genetic and hormonal components, and the 
social/environmental factors consist of components that include nutritional status, family size, socio-economic background, health, and intensive physical training. Data from a review (Malina, 1985) of seventeen studies suggest that menarche is attained later in athletes compared to the general population. This suggests that training delays menarche. To further this point, studies (Frisch, et al., 1981; Sidhu and Grewal, 1980) indicate later mean menarchal ages among athletes who began training before menarche as compared to athletes who began training after menarche. It is not surprising that menarche is also significantly related to skeletal maturity (Tanner, 1962; Malina, 1978), but the results of these studies and the other studies noted illustrate how highly complex the association between menarche and amenorrhea can be.

Elite-level female cross-country runners may well find it difficult to avoid occasional bouts of amenorrhea. In most cases these hormonal changes can be controlled such that their duration is short enough that while they may affect the duration of any specific cycle, it can be kept within the limits of normalcy. In order to minimize the health hazards, it is essential to plan properly by making adjustments to weight and/or body fat over reasonable time periods so as to allow the body to acclimate to the change (Krowchuk, Kreiter, \& Woods, 1998). Additionally, two other steps may be of value in combating the effects of amenorrhea - increased calcium intake and the addition of a resistance/strength training program.

As a dietary supplement calcium can help play a key role. The typical suggested dietary intake of calcium for women is $1000 \mathrm{mg}$ /day, physicians recommend increasing this amount to $1500 \mathrm{mg} / \mathrm{day}$ when the conditions conducive to amenorrhea are present (Lloyd, et al., 1993). Of this amount, the general rule is to try and obtain at least two- 
thirds from food intake and the remaining third from vitamin and mineral supplements (Matkovic, Kostial, Simonovic, Bradarec, \& Nordin, 1977). In addition to its role for bones and teeth, calcium is needed for a number of other vital body functions - muscle contraction, maintenance of cell membranes and cell division, DNA replication, etc (Kennedy, 1999). If enough calcium is not provided for these functions, the body will draw what it needs from the bones through resorption (Matkovic, Fontant, Tominic, Goal, \& Chestnut, 1990). This mechanism is acknowledged as a key component of osteoporosis. Because calcium requirements for adolescent females are at their peak due to rapid skeletal growth, it would seem likely that female athletes trying to restrict their caloric intake in order to drop weight would also be reducing their opportunity to obtain adequate levels of calcium. When this is factored into the other bodily functions requiring calcium, resorption is the likely result. However, increasing calcium intake by itself has not been shown to be totally effective. Studies conducted by Drinkwater, Nilson, Ott, \& Chestnut (1986) have shown that low bone mineral density can be improved through the aid of supplementation after normal menses resumes, but the recovery is rarely $100 \%$.

Resistance training has been identified as another viable route for increasing bone density. Research (Layne \& Nelson, 1999) suggests that resistance training positively affects bone mineral density at all ages, with the effects being specific to the muscles worked and the bones to which they attach. The authors noted that although aerobic exercise and weight bearing physical activity are important, resistance training seems to have a more potent impact on bone density. It is important to note that training activities that stimulate bone growth need to include progressive overload, variation of load, and specificity of loading (Conroy, Kraemer, Maresh, \& Dalsky, 1992). Specificity of loading 
refers to exercises that directly place a load on a certain skeletal region because increases of bone mineral density are site-specific. Additionally, programs designed to stimulate bone growth should be full-body in nature, including exercises, such as squats and lunges, that direct the forces through the axial skeleton and allow greater loads to be utilized (Conroy \& Earle, 1994). A point to be made is that most of the EAA studies conducted center around sports that traditionally avoid weight training, such as gymnastics and distance running. Because of the potential threat of bone density loss to amenorrheic athletes involved in these sports, resistance training should be an essential component of training. A resistance training program designed specifically for these sports could possibly provide positive and healthful results as well as an improvement in performance. 


\title{
Chapter III
}

\section{Methodology}

\subsection{Participants}

\author{
Population
}

The sample population consisted of twenty-eight female, adolescent student athletes who were recruited from an elite cross-country team of sixty-eight runners between the ages of 13 to 18 years old. The study was approved by the Committee for the Use of Human Subjects of the University of New Orleans. Written information explaining the research and detailing the methods and procedures of the study were provided to both the parents/guardians and participants. Before participating in the study, written informed consent was required by the parents (or legal guardians) and written assent was also required by the participants.

\section{Sampling Method}

The selection method was a convenience sample of those student-athletes who volunteered to participate in the study. The student athletes were team members from the same all-girl, parochial high school in New Orleans. Volunteers were solicited for the research at a joint parent/student-athlete team meeting at the school on a "first-come" sign-up basis. They were informed that participants would be given two full-body bone density scans six months apart, free of charge. The scans provided an analysis of the participants' body composition and bone density status. The clinical cost of these scans range in cost from $\$ 300$ - $\$ 500$ per scan, depending upon the facility. The risks and methods of the procedure were noted in writing in both the consent form for the parents/guardians and in the assent form for the participants. 


\section{Selection Criteria}

The school has a reputation for providing an elite cross-country program. According to the Louisiana High School Athletic Association (LHSAA), the school has finished as one of the top five female cross-country teams in the state for the last ten years. Furthermore, the program has a large number of runners on the squad from which to recruit. There were sixty-eight runners on the cross-country team. The school was also in close proximity to the University of New Orleans.

\subsection{Instrumentation}

\section{Height Measurement}

Participants were measured for standing height using a Schorr stadiometer measuring board. Subjects were asked to stand erect with body weight evenly distributed on both feet and to inhale deeply without altering their stance. The headboard was brought to the most superior part of the head with sufficient pressure to compress the hair.

\section{Weight Measurement}

Subjects were weighed using a Seca Model 770 scale. Subjects were asked to stand on the scale with body weight evenly distributed on both feet, feet next to one another and arms hanging freely by the sides of the body.

\section{Body Composition Measurement}

The subjects' body composition were measured by a Lunar Model DPX 7979 whole-body densitiometer (DXA). DXA emits x-rays at two energy levels and detects the 
absorption of this energy by body tissues. It is then able to segment the body into three components: bone mineral (BMC), fat (BF) soft tissue, and fat-free (LT) soft tissue. It has emerged as one of the best methods of assessing body composition because it is a simple, rapid test (generally less than twenty minutes) (Mazes, 1990). It has a low radiation dose (less than $1 / 100^{\text {th }}$ of the equivalent radiation exposure of a chest $\mathrm{x}$-ray), and it does not depend on hydration for accuracy.

All participants were screened for pregnancy prior to undergoing the DXA scan. Standard urine-based pregnancy kits were used to test for the presence of human chorionic gonadotropin (HCG). Any subject testing "positive" would not be scanned. The purpose of this procedure is purely a precautionary measure to insure normal fetal development in the event of a pregnancy. Both the subjects and their parents/guardians were informed of this procedure in writing prior to participation in the study.

\subsection{Procedures for Conducting the Study}

After obtaining written parental consent and participants' assent, the participants:

1. Had their height and weight measured.

2. Had their body composition measured by a DXA. This device measured body fat, lean tissue mass, bone mineral content, and bone mineral density.

3. While the risk of harm from radiation with the DXA procedure is extremely small, the long-term effects of exposure to a fetus is not known. Therefore, as a purely precautionary measure, the participants were screened for the presence of human chorionic gonadotropin (HCG) using a 
standard urine-based pregnancy kit. If the participant tested "positive" for HCG, she was not scanned. She would be informed that, while testing positive for HCG is not a positive indication of pregnancy, she should check with her physician to verify her status. In the study, no participant tested "positive" for HCG. If the participant tested negative for HCG and her measured BMD was one or more standard deviations below the age-related norm, she would be informed that she should check with her physician regarding her BMD. In the

study, one participant's BMD was more than standard deviation below the agerelated norm in the post-season analysis and was informed to consult her physician.

4. Responded to a questionnaire about their performance level, training regimen, incidence of stress fractures, nutritional supplementation, menarchal age, menstrual irregularity and maturational status. Height, weight, and DXA measurements were conducted on the UNO campus at the Department of Human Performance and Health Promotion at the student/athlete's convenience after school or on weekends.

\subsection{Data Analysis Procedures}

SPSS 11.0 for Windows was used for statistical analysis. The subject population was separated into eumenorrheic and amenorrheic subgroups by categorizing those subjects who indicated that they had missed 3 or more menstrual periods in the 12 months prior to the post season analysis as amenorrheic. The remaining subgroup who 
indicated that they had missed 3 or less menstrual periods in the 12 months prior to the post season analysis were categorized as eumenorrheic.

\section{Correlational Analysis}

Pearson product-moment correlation coefficients were calculated to determine the relationships among variables including weight, height, $\mathrm{BMD}, \mathrm{BMD}$ spine, $\mathrm{BMD}$ pelvis, BMDlegs, BMC, BF, LT, performance, training volume, maturational status, menarchal age, and age for both the pre-season and post-season. Partial correlations were also calculated to determine the relationships among the same variables, holding skeletal maturity (SM), constant.

Pearson product-moment correlation coefficients were employed to investigate the associations among BMD and other variables for both the preseason and postseason. Partial correlations were used to study the body composition relationships while holding skeletal maturity (SM) constant.

Pearson product-moment correlation coefficients were calculated to compare the associations among BMD and other body composition components for the two subgroups. Similarly, partial correlations were also calculated for the same variables and holding skeletal maturity constant.

Pearson product-moment correlation coefficients were calculated to investigate the relationships among menstrual dysfunction (menstrual periods missed in the last 12 months) and body composition components along with the subjects' training volume and 3.2 kilometer best performance time. Partial correlations were calculated for the same variables, holding menarchal age as a constant. 
In addition, Pearson product-moment correlation coefficients were calculated to compare the relationships among training volume (kmpw - kilometers run per week) and body composition components along with the subjects' 3.2 kilometer personal best performance time and skeletal maturity. Partial correlations were also calculated for the same variables holding menarchal age as a constant, and then holding skeletal maturity as a constant.

\section{Parametric Inferential Analysis}

Paired t-tests were used to determine the pre- and post- status of body composition components of the subjects: BMD, BMD spine, BMD pelvis, BMDlegs, BMC, LT, $\mathrm{BF}$, calcium, weight, and height. The level of significance was set at $\mathrm{p}<0.05$.

One-way multivariate analysis of variance (MANOVA) was used to investigate categorical differences of the participants, the independent variables, with respect to maturational status, age of menarche, age, and performance. The participants were divided into two categories: eumenorrheic cross-country runners and amenorrheic crosscountry runners. MANOVA was also be used to investigate categorical differences with respect to six variable groups consisting of different combinations of body composition variables; Group \#1: weight, height, BF, BMD, LT, and BMC; Group \#2: performance, BF, BMD, and LT; Group \# 3: BMD, BMD spine, BMDpelvis, and BMDlegs; Group \#4: menarchal age, BF, BMD, and LT; Group \#5: weight, height, body mass index (BMI), BF, BMD, and LT; and Group \#6: weight, calcium, BF, BMD, LT, and BMC. MANOVA was used because there were multiple, related dependent variables. Multivariate covariance analysis (MANCOVA) using the same two categories and the same six 
dependent variable groups were also employed using maturational status as a covariate. The level of significance for both the MANOVA and MANCOVA was be set at $p<0.05$. A one-way analysis of variance (ANOVA) was computed to compare the number of stress fractures (injuries) between the two subgroups. The level of significance was set at $\mathrm{p}<0.05$

A one-way analysis of variance (ANOVA) was computed to compare nutritional supplementation (regular ingestion of calcium and vitamin D) between the two subgroups. The level of significance was set at $\mathrm{p}<0.05$.

\section{Prediction Analysis}

Simple linear regression was used to investigate the independent variables that best predicted the criterion variable, BMD. The procedure examined the significance of each independent variable as well as the variance that the independent variable accounted for to predict BMD.

\subsection{Research Issues}

\section{Reliability}

1. All measurements were performed by the same operator.

2. Participants were weighed twice and re-weighed if the results deviated by more than 0.1 kilogram.

3. Participants' height was measured twice and re-measured if the results deviated by more than 0.1 centimeter.

4. A quality assurance test was run on the DXA before any testing was conducted. 


\section{Validity}

1. The Lunar Model DPX 7979 DXA whole-body densitiometer was calibrated before every measuring session using a standard calibration block provided by the manufacturer.

2. Subjects were positioned according to the standard protocol for full body scans.

3. Analyses were conducted with the manufacturer's automated algorithms. 4. All scans were visually inspected by the operator.

5. The Seca Model 770 scale was calibrated with a 5 kilogram weight before each session. If the scale was off by more than 0.1 kilograms, it would not be used. 


\section{Chapter IV}

\section{Results}

\subsection{Overview}

The purpose of this investigation was to examine the relationship of athletic amenorrhea and bone mineral density of adolescent cross-country runners from an elite cross-country high school program. Bone mineral density, bone mineral content, lean tissue mass, and fat tissue mass were estimated using dual-energy x-ray absorptiometry (DXA). Height and weight were measured using a Schoor stadiometer and a Seca digital scale, respectively. Run performance, training volume, menstrual history, menarchal age, incidence of injury, and nutritional supplementation were reported by the subjects using a data questionnaire. Relationships among variables were examined using correlation coefficients and scatter plots. Paired t-tests were used to investigate the seasonal bodycomposition changes of the subjects. Differences between amenorrheic and eumenorrheic subgroups were studied using multivariate analyses of variance. Finally, simple linear regression analysis was used to determine the best predictor variable for the criterion variable, post-season BMD. Eight research questions guided the investigation. They were as follows:

1. Does exercise-associated amenorrhea affect performance in adolescent crosscountry runners?

2. Is bone mineral density affected by exercise-associated amenorrhea in adolescent cross-country runners?

3. Is body composition affected by exercise-associated amenorrhea in adolescent cross-country runners? 
4. Is body weight affected by exercise-associated amenorrhea in adolescent crosscountry runners?

5. Is bone mineral density affected by cross-country running in adolescents?

6. Is the incidence of stress fractures greater in amenorrheic, adolescent cross-country runners than in eumenorrheic, adolescent cross-country runners?

7. Is there less nutritional supplementation by amenorrheic, adolescent crosscountry runners than by eumenorrheic, adolescent cross-country runners?

8. Is bodyweight the best predictor of BMD in female, adolescent cross-country runners?

A detailed presentation and interpretation of data from quantitative statistical and inferential analyses from the current study is divided into the following sections: $4.2-$ Participant Data; 4.3 - Bone Mineral Density and Body Composition; 4.4 - Performance and Training Volume; 4.5 - Stress Fractures; 4.6 - Nutritional Supplementation; 4.7 Predictor Variables for BMD; 4.8 - Results by Research Questions; 4.9 - Summary 
Table 1

Physical Characteristics

\section{Physical Characteristics $(\mathrm{n}=28)$}

\begin{tabular}{|c|c|c|}
\hline Variables & Preseason (mean $+\mathrm{SD})$ & Post-season (mean + SD) \\
\hline Age (yrs) & $15.4 \pm 1.5$ & $15.9 \pm 1.5$ \\
\hline Weight (kg) & $54.1 \pm 7.3$ & $55.3 \pm 7.1 *$ \\
\hline Height $(\mathrm{cm})$ & $160.1 \pm 5.9$ & $161.0 \pm 5.9 *$ \\
\hline Lean Tissue (kg) & $38.1 \pm 3.9$ & $38.2 \pm 3.6$ \\
\hline Body Fat (kg) & $12.9 \pm 4.5$ & $14.1 \pm 4.4^{*}$ \\
\hline Body Fat Percentage $(\%)$ & $23.7 \pm 5.8$ & $25.2 \pm 5.6$ \\
\hline Bone Mineral Content $(\mathrm{kg})$ & $2.4 \pm .4$ & $2.5 \pm .4 *$ \\
\hline $\mathrm{BMD}\left(\mathrm{gm} / \mathrm{cm}^{2}\right)$ & $1.12 \pm .08$ & $1.14 \pm .08 *$ \\
\hline $\mathrm{BMD}_{\text {spine }}\left(\mathrm{gm} / \mathrm{cm}^{2}\right)$ & $1.14 \pm .15$ & $1.18 \pm .15^{*}$ \\
\hline $\mathrm{BMD}_{\text {pelvis }}\left(\mathrm{gm} / \mathrm{cm}^{2}\right)$ & $1.17 \pm .13$ & $1.19 \pm .12$ \\
\hline $\mathrm{BMD}_{\text {legs }}\left(\mathrm{gm} / \mathrm{cm}^{2}\right)$ & $1.19 \pm .12$ & $1.20 \pm .11$ \\
\hline BMI $\left(\mathrm{kg} / \mathrm{m}^{2}\right)$ & $21.1+2.6$ & $21.3+2.5$ \\
\hline Calcium (gm) & $900.1 \pm 148.4$ & $935.7 \pm 147.7^{*}$ \\
\hline BMD z-score & $.65 \pm .9$ & $.70 \pm 1.0$ \\
\hline Skeletal Maturity (\%) & $98.06 \pm .02$ & - \\
\hline Menarchal Age (yr) & $12.7 \pm 1.1$ & - \\
\hline $3.2 \mathrm{~km}$ Performance (min) & - & $15.22 \pm 1.86$ \\
\hline Training Volume (kmpw) & - & $41.37 \pm 15.45$ \\
\hline
\end{tabular}

* Denotes significant seasonal increase using paired t-tests

\subsection{Participant Data}

There were twenty-nine high school cross-country runners in the study. There was a zero attrition rate for the study with all twenty-nine subjects participating in both the preseason and post-season segments. However, one of the twenty-nine participants was dropped from the study because feedback from the subject's data questionnaire indicated that the subject had not reached menarchal age by the post-season analysis, leaving twenty-eight subjects. 
The physical characteristics of the subjects were measured and are noted as a total group, preseason and post-season (Table 1), and by subgroups, preseason and post-season (Table 2).

For analysis purposes, the participants were divided into two categories or subgroups. Those who indicated on their questionnaires that they missed less than three menstrual periods in the twelve months prior to their post-season analysis were classified as eumenorrheic. Those who indicated that they missed three or more were classified as amenorrheic. Of the twenty-eight subjects, seventeen (60.7\%) were classified as eumenorrheic and eleven were classified as amenorrheic (39.3\%). At the pre-season analysis only three (10.7\%) of the twenty-eight subjects were classified as amenorrheic. The subjects' mean menarchal age was reported as $12.7+1.1(\mathrm{M}+\mathrm{SD})$ years; their mean $3.2 \mathrm{~km}$ run personal best was reported as $15.22+1.86(\mathrm{M}+\mathrm{SD})$ minutes; and their mean training volume was reported as $41.37+15.45(\mathrm{M}+\mathrm{SD})$ kilometers run per week (kmpw). While the subjects' training regimen was the same, their training volume varied. The cross-country team was divided into four groups with respect to training volume. These groups depended upon experience and performance. The first group, which consisted of younger, inexperienced runners, ran approximately $16.1-24.1 \mathrm{~km}$ per week during the season. The second group of more experienced runners ran approximately 32.2 $-40.2 \mathrm{~km}$ per week. The next group ran approximately $48.3-56.3 \mathrm{~km}$ per week; while the elite, experienced runners ran $64.4-72.4 \mathrm{~km}$ per week during the season. The training volume for the runners within each group was approximately the same during the season. 
Table 2

Physical Characteristics: Preseason \& Postseason by Subgroup

\begin{tabular}{|c|c|c|c|c|}
\hline \multirow[b]{3}{*}{ Variables } & \multicolumn{4}{|c|}{ Physical Characteristics } \\
\hline & \multicolumn{2}{|c|}{$\begin{array}{l}\text { Eumenorrheic Subgroup } \\
\qquad(\mathrm{n}=17)\end{array}$} & \multicolumn{2}{|c|}{$\begin{array}{l}\text { Amenorrheic Subgroup } \\
\qquad(\mathrm{n}=11)\end{array}$} \\
\hline & $\begin{array}{l}\text { Preseason } \\
(\text { mean }+ \text { SD) }\end{array}$ & $\begin{array}{l}\text { Post-season } \\
(\text { mean }+ \text { SD) }\end{array}$ & $\begin{array}{c}\text { Preseason } \\
(\text { mean }+\mathrm{SD})\end{array}$ & $\begin{array}{l}\text { Post-season } \\
(\text { mean }+ \text { SD) }\end{array}$ \\
\hline Age (yrs) & $15.6+1.6$ & $16.1+1.6$ & $15.0+1.3$ & $15.5+1.3$ \\
\hline Weight $(\mathrm{kg})$ & $56.0 \pm 6.5$ & $57.3 \pm 6.5^{*}$ & $51.0 \pm 7.6$ & $52.2 \pm 7.2 *$ \\
\hline Height $(\mathrm{cm})$ & $160.2+4.0$ & $160 . \overline{7}+4.1$ & $160.0+8.3$ & $161.4+8.3 *$ \\
\hline $\mathrm{LT}(\mathrm{kg})$ & $38.7+4.0$ & $38.6+3.7$ & $37.1+3.7$ & $37.5+3.5$ \\
\hline $\mathrm{BF}(\mathrm{kg})$ & $14.2 \pm 3.9$ & $15.4 \pm 3.9 *$ & $11.1 \pm 4.8$ & $11.9 \pm 4.4$ \\
\hline BF Percentage $(\%)$ & $25.3 \pm 4.9$ & $26.9+4.8$ & $21.2 \pm 6.5$ & $22.3 \pm 5.8$ \\
\hline $\mathrm{BMC}(\mathrm{kg})$ & $2.5 \pm .36$ & $2.6 \pm .36^{*}$ & $2.2+.39$ & $2.3 \pm .37 *$ \\
\hline $\mathrm{BMD}\left(\mathrm{gm} / \mathrm{cm}^{2}\right)$ & $1.15+.07$ & $1.17+.07 *$ & $1.08+.08$ & $1.09+.06$ \\
\hline BMDspine $\left(\mathrm{gm} / \mathrm{cm}^{2}\right)$ & $1.17 \pm .14$ & $1.23 \pm .12 *$ & $1.10 \pm .16$ & $1.09 \pm .14$ \\
\hline BMDpelvis $\left(\mathrm{gm} / \mathrm{cm}^{2}\right)$ & $1.22 \pm .13$ & $1.24 \pm .11$ & $1.10 \pm .11$ & $1.12 \pm .10$ \\
\hline BMDlegs $\left(\mathrm{gm} / \mathrm{cm}^{2}\right)$ & $1.22+.11$ & $1.23+.10$ & $1.14+.12$ & $1.16+.12$ \\
\hline BMI $\left(\mathrm{kg} / \mathrm{m}^{2}\right)$ & $21.8+2.4$ & $22.2+2.3$ & $19.9+2.6$ & $20.0+2.4$ \\
\hline Calcium (gm) & $942.7 \pm 137.1$ & $981.2 \pm 137.0 *$ & $836.4 \pm 147.8$ & $865.3 \pm 141.1^{*}$ \\
\hline BMD z-score & $.91 \pm .93$ & $1.05 \pm .92 *$ & $.25 \pm .68$ & $.16 \pm .79$ \\
\hline Skeletal Maturity (\%) & $98.6 \pm .01$ & - & $97.2 \pm .02$ & $\overline{-}$ \\
\hline Menarchal Age (yr) & $12.5+1.0$ & - & $13.1+1.2$ & - \\
\hline $3.2 \mathrm{~km}$ Run (min) & - & $15.36+2.2$ & - & $15.03+1.3$ \\
\hline Training (kmpw) & - & $43.54 \pm 16.85$ & - & $38.04 \pm 14.17$ \\
\hline
\end{tabular}

* Denotes significant seasonal increase using paired t-tests

Nutritional supplementation and stress fracture history were also reported by the subjects. Five $(17.9 \%)$ of the twenty-eight athletes indicated that they ingested calcium and vitamin D on a regular basis. Four were eumenorrheic and one was amenorheic. In regard to stress fracture, three $(10.7 \%)$ of the subjects reported a diagnosis of a stress fracture in the twelve months preceding the post-season analysis. Two were eumenorrheic and one was amenorrheic. 


\subsection{Bone Mineral Density and Body Composition}

Bone mineral density and body composition were examined using correlational relationships, paired t-test analyses, and multivariate analyses.

These analyses revealed that the eumenorrheic subgroup had significantly greater BMD, body weight, body fat, and bone mineral content than the amenorrheic subgroup.

Furthermore, the eumenorrheic subgroup had significant seasonal increases in BMD, bodyweight, body fat, bone mineral content, and bone calcium, while the amenorrheic subgroup had only significant seasonal increases in body weight, height, bone mineral calcium, and bone calcium. In addition, correlational and multivariate analyses demonstrated that skeletal maturity and menarchal age influenced the BMD and body composition component associations. The detailed results are presented as follows:

\section{Correlational Relationships}

Pearson product-moment correlation coefficients were calculated to determine the associations among body composition components and other variables for both the preseason (Table 3) and the post-season (Table 4). Pearson product-moment correlation coefficients were also employed to investigate the associations among BMD and other variables for both the preseason and postseason; and partial correlations were used to study the body composition relationships while holding skeletal maturity (SM) constant (Table 5). There were moderate-to-strong, positive correlations between overall postseason BMD and post-season bodyweight $(r=0.801, \rho=.648)$, LT $(r=0.715, \rho=.600)$, BF $(r=0.647, \rho=.295)$, and BMI $(r=0.720, \rho=.546)$, respectively. The decreased values in the partial correlations suggest that BMD is influenced by skeletal maturity. 
Figures 1-4 are overall post-season BMD scatter plots versus post-season bodyweight, LT, BF, and BMI, respectively.

Table 3

Preseason Body Composition Associations

\begin{tabular}{|c|c|c|c|c|c|c|c|c|}
\hline \multirow[b]{3}{*}{ Age } & \multirow{3}{*}{$\frac{\text { Age }}{-}$} & \multirow{3}{*}{$\underline{\mathrm{Wgt}}$} & \multicolumn{3}{|c|}{ Preseason Correlations (r) } & \multirow{3}{*}{$\underline{\mathrm{BMC}}$} & \multirow{3}{*}{$\underline{\mathrm{BMD}}$} & \multirow{3}{*}{$\underline{\mathrm{BMI}}$} \\
\hline & & & $\underline{\mathrm{Hgt}}$ & $\underline{\mathrm{LT}}$ & $\underline{B F}$ & & & \\
\hline & & & & & & & & \\
\hline Weight & .361 & - & & & & & & \\
\hline Height & .201 & $.439 *$ & - & & & & & \\
\hline $\mathrm{LT}$ & $.395^{*}$ & $.808^{*}$ & $.620^{*}$ & - & & & & \\
\hline BF & .230 & $.853^{*}$ & .158 & $.385^{*}$ & - & & & \\
\hline BMC & $.408^{*}$ & $.910^{*}$ & $.526^{*}$ & $.882^{*}$ & $.636^{*}$ & - & & \\
\hline BMD & $.402 *$ & $.806^{*}$ & .353 & $.753 *$ & $.579 *$ & $.931 *$ & - & \\
\hline BMI & .275 & $.861^{*}$ & -.077 & $.538^{*}$ & $.859 *$ & $.715^{*}$ & $.703 *$ & - \\
\hline Calcium & $.400^{*}$ & $.912 *$ & $.519 *$ & $.879 *$ & $.641^{*}$ & $1.000 *$ & $.932 *$ & $.720 *$ \\
\hline
\end{tabular}

Table 4

Postseason Body Composition Associations

\begin{tabular}{|c|c|c|c|c|c|c|c|c|}
\hline \multirow[b]{3}{*}{ Age } & \multirow{3}{*}{$\frac{\text { Age }}{-}$} & \multirow{3}{*}{$\underline{\text { Wgt }}$} & \multicolumn{3}{|c|}{ Post-Season Correlations (r) } & \multirow{3}{*}{$\underline{\mathrm{BMC}}$} & \multirow{3}{*}{$\underline{\mathrm{BMD}}$} & \multirow{3}{*}{$\underline{\mathrm{BMI}}$} \\
\hline & & & $\underline{\text { Hgt }}$ & $\underline{\mathrm{LT}}$ & $\underline{B F}$ & & & \\
\hline & & & & & & & & \\
\hline Weight & $.377^{*}$ & - & & & & & & \\
\hline Height & .104 & $.418^{*}$ & - & & & & & \\
\hline LT & .332 & $.779 *$ & $.616^{*}$ & - & & & & \\
\hline $\mathrm{BF}$ & .302 & $.870^{*}$ & .133 & $.378^{*}$ & - & & & \\
\hline BMC & $.396^{*}$ & $.923 *$ & $.420 *$ & $.863^{*}$ & $.699 *$ & - & & \\
\hline BMD & .341 & $.801^{*}$ & .216 & $.715^{*}$ & $.647^{*}$ & $.920 *$ & - & \\
\hline BMI & .340 & $.844 *$ & -.048 & $.548^{*}$ & $.821^{*}$ & $.767^{*}$ & $.720^{*}$ & - \\
\hline Calcium & $.396^{*}$ & $.923^{*}$ & $.421^{*}$ & $.863^{*}$ & $.699 *$ & $1.000^{*}$ & $.919^{*}$ & $.767^{*}$ \\
\hline
\end{tabular}
* - Significant 
Table 5

BMD Associations Among Body Composition Components

$\underline{\text { BMD Correlation Coefficients }(\mathrm{n}=28)}$

Variable

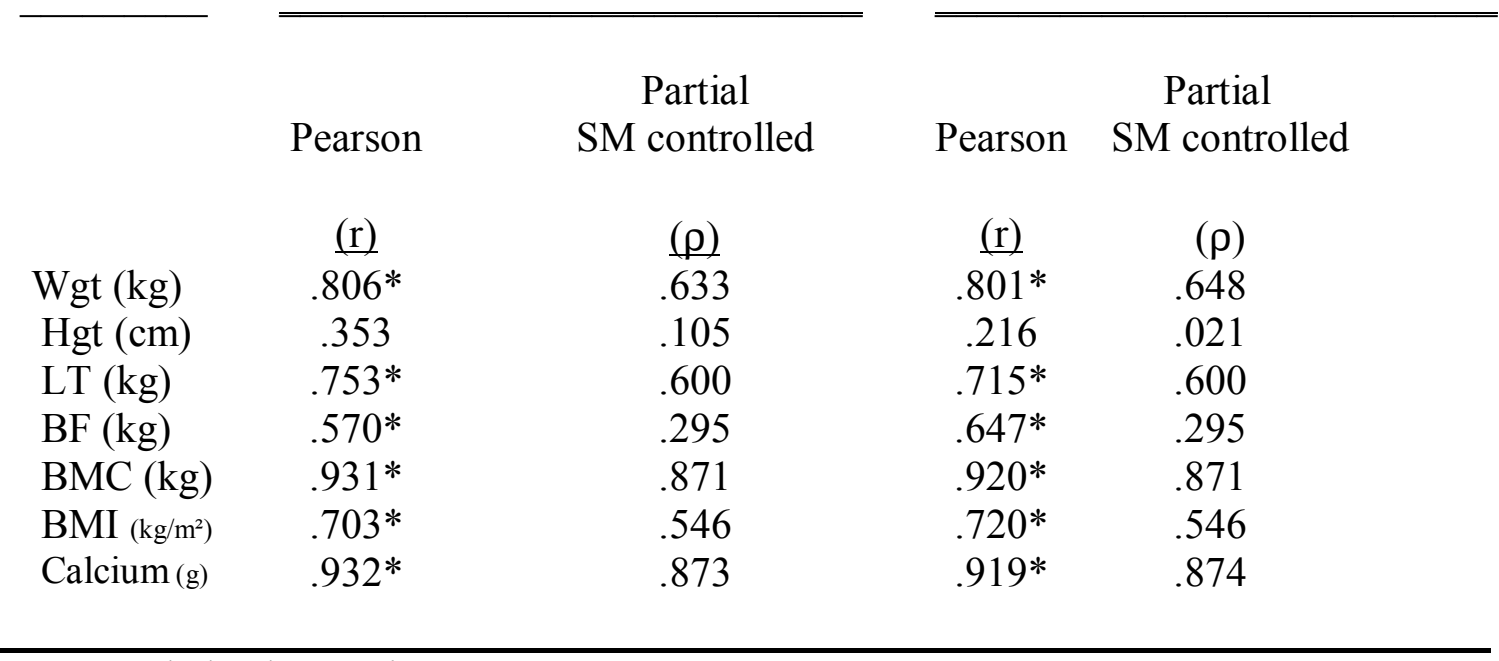

SM - Skeletal Maturity

*- Significant

Skeletal maturity was used as a control because adolescent bone development and body composition are influenced by maturation as well as physical activity levels (Zacharias, Rand \& Wurtman, 1976). Therefore, when examining the complex relationship between body composition, bone development, and physical activity in adolescents, maturity levels must be considered (Beunen et al., 1994). Throughout the current study, skeletal maturity was used as a control in lieu of the subjects' age. While the data from the current study reveals that there was a strong relationship between age and skeletal maturity $(\mathrm{r}=0.816)$ of the subjects, skeletal maturity is a better and more powerful control, especially in analyses involving body composition components such as 
bodyweight, height, BMC, and BMD. Skeletal maturity was estimated using an algorithm developed by Bayer and Bayley (1976) that uses the subject's current age and height and the adult heights of the subject's biological father and mother for predicting the degree (percentage) of the subject's adult physical development.

Pearson product-moment correlation coefficients were calculated to compare the associations among BMD and other body composition components for the two subgroups (Table 6). Similarly, partial correlations were also calculated for the same variables by holding skeletal maturity constant (Table 6). As noted in previous partial correlation examinations in the current study, skeletal maturity was used as a control because of its association with BMD and body composition (Beunen et al., 1994). Results (Table 6) indicated that the amenorrheic subgroup is influenced more by skeletal maturity than the eumenorrheic subgroup. 
Figure 1 - Scatterplot of Overall Post-Season

BMD vs. Post-Season Bodyweight

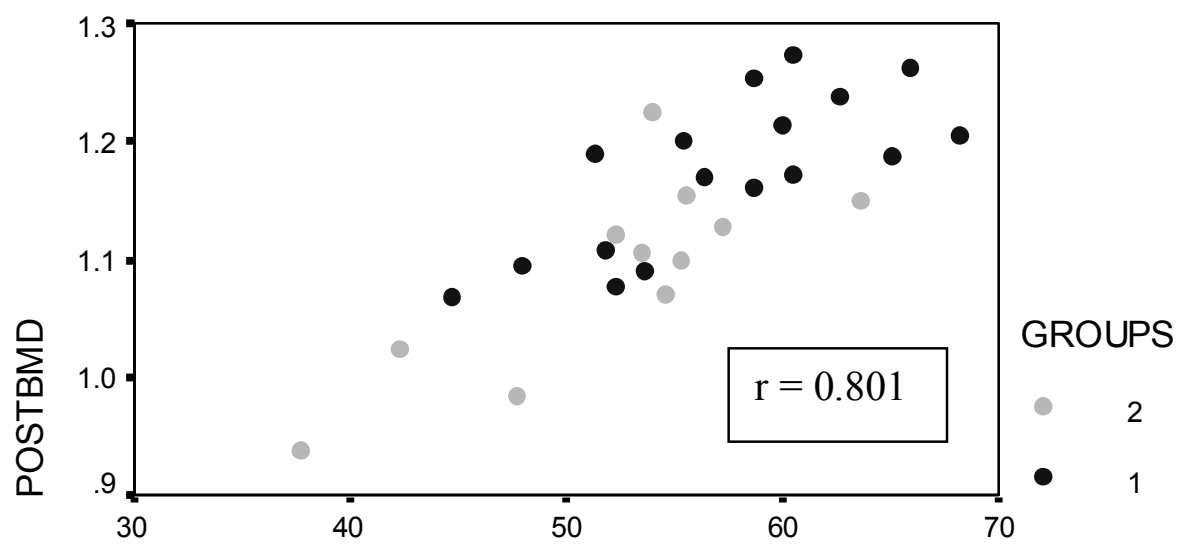

POSTWGT

POSTBMD = Postseason BMD (g/cc); POSTWGT = Postseason Bodyw eight $(\mathrm{kg})$

Group 1 = Eumenorrheic; Group 2 = Amenorrheic

Figure 2 - Scatterplot of Overall Post-Season

BMD vs. Post-Season Lean Tissue

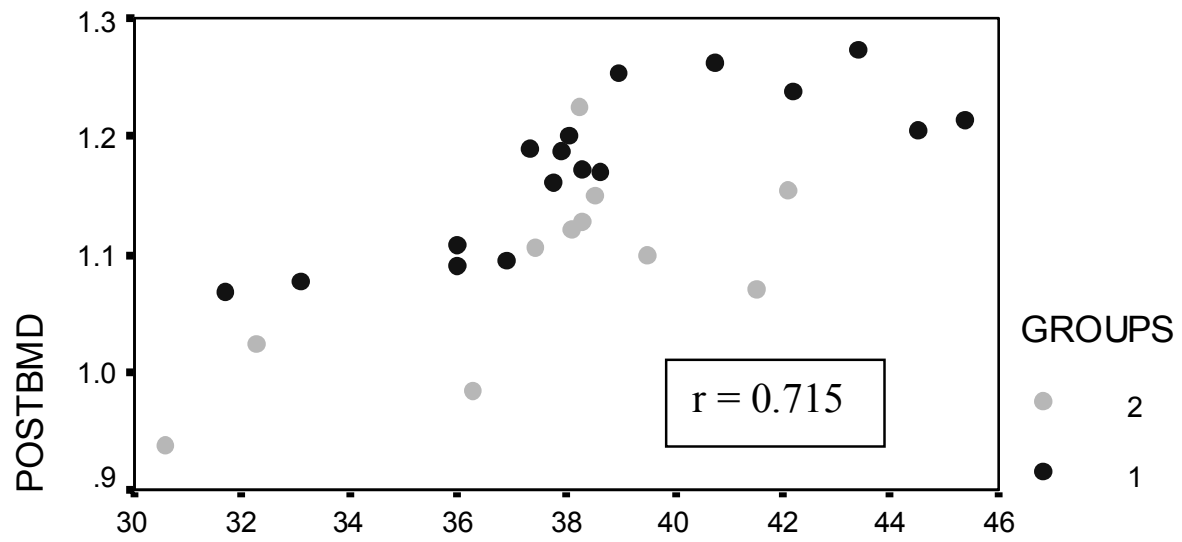

POSTLT

POSTBMD = Potseason BMD (g/cc); POSTLT = Postseason Lean Tissue $(\mathrm{kg})$

Group 1 = Eumenorrheic; Group 2 = Amenorrheic 
Figure 3 - Scatterplot of Overall Post-Season

BMD vs. Post-Season Fat Tissue

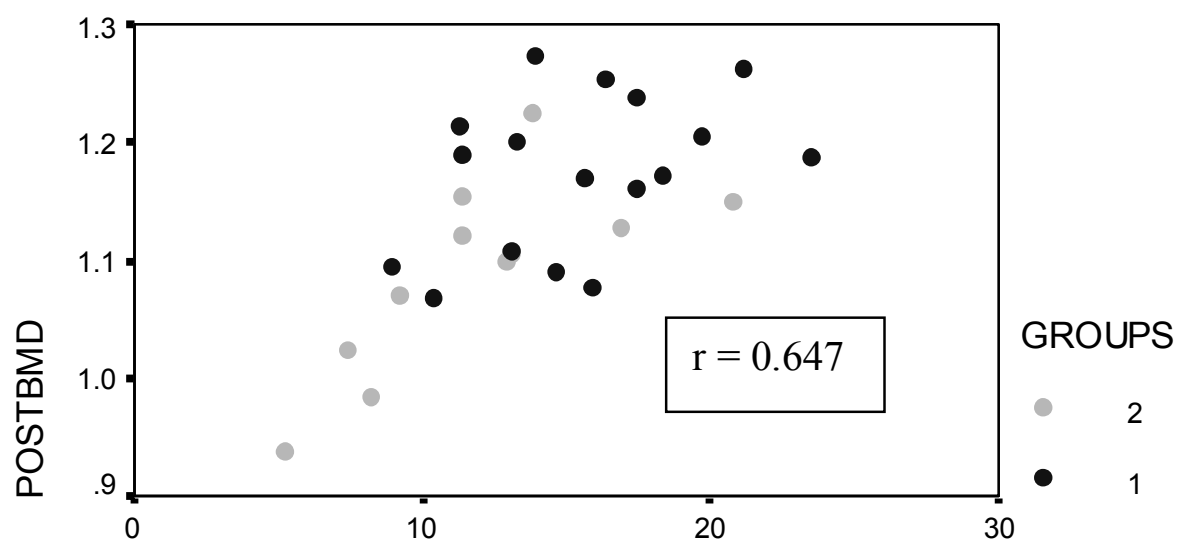

POSTBF

POSTBMD = Postseason BMD (g/cc); POSTBF = Postseason Body Fat $(\mathrm{kg})$

Group 1 = Eumenorrheic; Group 2 = Amenorrheic

Figure 4 - Scatterplot of Overall Post-Season

BMD vs. Post-Season Body Mass Index

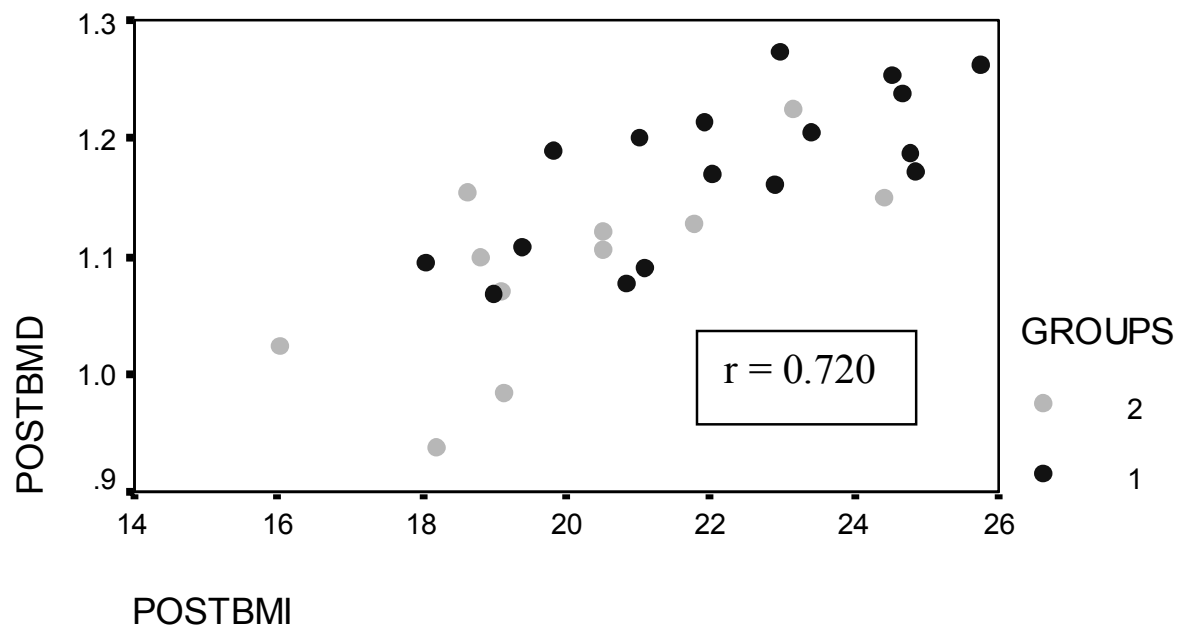

POSTBMD = Postseason BMD; POSTBMl = Postseason BMl

Group 1 = Eumenorrheic; Group 2 = Amenorrheic 
Table 6

BMD Subgroup Associations Among Body Composition Components

Post-Season BMD Associations and Partial Associations (SM controlled)

Variable $\quad$ Eumenorrheic $(\mathrm{n}=17) \quad$ Amenorrheic $(\mathrm{n}=11)$

Pearson Partial Pearson Partial

SM - Skeletal Maturity

* - Significant

Pearson product-moment correlation coefficients were also calculated to examine the relationships among menstrual dysfunction (menstrual periods missed in the last 12 months) and body composition components. Partial correlations were also calculated for the same variables holding menarchal age as a constant. Menarchal age (MA) was used as a control because it is highly associated with amenorrhea (Cobb et al., 2003; Dhuper et al., 1990). Menarchal age and the number of menstrual periods missed in the past 12 months were reported on the research data questionnaire by the subjects. There were moderate, negative correlations between menstrual dysfunction and bodyweight $(\mathrm{r}=\mathrm{-}$ $0.419, \rho=-0.466), \operatorname{BMD}(\mathrm{r}=-0.491, \rho=-0.519), \mathrm{BF}(\mathrm{r}=-0.509, \rho=-0.525)$, and BMI $(\mathrm{r}$ $=-0.438, \rho=-0.454)$, respectively. The negative increases in the partial correlations 
suggest that menstrual dysfunction is influenced by menarchal age. Table 7 presents the Pearson product-moment correlation coefficients and partial correlation coefficients for the menstrual dysfunction associations.

\section{Table 7}

Menstrual Dysfunction Associations

\begin{tabular}{|c|c|c|}
\hline Variable & Pearson & Partial - MA controlled \\
\hline & $\underline{r}$ & $\underline{\varrho}$ \\
\hline Post-Bodyweight (kg) & $-0.419 *$ & -0.466 \\
\hline Post-BMD (g/ $\left.\mathrm{cm}^{2}\right)$ & $-0.491 *$ & -0.519 \\
\hline Post-Body Fat (kg) & $-0.509 *$ & -0.525 \\
\hline Post-Lean Tissue (kg) & -0.1690 & -0.239 \\
\hline Post-BMI $\left(\mathrm{kg} / \mathrm{m}^{2}\right)$ & $-0.438 *$ & -0.454 \\
\hline
\end{tabular}

Menstrual Dysfunction - Menstrual periods missed in the past 12 mos.

MA - Menarchal Age

*- Significant

\section{Paired t-test Analyses}

Seasonal BMD and body composition changes were examined. Paired t-tests were used to investigate whether body composition components increased significantly during the six-month study interval. The level of significance was set at $p<.05$. The paired $t-$ tests were calculated using the subject population and also by category classification to determine whether there were group differences over time. The paired t-tests were calculated to compare the preseason body composition components to the mean post- 
season body composition components. Overall, there were significant seasonal increases in weight $(\mathrm{t}(27)=-3.61, \mathrm{p}<.05)$, height $(\mathrm{t}(27)=-3.59, \mathrm{p}<.05), \mathrm{BMD}(\mathrm{t}(27)=-4.01, \mathrm{p}<$ $.05), \mathrm{BF}(\mathrm{t}(27)=-3.29, \mathrm{p}<.05), \mathrm{BMC}(\mathrm{t}(27)=-5.85, \mathrm{p}<.05)$, calcium $(\mathrm{t}(27)=-5.87, \mathrm{p}<$ $.05)$, and $\mathrm{BMD}_{\text {spine }}(\mathrm{t}(27)=-2.32, \mathrm{p}<.05)$. Table 1 shows the preseason and post-season values of the variables and indicates the variables that increased significantly. The eumenorrheic subgroup had significant seasonal increases in weight $(t(16)=-2.54, p<$ $.05)$, BMD $(\mathrm{t}(16)=-3.90, \mathrm{p}<.05), \operatorname{BMDs}(\mathrm{t}(16)=-3.12, \mathrm{p}<.05)$, BMD z-score $(\mathrm{t}(16)=$ 2.51, $\mathrm{p}<.05)$, BMC $(\mathrm{t}(16)=-5.30, \mathrm{p}<.05), \mathrm{BF}(\mathrm{t}(16)=-2.96, \mathrm{p}<.05)$, calcium $(\mathrm{t}(16)=$ $--5.18, \mathrm{p}<.05)$. The amenorrheic subgroup showed significant seasonal increases in weight $(\mathrm{t}(10)=-2.67, \mathrm{p}<.05)$, height $(\mathrm{t}(10)=-2.55, \mathrm{p}<.05), \mathrm{BMC}(\mathrm{t}(10)=-2.79, \mathrm{p}<$ $.05)$, and calcium $(\mathrm{t}(10)=-2.92, \mathrm{p}<.05)$. Table 2 shows the preseason and post-season values of the variables and indicates the variables that increased significantly. Appendix $\mathrm{C}$ provides detailed comparative seasonal analyses of the paired t-tests of the variables that were measured overall and by subgroups.

Figures 5-9 depict seasonal changes by subgroup with respect to BMD, BMD zscores, bodyweight, $\mathrm{BF}$, and $\mathrm{LT}$, respectively. It is interesting to note that although the amenorrheic seasonal change in BMD was not significant, it did increase at half the rate of the eumenorrheic subgroup (Figure 5); however, the amenorrheic seasonal BMD zscore actually decreased while the eumenorrheic seasonal BMD z-score increased significantly (Figure 6). This indicates that during the season the eumenorrheic subgroup BMD was increasing and moving away from the U.S. BMD norm, while the amenorrheic subgroup was decreasing and moving toward the U.S. BMD norm. A z-score specifies the location of a single value in reference to the mean. Its magnitude is given in units of 
standard deviation and its polarity specifies whether the value is above $(+)$ or below (-) the mean. BMD z-scores were computed by the DXA using U.S. age and weight normative values by gender and ethnicity. For example, a BMD z-score equal to one standard deviation above the U.S. BMD mean for a specific gender, age, weight, and ethnicity is +1.0 ; a BMD z-score equal to the U.S. BMD mean for a specific gender age, weight, and ethnicity is zero; and a BMD z-score equal to one standard deviation below the U.S. BMD mean for a specific gender, age, weight, and ethnicity is -1.0 .

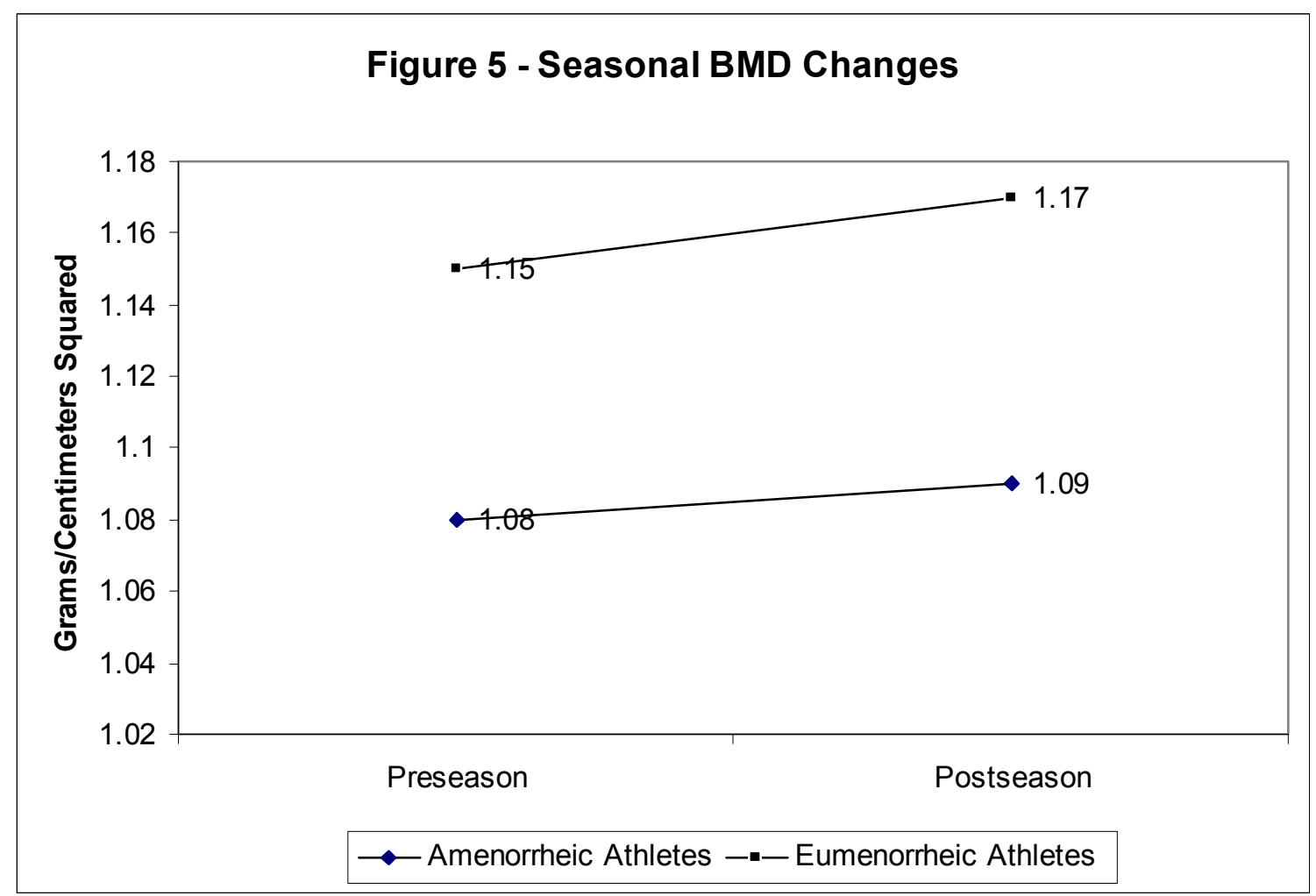




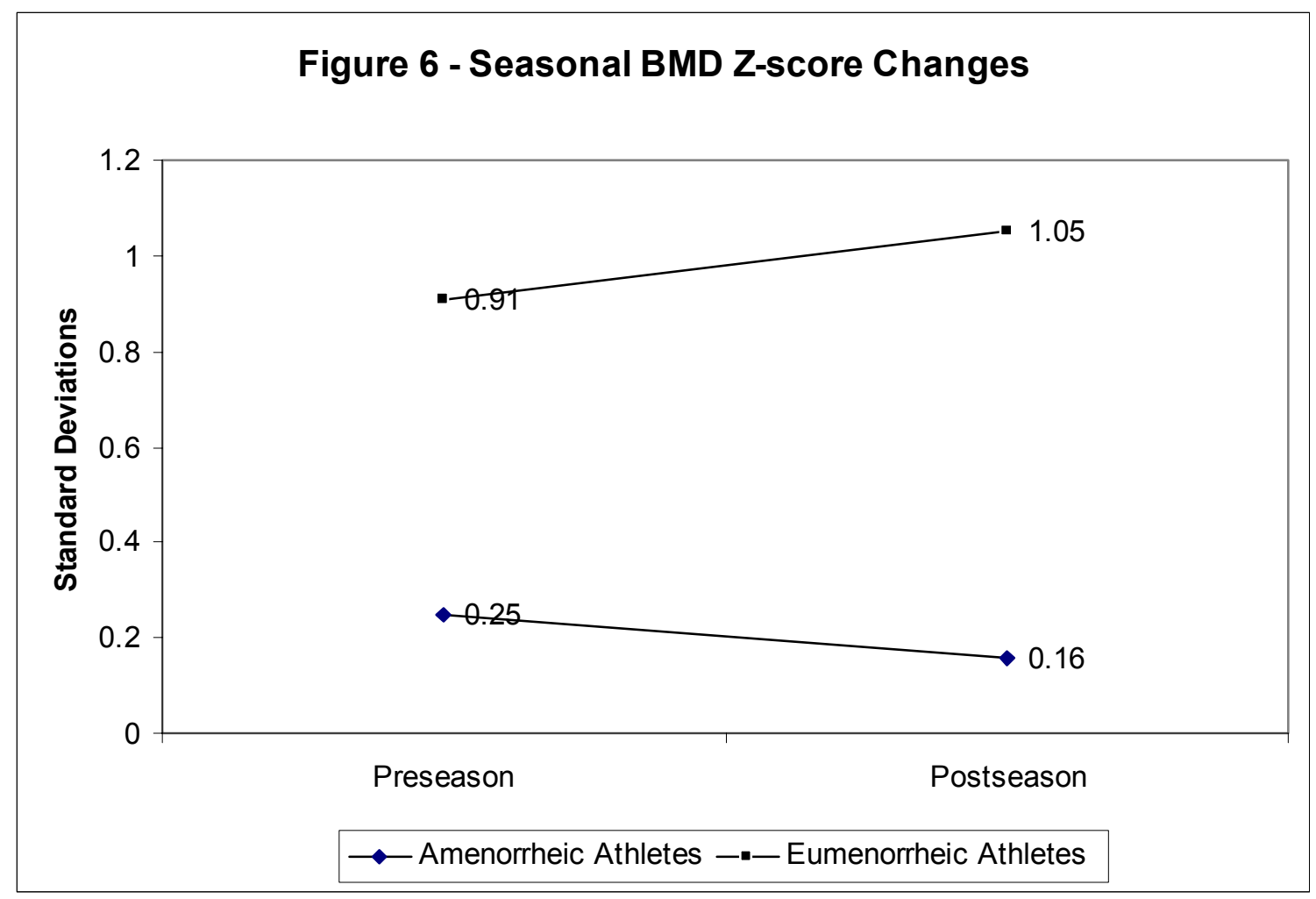

Figure 7 - Seasonal Bodyweight Changes

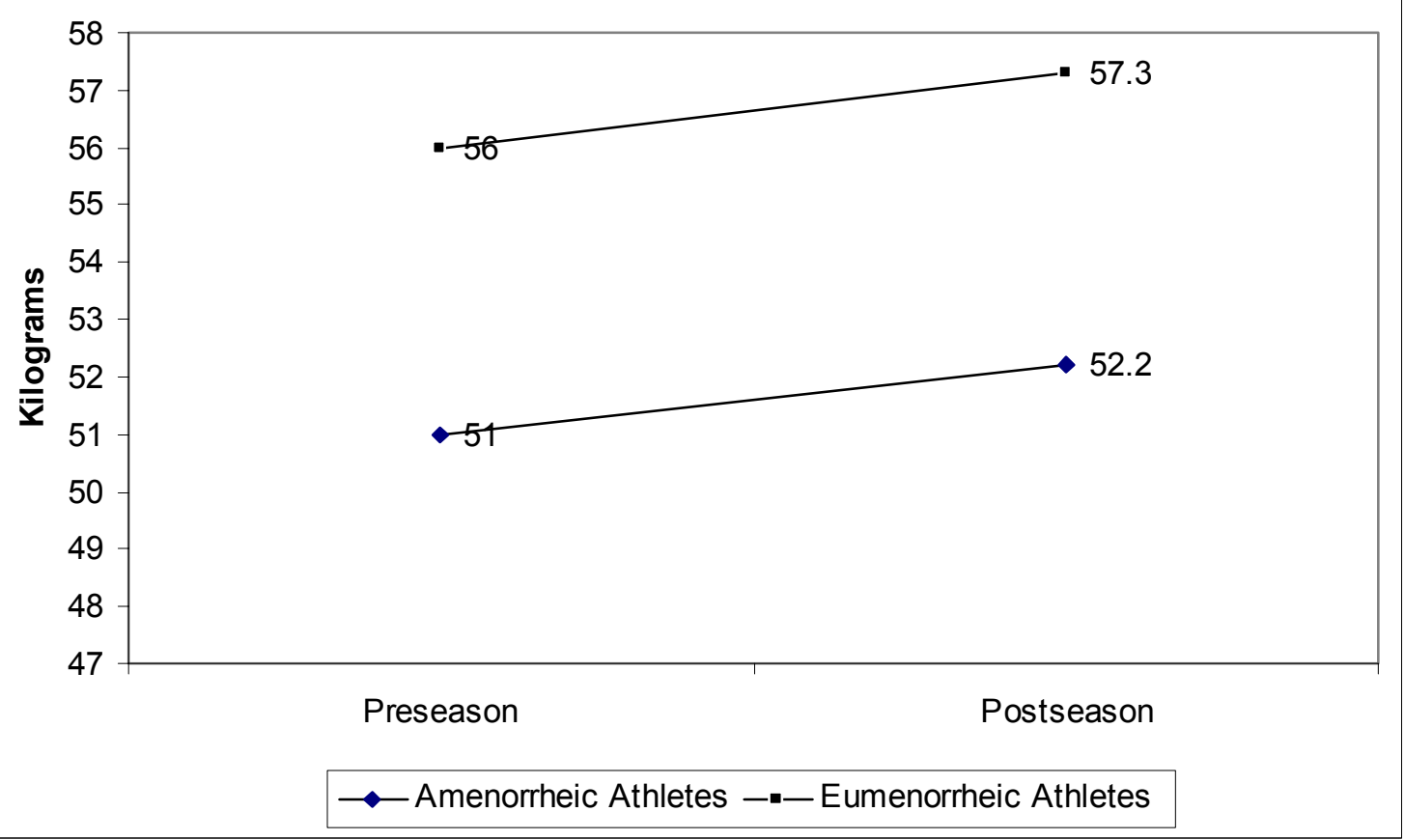



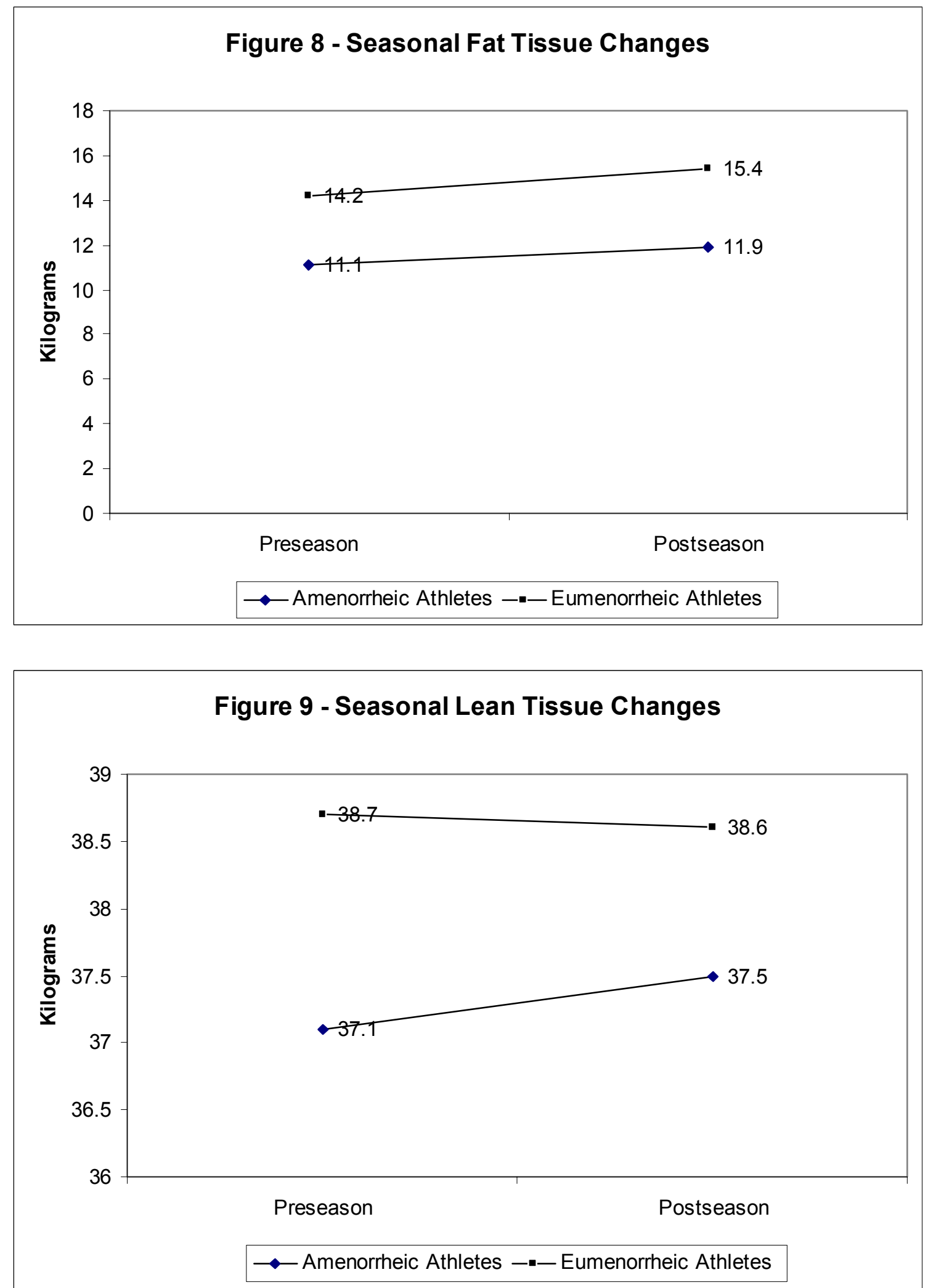


\section{Multivariate Analyses of Variance}

Multivariate analyses (MANOVA \& ANOVA) were conducted to determine if significant subgroup differences existed among BMD and body composition components. In order to determine the influence of skeletal maturity on the same variables, MANCOVA \& ANCOVA were employed with skeletal maturity as a covariate. Finally, to determine the influence of both skeletal maturity and menarchal age on the same variables, MANCOVA \& ANCOVA were again utilized with both skeletal maturity and menarchal age as covariates. Table 8 summarizes the results from the multivariate analyses. The summary demonstrates that skeletal maturation and menarchal age influence the variables analyzed. In all of the variables that had significant subgroup differences, the eumenorrheic subgroup variables were significantly greater than the amenorrheic subgroup, except for menarchal age. The amenorrheic subgroup had a significantly greater (older) mean menarchal age $(13.1 \pm 1.2$ years $)$ than the eumenorrheic subgroup $(12.5+1.0$ years $)$. Appendix D provides detailed results of the multivariate analyses. 


\title{
Table 8
}

Summary of Multivariate Analyses of Significant Subgroup Differences

\author{
Summary of Multivariate Analyses \\ of \\ $\underline{\text { Significant Subgroup Body Composition Differences }}$
}

\begin{tabular}{|c|c|c|c|}
\hline Variables & MANOVA & $\begin{array}{c}\text { MANCOVA } \\
\text { Covariate - SM } \\
\end{array}$ & $\begin{array}{c}\text { MANCOVA } \\
\text { Covariates - SM \& MA } \\
\end{array}$ \\
\hline SM & $\mathrm{E}>\mathrm{A}$ & - & - \\
\hline $\begin{array}{l}\text { MA } \\
\text { Age }\end{array}$ & $\mathrm{E}<\mathrm{A}$ & $\mathrm{E}<\mathrm{A}$ & - \\
\hline $\begin{array}{c}\text { Run Perf. } \\
\text { BMD } \\
\text { BMDL }\end{array}$ & $E>A$ & $\mathrm{E}>\mathrm{A}$ & \\
\hline $\begin{array}{l}\text { BMD } \\
\text { BMDs } \\
\text { Weight } \\
\text { Height }\end{array}$ & $\begin{array}{l}E>A \\
E>A \\
E>A\end{array}$ & $E>A$ & $E>A$ \\
\hline $\begin{array}{l}\text { Body Fat } \\
\text { LT }\end{array}$ & $E>A$ & & \\
\hline Calcium & $\mathrm{E}>\mathrm{A}$ & & \\
\hline BMI & $E>A$ & & \\
\hline $\mathrm{BMC}$ & $E>A$ & & \\
\hline
\end{tabular}

SM - Skeletal Maturity

MA - Menarchal Age

E - Eumenorrheic Subgroup

A - Amenorrheic Subgroup 


\subsection{Performance and Training Volume}

Performance

A one-way multivariate analysis of variance (MANOVA) was used to investigate subgroup differences in regard to various dependent variables. First, a one-way MANOVA was conducted to determine subgroup differences between skeletal maturity, age of menarche, age, and run performance. MANOVA results revealed significant subgroup differences (Table 9) with respect to the dependent variables, Wilk's $\lambda=.628$, $\mathrm{F}(4,51)=5.26, \mathrm{p}<.05$, multivariate $\eta^{2}=.372$. Analysis of variance (ANOVA) was conducted on each dependent variable as a follow-up test to MANOVA. The results indicated significant subgroup differences (Table 10) with respect to skeletal maturity (Eumenorrheic $\mathrm{SM}=98.6 \pm .01 \%$, Amenorrheic $\mathrm{SM}=97.2 \pm .02 \%, \mathrm{~F}(1,54)=11.68$ $\mathrm{p}<.05$, partial $\eta^{2}=.178$ ) and menarchal age (Eumenorrheic MA $=12.5 \pm 1.0 \mathrm{yrs}$, Amenorrheic $\mathrm{MA}=13.1 \pm 1.2 \mathrm{yrs}, \mathrm{F}(1,54)=4.46, \mathrm{p}<.05$, partial $\left.\eta^{2}=.076\right)$. However, there were no significant subgroup differences with respect to age and run performance.

\section{Training Volume}

In addition, Pearson product-moment correlation coefficients were calculated to compare the relationships among training volume (kmpw - kilometers run per week) and body composition components along with the subjects' $3.2 \mathrm{~km}$ "personal best" performance-time. Partial correlations were also calculated for the same variables, separately holding menarchal age ( $\rho 1)$ as a constant, and then holding skeletal maturity ( $\rho 2)$ as a constant. There was a moderate, negative correlation between training volume and performance $(\mathrm{r}=-0.663, \rho 1=-0.649, \rho 2=-0.770)$. The partial correlation results using SM as a control suggest that training volume is influenced by skeletal maturity. In 
the current study, the older, more experienced runners were generally better performers and were also assigned to higher volume training groups. Table 9 presents the training volume comparisons.

Table 9

Training Volume Associations

Training Volume Associations

\begin{tabular}{|c|c|c|c|}
\hline Variable & Pearson & $\begin{array}{c}\text { Partial } \\
\text { (Controlled } \\
\text { for MA) }\end{array}$ & $\begin{array}{c}\text { Partial } \\
\text { (Controlled } \\
\text { for SM) }\end{array}$ \\
\hline & $\underline{\mathrm{r}}$ & $\rho 1$ & $\rho 2$ \\
\hline Post-Weight (kg) & $.375 *$ & .361 & -.041 \\
\hline Post-BMD $\left(\mathrm{g} / \mathrm{c}^{2}\right)$ & .371 & .370 & -.005 \\
\hline Post-BF (kg) & .161 & .166 & -.309 \\
\hline Post-LT (kg) & $.527^{*}$ & .502 & .328 \\
\hline 3.2 km Run (min) & $-.663^{*}$ & -.649 & -.770 \\
\hline
\end{tabular}

\subsection{Stress Fractures}

A comparison of the number of diagnosed stress fractures between the two subgroups was conducted using a one-way analysis of variance (ANOVA). No significant difference was found $(\mathrm{F}(1.26)=0.046, \mathrm{p}=0.831)$ between the amenorrheic and eumenorrheic subgroups. 


\subsection{Nutritional Supplementation}

Nutritional supplementation between the two subgroups was compared using a one-way analysis of variance (ANOVA). No significant difference was found $(\mathrm{F}(1.26)=$ $0.912, p=0.348$ ) between the amenorrheic and eumenorrheic subgroups.

\subsection{Predictor Variables for BMD}

Simple linear regressions were calculated to determine what body composition component best predicted the subjects' post-BMD. Table 10 displays the $\mathrm{R}$ and $\mathrm{R}$ square values of the body composition components, overall and by subgroup, to determine what predictor variable accounts for the greatest amount of variance in the criterion variable, post-BMD. Overall, post-bodyweight was the best predictor of post-BMD $\left(\mathrm{R}^{2}=0.641\right.$, $\mathrm{F}(1,26)=46.434, \mathrm{p}<.05)$. Using this linear regression, the athletes' predicted BMD is equal to $.624+.009366$ (bodyweight) $\mathrm{g} / \mathrm{c}^{2}$ when bodyweight is measured in kilograms. Figure 10 is a scatter plot of post-BMD versus post-bodyweight. 
Table 10

Coefficients of Determination of Predictor Variables

Coefficients of Determination of Post Body Composition Components

as

Independent Predictor Variables

for

Post-BMD

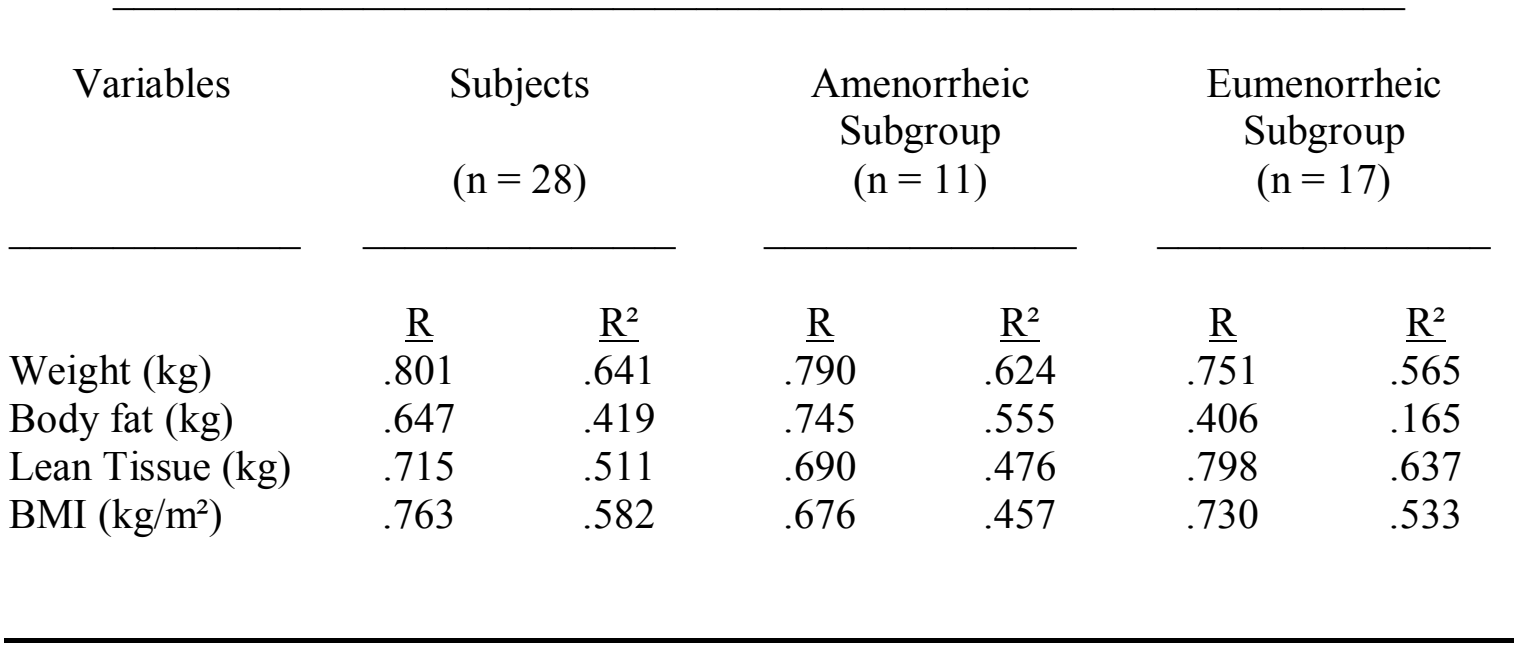




\section{Figure 10}

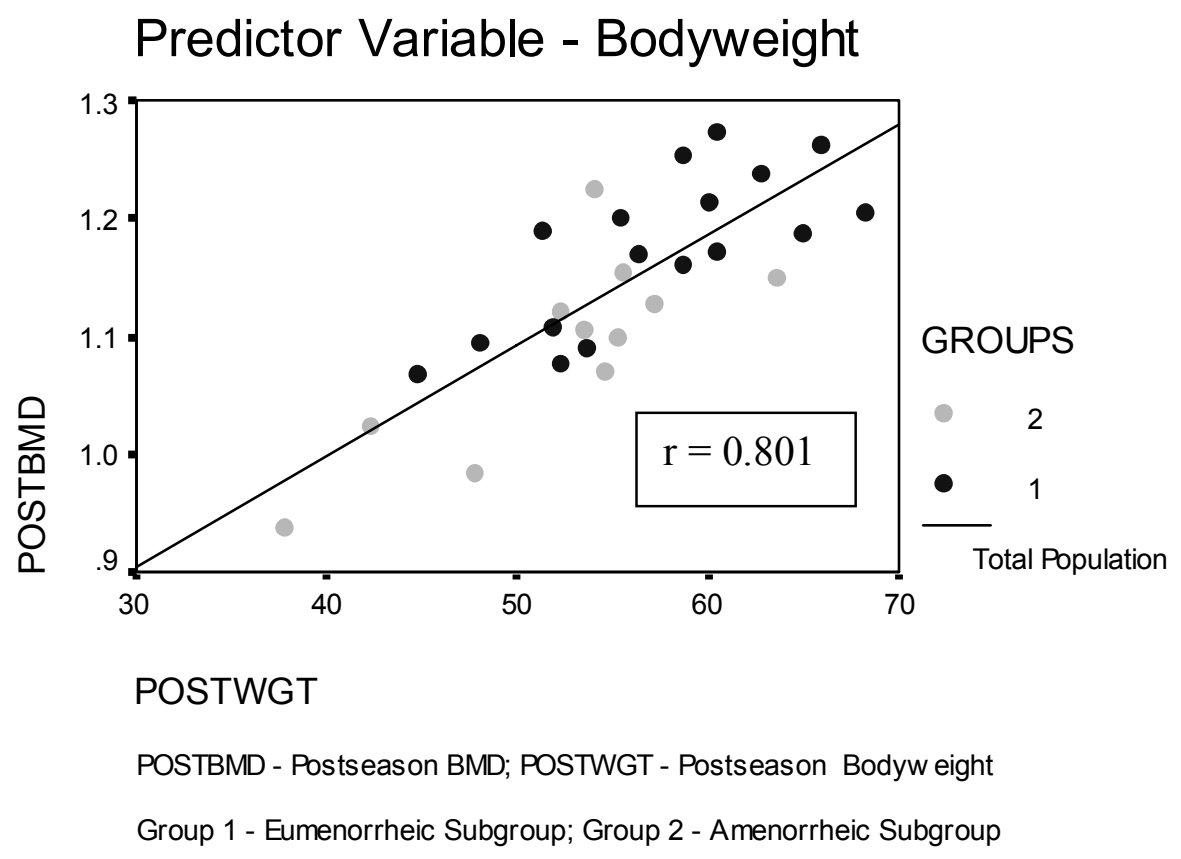

Simple linear regressions were also calculated to determine what body composition component best predicted the amenorrheic subjects' post-BMD. For the amenorrheic subgroup, post-bodyweight was the best predictor of post-BMD $\left(\mathrm{R}^{2}=0.624\right.$, $\mathrm{F}(1,9)=14.947, \mathrm{p}<.05)$. Using this linear regression, the amenorrheic athletes' predicted BMD is equal to $.618+.009072$ (bodyweight) $\mathrm{g} / \mathrm{c}^{2}$ when bodyweight is measured in kilograms. Figure 11 is a scatter plot of post-BMD versus post-bodyweight for the amenorrheic subgroup. 


\section{Figure 11}

\section{Predictor Variable - Bodyweight}

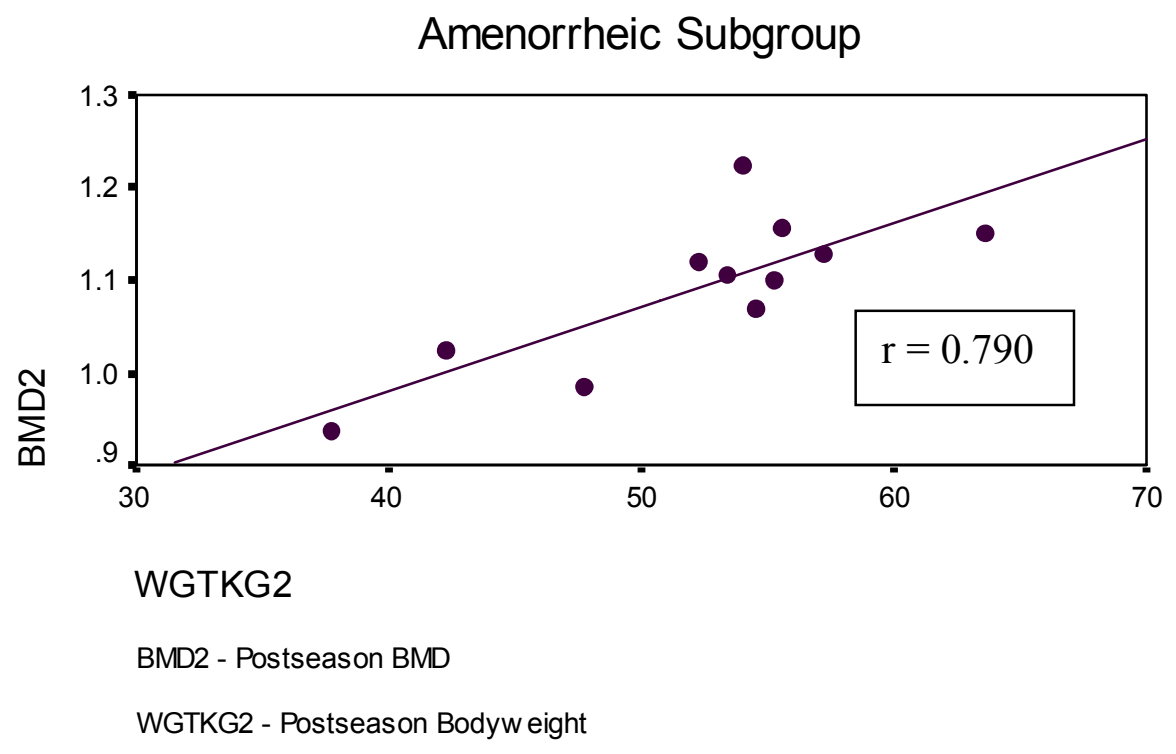

Simple linear regressions were calculated to determine what body composition component best predicted the eumenorrheic subjects' post-BMD. For the eumenorrheic subgroup, post-LT was the best predictor of post-BMD $\left(\mathrm{R}^{2}=0.637, \mathrm{~F}(1,15)=26.374, \mathrm{p}<\right.$ $.05)$. Using this linear regression, the eumenorrheic athletes' predicted BMD is equal to $.620+.0143$ (lean tissue) $\mathrm{g} / \mathrm{c}^{2}$ when lean tissue is measured in kilograms. Figure 12 is a scatter plot of post-BMD versus LT for the eumenorrheic subgroup. 


\section{Figure 12}

\section{Predictor Variable - Lean Tissue}

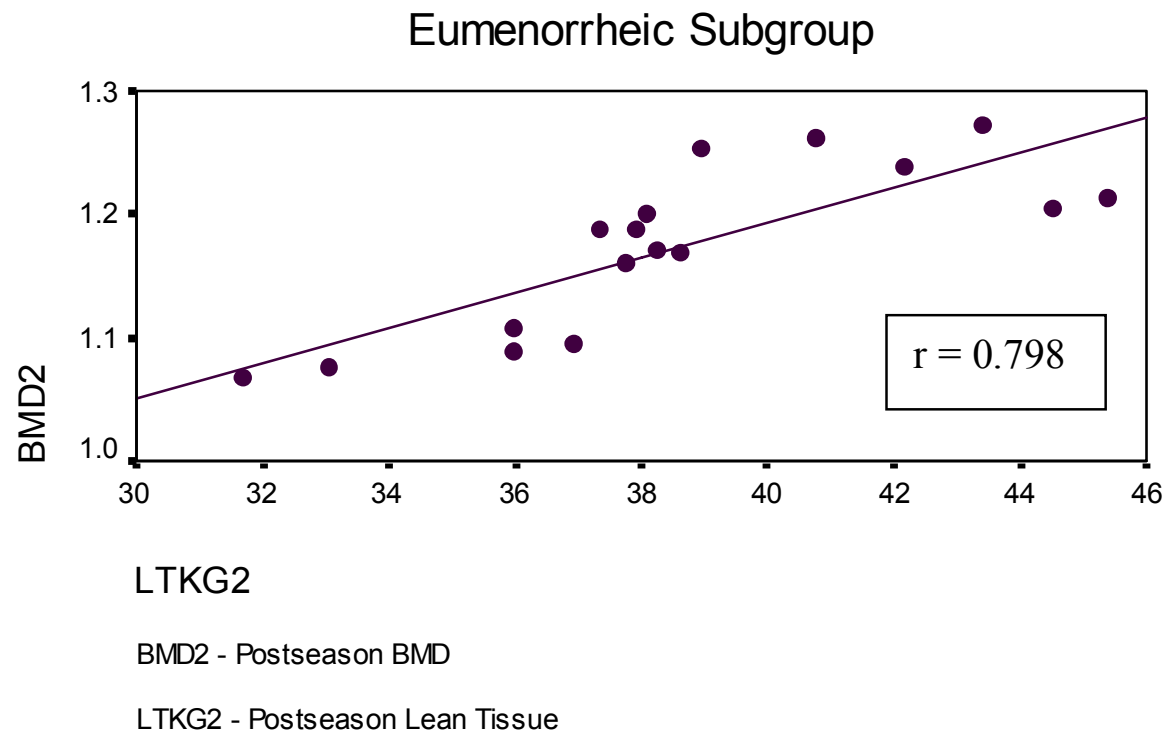

\subsection{Results by Research Question}

Data from the current study is also organized and presented to provide the specific data to address the eight research questions.

\subsection{1 - Does exercise-associated amenorrhea affect performance in adolescent cross- country runners?}

While the mean performance time for the amenorrheic subgroup (15.03 min) was 19.8 seconds faster than the eumenorrheic subgroup's mean performance time (15.36 min), examination of the multivariate analysis results of the current study indicated that there was no significant difference in performance time $(\mathrm{F}(1,54)=.427, \mathrm{p}=.516$, partial $\left.\eta^{2}=.008\right)$ between the amenorrheic and eumenorrheic subgroups. 


\subsection{2 - Is bone mineral density affected by exercise-associated amenorrhea in adolescent cross-country runners?}

Examination of the results from the multivariate analyses of the current study revealed significant subgroup differences in $\operatorname{BMD}\left(F(1,54)=16.22, p<.05\right.$, partial $\eta^{2}=$ $.231)$, with the eumenorrheic subgroup BMD $\left(1.17 \pm .07 \mathrm{~g} / \mathrm{cm}^{2}\right)$ greater than the amenorrheic subgroup BMD $\left(1.09+.06 \mathrm{~g} / \mathrm{cm}^{2}\right)$.

\subsection{3 - Is body composition affected by exercise-associated amenorrhea in adolescent cross-country runners?}

Examination of the results from the multivariate analyses of the current study revealed significant subgroup differences $\left(F(1,54)=8.56, p<.05\right.$, partial $\left.\eta^{2}=.137\right)$ in fat tissue (eumenorrheic FT $=15.4 \pm 3.9 \mathrm{~kg}$, amenorrheic FT $=11.9 \pm .06 \mathrm{~kg}$ ) and bone mineral content $\left(\mathrm{F}(1,54)=8.52, \mathrm{p}<.05\right.$, partial $\eta^{2}=.136$, eumenorrheic $\mathrm{BMC}=2.6 \pm .36$ $\mathrm{kg}$, amenorrheic $\mathrm{BMC}=2.3 \pm .37 \mathrm{~kg}$ ). The only body composition component that was not significantly different between the subgroups was lean tissue $(F(1,54)=1.82, p=$ .183 , partial $\left.\eta^{2}=.033\right)$.

\subsection{4 - Is bodyweight affected by exercise-associated amenorrhea in adolescent cross-country runners?}

Examination of the results from the multivariate analyses of the current study revealed significant subgroup differences in body weight $(\mathrm{F}(1,54)=7.65, \mathrm{p}<.05$, partial $\left.\eta^{2}=.124\right)$ with the eumenorrheic subgroup bodyweight $(57.3 \pm 6.5 \mathrm{~kg})$ greater than the amenorrheic subgroup bodyweight $(52.2 \pm 7.2)$. 


\subsection{5 - Is bone mineral density affected by cross-country running in female adolescents?}

Examination of the pre- and post season paired t-test results of the current study revealed significant overall increases in BMD $(\mathrm{t}(27)=-4.01, \mathrm{p}<.05$, preseason $\mathrm{BMD}=$ $1.12 \pm .15 \mathrm{~g} / \mathrm{cm}^{2}$, postseason BMD $=1.14 \pm .08 \mathrm{~g} / \mathrm{cm}^{2}$ ). The eumenorrheic subgroup also had a significant increase in BMD $(\mathrm{t}(16)=-3.90, \mathrm{p}<.05$, preseason $\mathrm{BMD}=1.15 \pm .07$ $\mathrm{g} / \mathrm{cm}^{2}$, postseason $\mathrm{BMD}=1.17 \pm .07 \mathrm{~g} / \mathrm{cm}^{2}$ ) from the pre-season to the post season, while the amenorrheic subgroup did not $(\mathrm{t}(10)=-1.80, \mathrm{p}=.102)$.

\subsection{6 - Is the incidence of stress fractures greater in amenorrheic, adolescent cross-country runners than in eumenorrheic, adolescent cross-country runners?}

A one-way analysis of variance was calculated to compare the number of stress fractures between the two subgroups. No significant difference $(F(1.26)=0.046, p=$ 0.831, partial $\eta^{2}=0.002$ ) was found. Of the three stress fractures reported, two stress fractures were reported from two eumenorrheic athletes, one with a training volume of 32.2 kilometers per week and the other with a training volume of 48.3 kilometers per week. The third stress fracture was reported by an amenorrheic athlete whose training volume was 32.2 kilometers per week.

\subsection{7 - Is there less nutritional supplementation by amenorrheic, adolescent cross- country runners than by eumenorrheic, adolescent cross-country runners?}


Nutritional supplementation between the two subgroups was compared using a one-way analysis of variance (ANOVA). No significant difference was found $(\mathrm{F}(1.26)=$ $0.912, p=0.348)$ between the amenorrheic and eumenorrheic subgroups. Of the five subjects that reported nutritional supplementation four were eumenorrheic and one was amenorrheic.

\subsection{8 - Is bodyweight the best predictor of BMD in adolescent cross-country runners?}

Simple linear regression analysis revealed that bodyweight was the best predictor of $\operatorname{BMD}(\mathrm{F}(1,26)=46.434, \mathrm{p}<.05)$ with an $\mathrm{R}^{2}$ of .641 . Similar analysis also revealed that bodyweight was the best predictor variable of BMD for the amenorrheic subgroup $(F(1,9)$ $=14.947, \mathrm{p}<.05)$ with an $\mathrm{R}^{2}$ of .624 ; however, the best predictor of BMD for the eumenorrheic subgroup was $\operatorname{LT}(\mathrm{F}(1,15)=26.374, \mathrm{p}<.05)$ with an $\mathrm{R}^{2}$ of .637 .

\subsection{Summary}

A summary of the findings follows: An examination of the multivariate analysis results of the current study indicated that there was no significant difference in run performance time $\left(\mathrm{F}(1,54)=.427, \mathrm{p}=.516\right.$, partial $\left.\eta^{2}=.008\right)$ between the amenorrheic and eumenorrheic subgroups.

Examination of the results from the multivariate analyses of the current study revealed significant subgroup differences in BMD (Eumenorrheic BMD $=1.17 \pm .07$ $\mathrm{g} / \mathrm{cm}^{2}$, Amenorrheic $\mathrm{BMD}=1.09 \pm .06 \mathrm{~g} / \mathrm{cm}^{2}, \mathrm{~F}(1,54)=16.22, \mathrm{p}<.05$, partial $\left.\eta^{2}=.231\right)$, body weight (Eumenorrheic BW $=57.3 \pm 6.5 \mathrm{~kg}$, Amenorrheic BW $=52.2 \pm 7.2 \mathrm{~kg}$, 
$\mathrm{F}(1,54)=7.65, \mathrm{p}<.05$, partial $\left.\eta^{2}=.124\right)$, fat tissue $($ Eumenorrheic $\mathrm{BF}=15.4 \pm 3.9 \mathrm{~kg}$, Amenorrheic $\mathrm{BF}=11.9 \pm 4.4 \mathrm{~kg}, \mathrm{~F}(1,54)=8.56, \mathrm{p}<.05$, partial $\left.\eta^{2}=.137\right)$, and bone mineral content (Eumenorrheic $\mathrm{BMC}=2.6 \pm .36 \mathrm{~kg}$, Amenorrheic $\mathrm{BMC}=2.3 \pm .37 \mathrm{~kg}$, $\mathrm{F}(1,54)=8.52, \mathrm{p}<.05$, partial $\left.\eta^{2}=.136\right)$

Examination of the pre- and post season paired t-test results of the current study for BMD indicated significant seasonal increases in BMD (Preseason BMD $=1.12 \pm .08$ $\mathrm{g} / \mathrm{cm}^{2}$, post-season BMD $\left.=1.14 \pm .08 \mathrm{~g} / \mathrm{cm}^{2}, \mathrm{t}(27)=-4.01, \mathrm{p}<.05\right)$ overall.

A one-way analysis of variance was calculated to compare the number of stress fractures between the two subgroups.

No significant difference $\left(F(1.26)=0.046, p=0.831\right.$, partial $\left.\eta^{2}=0.002\right)$ was found.

Nutritional supplementation between the two subgroups was compared using a one-way analysis of variance (ANOVA). No significant difference was found $(\mathrm{F}(1.26)=$ $0.912, p=0.348$ ) between the amenorrheic and eumenorrheic subgroups. Simple linear regression analysis revealed that bodyweight was the best predictor $(F(1,26)=46.434, p<$ $\left..05, \mathrm{R}^{2}=.641\right)$. 


\section{Chapter V}

\section{Discussion}

\subsection{Overview}

Chapter five provides the purpose of the study and summarizes the findings relative to the research questions. In addition, the chapter includes a discussion of the findings, recommendation for future research, implications, and a summary.

\subsection{Purpose of the Study}

The purpose of the study was to examine the relationship of exercise-associated amenorrhea and bone mineral density in 28 adolescent cross-country runners who belonged to an elite cross-country high school program.

The study posed the following eight research questions:

1. Does exercise-associated amenorrhea affect performance in female, adolescent cross-country runners?

2. Is bone mineral density affected by exercise-associated amenorrhea in female, adolescent cross-country runners?

3. Is body composition affected by exercise-associated amenorrhea in female, adolescent cross-country runners?

4. Is body weight affected by exercise-associated amenorrhea in female, adolescent cross-country runners?

5. Is bone mineral density affected by cross-country running in female adolescents?

6. Is the incidence of stress fractures greater in amenorrheic, adolescent 
cross-country runners than in eumenorrheic, adolescent cross-country runners?

7. Is there less nutritional supplementation by amenorrheic, adolescent crosscountry runners than by eumenorrheic, adolescent cross-country runners?

8. Is bodyweight the best predictor of BMD in female, adolescent cross$\underline{\text { country runners? }}$

\subsection{Summary of the Findings}

Eight research questions formed the basis for this study. Data analysis using statistical and inferential procedures revealed statistically significant results for five of these questions. There were significant differences in BMD (research question \# 2), body composition (research question \#3), and bodyweight (research question \#4) between the eumenorrheic and amenorrheic subgroups, with the eumenorrheic subgroup having significantly greater $\mathrm{BMD}, \mathrm{BF}, \mathrm{BMC}$, and bodyweight than the amenorrheic subgroup. There was a significant seasonal increase in BMD for the sample from pre-season to postseason (research question \# 5). A simple linear regression revealed a significant relationship between the criterion variable, BMD, and the predictor variable, bodyweight, and also proved to be the best predictor as compared to other linear regressions (research question \#8). There were no significant subgroup differences with respect to run

performance (research question \#1), stress fractures (research question \#6), and nutritional supplementation (research question \#7). 


\subsection{Discussion of the Findings}

This study provides quantitative data regarding the relationship of athletic amenorrhea to bone mineral density in elite adolescent cross-country runners. An examination of the pertinent findings within the context of the theoretical framework of this study supports as well as contradicts past research regarding various aspects of athletic amenorrhea and BMD.

\section{Bone Mineral Density}

The main finding of the study was that within the adolescent cross-country group, the amenorrheic subgroup had significantly lower BMD $\left(1.09 \pm .06 \mathrm{~g} / \mathrm{cm}^{2}\right)$ than the eumenorrheic subgroup $\left(1.17 \pm .07 \mathrm{~g} / \mathrm{cm}^{2}\right)$ These findings support numerous research articles that found lower levels of BMD in adult amenorrheic runners (Drinkwater, 1984, 1994; Drinkwater, Bruemner, \& Chestnut, 1990; Drinkwater, Nelson, Chestnut, Bruemner, \& Shainholtz, 1984; Drinkwater, Nelson, Ott, \& Chestnut, 1986; Nattiv, Agostini, Drinkwater, \& Yeager, 1994). While all of the studies cited examined factors relating to diet and training programs of the subjects, all suggested that decreases in bone mineral density may be due to an interaction of low estrogen levels with some other variable or factor that has not yet been identified. Although it is generally accepted that low estrogen levels are associated with osteoporosis, estrogen's role in bone dynamics is not completely understood. Since estrogen receptors have not been found in bone, it is generally assumed that the estrogen effect is indirect (Drinkwater, et al., 1984). One such indirect route may be the effect of estrogen on calcium balance, since there is ample 
evidence that the lack of estrogen increases daily calcium requirements (Lloyd, et al., 1993).

Other studies (Kanalay, Boileau, Bahr, Misner, \& Nelson, 1992; McLean, Barr, \& Prior, 2001) suggest that a hormonal response in the neuroendocrine system may attenuate the positive effects of exercise on bone in amenorrheic athletes. McLean, et al. (2001) examined the relationships of cortisol levels, exercise, and bone health in 62 eumenorrheic women (Mean Age $\pm \mathrm{SD}=21.7 \pm 2.5$ years). The researchers concluded that higher cortisol levels may reduce the benefits of exercise on bone growth. Kanalay, et al. (1992) investigated the cortisol response of 14 female athletes (Mean Age $\pm \mathrm{SD}=$ $23.7 \pm 1.2$ years), eight eumenorrheic and six amenorrheic, at rest and during 90 minutes of treadmill running at $60 \%$ of $\mathrm{VO} 2 \mathrm{max}$. The researchers concluded that elevated cortisol levels in amenorrheics at rest and throughout exercise provided further evidence that disturbances in the hypothalamic-pituitary-adrenal axis were associated with exerciseassociated amenorrhea.

It is obvious that the relationship between athletic amenorrhea and lower levels of BMD is a complex one. Whether lower levels of BMD in amenorrheics are symptoms of a calcium imbalance, a hormonal response, or a combination of many different factors, the lower levels of BMD in adolescent, amenorrheic athletes place them at greater risk of osteoporosis.

Not only was the eumenorrheic subgroup BMD significantly greater than the amenorrheic subgroup $\operatorname{BMD}\left(\mathrm{F}(1,54)=16.22, \mathrm{p}<.05\right.$, partial $\left.\eta^{2}=.231\right)$, there were also significant differences in the seasonal BMD changes between the subgroups. Figure 5 plots the seasonal changes by subgroup and reveals that the BMD seasonal increase by 
the eumenorrheic subgroup was twice as great as the amenorrheic BMD seasonal increase. Paired t-tests indicated that there was a significant seasonal increase in BMD for the eumenorrheic subgroup $(\mathrm{t}(17)=-3.90, \mathrm{p}<.05)$. That was not the case for the amenorrheic subgroup. Even though the seasonal BMD increased slightly (pre-season $\mathrm{BMD}=1.08 \mathrm{~g} / \mathrm{cc}$; post-season $\mathrm{BMD}=1.09 \mathrm{~g} / \mathrm{cc}$ ) for the amenorrheic subgroup, it did not show a significant seasonal BMD increase $(\mathrm{t}(10)=-1.80, \mathrm{p}<.05)$. Furthermore, while the eumenorrheic subgroup had a significant seasonal increase in BMD z-scores (preseason $\mathrm{z}=+0.91 \mathrm{SD}$; post-season $\mathrm{z}=1.05 \mathrm{SD})$, the seasonal BMD $\mathrm{z}$-scores actually decreased (pre-season $\mathrm{z}=0.25 \mathrm{SD}$, post-season $\mathrm{z}=0.16 \mathrm{SD}$ ) in the amenorrheic subgroup. Figure 6 shows the seasonal z-score changes by subgroup. This indicates that during the season, the BMD of the eumenorrheic subgroup was significantly increasing relative to the U.S. BMD norm, while the BMD of the amenorrheic subgroup was declining relative to the U.S. BMD norm. As previously noted in Chapter 4, BMD zscores were calculated by DXA using U.S. age/weight norms by gender and ethnicity, and specifies the location of a BMD value in reference to the U.S. BMD mean, using standard deviations as a unit of measurement. Furthermore, z-scores are frequently used in the discussion of BMD because z-scores are used to define both osteopenia (BMD zscore $<-1.0$ and $>-2.5$ of the age/weight norm) and osteoporosis (BMD z-score $\leq-2.5$ of the age/weight norm).

The findings of the current study that seasonal BMD increases differ by subgroup are in agreement with previous research by Lee and Lanyon (2004) that concluded that physical activity may not enhance bone growth in amenorrheic athletes. The researchers found that the potential to stimulate bone growth through mechanical loading during the 
pubertal period is associated with marked increases in serum estrogen. In states of relative estrogen deficiency, such as amenorrhea, the bone's adaptive response to mechanical loading failed to maintain appropriate bone mass and architecture (Whalen \& Carter, 1988).

The current study also found subgroup BMD associations were influenced differently by skeletal maturity. In Table 6 Pearson product-moment correlations and partial correlations note BMD associations by subgroup using skeletal maturity as a control. While the Pearson product-moment correlations indicate strong associations among BMD and body composition components in both subgroups (For BMD vs BMC: eumenorrheic $r=.936$, amenorrheic $r=.913$ ), the partial associations by subgroup differ. Partial correlations of the eumenorrheic subgroup reveal strong BMD associations, while the partial correlations of the amenorrheic subgroup show moderate BMD associations (For BMD vs. BMC: eumenorrheic $\rho=.926$, amenorrheic $\rho=.675$ ). Furthermore, multivariate analysis of the current study found eumenorrheic skeletal maturity (eumenorrheic $\mathrm{SM}=98.6 \pm .01 \%$ ) to be significantly greater than the amenorrheic subgroup's skeletal maturity (amenorrheic $\mathrm{SM}=97.1 \pm .02 \%$ ). These findings further support Lee and Lanyon's research (2004) that concluded maturation levels during puberty are associated with the potential to stimulate bone growth through mechanical loading. Consequently, mechanical loading does not appear to enhance bone growth in amenorrheic athletes. Another study (Dhuper et al., 1990) had similar findings. The researchers studied the factors affecting peak bone density in 43 Caucasian females, aged 13-20 years old, and concluded that bone mass in the active, adolescent female was affected by the absence of estrogen exposure. 
Despite the subgroup differences in BMD, paired t-tests indicated that there was an overall significant seasonal increase in BMD $(\mathrm{t}(27)=-4.01, \mathrm{p}<.05)$. These findings support previous research that physical activity promoted bone growth (Janz, et al., 2001; Margulies, Simkin, and Leichter, 1986). Margulies, Simkin, and Leichter (1986) found endurance running had a positive osteogenic effect on lower-body skeletal sites in 53 young adults, aged 18-23 years old. Furthermore, in the Iowa Bone Development Study, Janz et al. studied 368 pre-school children, aged 4-6 years old, and found statistically significant relationships between bone development and physical activity, especially vigorous physical activity; and concluded that physical activity in young children could contribute to optimal bone development.

Findings of similar studies are frequently compared to determine if the findings are in agreement with each other. Although there were no previous studies of adolescent crosscountry runners to compare to the BMD results of the current study, a comparison can be made with a previous study of adult, long distance runners (Drinkwater, et al., 1984). Table 11 provides a comparison of findings from the current study of 28 adolescent cross-country runners and a previous study, Drinkwater et al. (1984), of 28 adult longdistance runners. Both studies used DXA to determine BMDspine. However, the current study employed a Lunar DPX 7979 whole-body densitiometer to measure BMDspine, overall body fat percentage, and overall lean tissue, while the previous study used a regional bone mineral analyzer to measure BMD of the lumbar vertebrae and hydrostatic weighing to estimate body fat percentage and lean body mass, using the Brozek equation, $\mathrm{BF}=100(4.570 / \mathrm{D}-4.142)$. 
Table 11

Physical Characteristics and Training Regimens by subgroup of Adult and Adolescent Long-Distance Runners

Adolescent Runners

(Current study)

$\underline{\text { Amenorrheic } \quad \underline{\text { Eumenorrheic }}}$

Subjects (n)

Age (yr)

Height (cm)

Weight (kg)

Body Fat (\%)

Lean Tissue (kg)

BMDspine (g/cm²)

Training (kmpw)
11

$$
15.5+1.3
$$

$161.4+8.3$

17
$52.2+7.2 \quad 57.3+6.5$

$22.3+5.8 \quad 26.9+4.8$

$37.5+3.5 \quad 38.6+3.7$

$1.09+.14$

$1.23+.12$

$38.0+14.1$

$43.5+16.8$
Adult Runners

(Drinkwater, et al., 1984)

Eumenorrheic

14

14

$24.9+1.3 \quad 25.5+1.4$

$166.1+2.5 \quad 165.7+2.2$

$54.4+2.3$

$57.9+2.2$

$15.8+1.4$

$16.9+0.8$

$45.6+1.6$

$48.0+1.6$

$1.12+0.04$

$1.30+0.03$

$67.3+8.2$

$40.1+4.7$

Before comparing the BMD findings of the adolescent runners with the adult runners, an overview comparison of Table 11 reveals that the adult runners are approximately 10 years older than the adolescent runners. Their weight and height are similar. However, the adult runners are leaner and have less body fat than the adolescent 
runners. The adolescent eumenorrheic and amenorrheic BMD values of the spinal region are very similar to but less than the adult runners' BMDspine. However, given the fact that the adolescents' mean skeletal maturity is $98.06 \pm 1.1 \%$, it is likely that the adolescents' BMDspine could increase to equal or surpass the BMDspine of their adult counterparts. The seasonal BMDspine growth rate computed from the pre- and postBMDspine values from Table 2 reveals that the eumenorrheic adolescent runners could achieve the adult eumenorrheic levels noted in Drinkwater, et al. (1984). However, according to Table 2, the BMDspine seasonal growth rate for the amenorrheic adolescents was virtually zero. Therefore, even if the ammenorrheic adolescents were not at adult maturation levels, it would be difficult to attain the adult amenorrheic levels noted in Drinkwater, et al. (1984) if the mean seasonal spinal BMD ammenorrheic growth rate remained the same.

\section{Bodyweight \& Body Composition}

Bodyweight and body composition components other than BMD were also examined. Although paired t-tests indicated that there were overall significant seasonal increases in bodyweight, body fat, and bone mineral content, multivariate analyses (MANOVA) showed the eumenorrheic subgroup to have significantly greater bodyweight, body fat, bone mineral content, and body mass index.

Although bodyweight and body fat variances between eumenorrheics and amenorrheics within a specific group may not be readily discernable; generally, eumenorrheics tend to have greater bodyweight and body fat than their amenorrheic counterparts. Prior research by Dhuper, et al. (1990) found significantly greater 
bodyweight in eumenorrheic subjects as compared to amenorrheic subjects. The researchers investigated the relationship between estrogen exposure and bone growth in 43 females aged 13-20 years and concluded that bone mass (BMD and BMC) in the female adolescent was negatively affected by lower estrogen levels. The study did not provide body fat information.

Drinkwater, et al. (1990) investigated the relationship of menstrual status to bone mineral density of ninety-seven adult runners (Mean Age $+\mathrm{SD}=27.6+0.7$ years) and found the eumenorrheic runners to have significantly greater BMD and bodyweight than the amenorrheic runners. Body fat information was not provided.

Drinkwater, et al. (1984) also examined the hypoestrogenic status of 14 amenorrheic adult runners as compared to 14 eumenorrheic runners and found that the eumenorrheic runners had significantly greater BMD than the amenorrheic runners. Although the mean bodyweight $(57.9 \pm 2.2 \mathrm{~kg})$ of the eumenorrheic group was greater than the mean bodyweight $(54.4 \pm 2.3 \mathrm{~kg})$ of the amenorrheic group, it was not significantly greater. The same was the case in regard to body fat. While the mean body fat percentage $(16.9 \pm 0.8 \%)$ of the eumenorrheic group was greater than the amenorrheic group $(15.8 \pm 1.4 \%)$, it also was not significantly greater.

In another study, Cobb, et al. (2003) examined the relationships among disordered eating, menstrual dysfunction, and low BMD of 91 adult runners (Mean Age $+\mathrm{SD}=21.7$ \pm 0.3 years; 58 eumenorrheic, 33 amenorrheic), and found similar results. Although the BMD for the eumenorrheic runners was significantly greater than the amenorrheic runners, bodyweight and body fat percentage was not. The mean eumenorrheic bodyweight was $129.1 \pm 1.9$ kilograms, and the mean amenorrheic bodyweight was 128.1 
\pm 2.7 kilograms. The eumenorrheic mean body fat percentage was $23.9 \pm 0.6 \%$, and the amenorrheic mean body fat percentage was $22.7 \pm 1.0 \%$.

Furthermore, results from multivariate covariant analyses (MANCOVA), using skeletal maturity and menarchal age as covariants, suggest that both skeletal maturity and menarchal age influenced changes in bodyweight and body composition. These findings agreed with previous research by Beunen, et al. (1994) who found a significant relationship between maturation levels and body composition in adolescents. The study found that bone growth in adolescent girls was positively correlated with body weight ( $\mathrm{r}$ $=0.64)$, height $(\mathrm{r}=0.78)$, age $(\mathrm{r}=0.53)$, and maturation levels $(\mathrm{r}=0.64)$. However, the positive associations of weight, height, and age with respect to bone development were greatly diminished when maturation levels were controlled. In a related study, Dhuper et al. (1990) found that menarchal age was significantly related to amenorrhea in 43 females aged 13-20 years old.

The associations among menstrual dysfunction and body composition components were also examined. Pearson product-moment correlations were calculated and Table 7 revealed moderate, negative associations between menstrual dysfunction and body composition components. Previous research by Drinkwater, Bruemner, and Chestnut (1990) found an interaction between bodyweight, bone density, and menstrual history. According to Drinkwater, et al. (1990) normal estrogen levels seemed to override any negative effect of decreased bodyweight; however, as menstrual irregularities increased in severity, bodyweight became a more important factor. Dhuper et al. (1990) also found an interdependence between body weight and estrogen exposure on bone density. These findings were also consistent with research by Wolman, et al. (1991) that found a 
relationship between bodyweight and menstrual dysfunction. In a study of 226 elite female adult athletes, the incidence of amenorrhea for size- or weight-sensitive sports was higher than for sports not associated with weight or size. While the incidence rate for the general female population is only $2-5 \%$, non-weight related sports had rates that ranged from $25-33 \%$, and for weight- or size-related sports had rates that ranged from $40-$ $71 \%$ (distance runners - $45 \%$ ).

In addition, partial correlations were calculated for the same associations using menarchal age as a control. Partial correlations revealed a slight negative increase in body composition components that suggest an influence of menarchal age on body composition components and support a previous study (Cobb et al., 2003) of 91 competitive female distance runners, aged 18-26 years old, that menarchal age was associated with menstrual dysfunction.

\section{Performance \& Training Volume}

Post-season run performance of the subjects was examined. While the mean performance results of the $3.2 \mathrm{~km}$ run of the amenorrheic subgroup was 19.8 seconds faster than the mean performance results of the eumenorrheic subgroup, no statistical difference was noted. These results agreed with similar research conducted by DeSouza, Maguire, Rubin, \& Maresh (1990). The purpose of the study was to measure selected physiological and metabolic responses to maximal and submaximal exercise in eumenorrheic and amenorrheic adult runners. The runners performed one VO2max and one submaximal (40 minutes at $80 \% \mathrm{VO} 2 \mathrm{max}$ ) treadmill run. No differences were observed in $\mathrm{VO} 2 \mathrm{max}$ times as well as oxygen uptake, ventilation, heart rate, respiratory exchange ratio, rating of perceived exertion, and plasma lactate for both max and submax 
runs. The conclusion was that menstrual status (eumenorrheic or amenorrheic) did not alter or limit exercise performance in adult, female runners.

Training volume was also investigated and found a moderate, negative association with run performance $(\mathrm{r}=-.663)$. This relationship seems logical because in the current study better performing athletes were assigned to higher volume training groups. Using skeletal maturity as a control, the partial correlation between performance and training volume strengthened $(\rho=-.770)$. Again, this is not surprising. Maturation levels are strongly associated with physical development in adolescents (Zacharias, Rand \& Wurtman, 1976). Furthermore, Beunen, et al. (1994) found that the positive associations of body composition with respect to bone development were greatly diminished when maturation levels were considered. By controlling for this variable, a stronger, more representative association was revealed.

The associations among training volume, body composition, skeletal maturity, and menarche were also examined. Table 9 lists Pearson product-moment correlations of training volume versus body composition components and similar partial correlations using menarche age and skeletal maturity as controls. The current findings agreed with previous research that found SM and MA associations with body composition and training. For example, data from a review (Malina, 1985) of seventeen studies found that menarche occured later in athletes compared to the general population, suggesting that training delays menarche. In addition, studies by Frisch, et al. (1981) and Sidhu and Grewal (1980) found menarchal age occurred later among athletes who began training before menarche as compared to athletes who began training after menarche. Furthermore, Malina (1985) also found menarchal age to be significantly related to 
skeletal maturity. Multivariate analysis of the current study found the eumenorrheic subgroup to have significantly greater skeletal maturity and a significantly younger menarchal age than the amenorrheic subgroup, suggesting an association between greater skeletal maturity and a younger menarchal age.

Another perspective regarding the association between training and later-maturing female athletes is that the characteristics of the late-maturing female are more suitable for successful athletic performance in sports where long legs, physical linearity, lighter bodyweight, and low body fat are an advantage (Malina, 1978). This hypothesis suggests that training does not delay menarche. Conversely, it suggests that later-maturing athletes train more because they are naturally more apt to be successful in the performance of this sport. Whichever hypothesis is correct, training is associated with menarchal age.

Pearson product-moment correlations revealed moderate, positive associations between training volume and body composition components. The partial correlations using menarchal age as a control showed little change in the associations, suggesting that menarchal age did not influence the associations among training volumes and body composition components in the current study. However, the partial correlations using skeletal maturity as a control reduced the associations from moderate to low values. This suggests that skeletal maturity influenced the associations among training levels and body composition components. Considering the strong correlation of skeletal maturity to age ( $\mathrm{r}$ $=0.816$ ), the suggestion seems logical. In the current study older, more mature runners were generally better conditioned and performed better than younger runners, and were assigned to the team's higher-volume training groups. 


\section{Stress Fractures}

Perhaps the most unexpected finding was the absence of a significant difference in stress fractures between the subgroups. Because previous research had found that lower levels of BMD were associated with an increased incidence of stress fractures (Johnson, Weiss \& Wheeler, 1994; Loucks, 1985; Modelesky \& Lewis, 2002; Torstveit \& Sundgot-Borgen, 2005; Warren, 1983), a greater number of stress fractures in the amenorrheic subgroup was expected. However, only three fractures were reported by the 28 runners within the 12 months preceding the post-season analysis, and no statistical difference was noted. Furthermore, of the three stress fractures diagnosed, two stress fractures were diagnosed in eumenorrheic runners and one was diagnosed in an amenorrheic runner. This may suggest that other factors besides bone mineral status plays a role in stress fractures.

The American College of Sports Medicine (February 2000) identified 10 risk factors for stress fractures including: low BMD, training changes, inappropriate footwear, poor running technique, running and jumping activities, muscle inflexibility, muscle weakness, excessive muscle strength, lower extremity alignment anomalies, and previous history of stress fractures. It is obvious that the development of stress fractures is a complex process; however, despite how an athlete is categorized (eumenorrheic or amenorrheic), lower levels of BMD put the athlete at increased risk of stress fracture. For example, research by Drinkwater (1992) found increased incidence in stress fractures in postmenopausal master runners.

Finally, it is interesting to note that, although there was not a significant difference in stress fractures between the subgroups in the current study, $10.7 \%$ (3 of 28 ) 
of the subjects reported that they had stress fractures. This incidence of stress fractures agreed with previous research that $10.7 \%$ of female, collegiate runners suffered from stress fractures (Nattiv, Casper, Abdelkerim, Dory, Hecht, \& Puffer, 2002). Two hundred eleven athletes (116 males, 95 females) on the UCLA track and cross-country teams were followed prospectively from fall 1996 to spring 2001 to investigate the gender difference in stress fracture incidence. The researchers found the incidence of stress fractures for the female athletes was $10.7 \%$ and $5.1 \%$ for the male athletes. In a similar two-year study investigating the incidence of stress fractures in army recruits, Macleod, Houston, Sanders, and Ananostopoulos (1999) found the incidence of stress fractures to be $3 \%$ for men and $10.9 \%$ for women. Not all studies are in agreement with the incidental rate of stress fractures. Bennell, Malcolm, Thomas, Wark, and Brukner (1996) examined the incidence of stress fractures in a 12-month prospective study of 53 female and 58 male track and field athletes, 17-26 years old. The investigators found an overall incidence of stress fractures of $21.1 \%$ with no significant gender differences observed.

\section{Nutritional Supplementation}

Nutritional supplementation of the subjects was examined. Regular, daily ingestion of calcium and vitamin D supplementation was reported by five subjects. Four were eumenorrheic and one was amenorrheic, and no statistical difference was found with respect to nutritional supplementation between the eumenorrheic runners and the amenorrheic runners. Previous research by Lloyd, et al. (1993) found that calcium supplementation of $1,500 \mathrm{mg} /$ day helped maintain proper bone health when the conditions conducive to amenorrhea were present. Another study (Matkovic et al., 1990), 
consisting of thirty-one 14-year old females, suggested that calcium supplementation of $1,800 \mathrm{mg} /$ day may be necessary to overcome the negative imbalance of a regular, unsupplemented diet and the high calcium requirements of increased bone growth and strenuous physical activity. However, all five subjects reported that their nutritional supplementation consisted only of daily multivitamins, and according to the recommendations of the two previous studies, this supplementation was insufficient to provide the calcium necessary to restore the levels reduced by intense physical activity.

\section{Predictor Variable}

Simple linear regressions were calculated to determine what body composition component best predicted BMD for the study. A comparison of coefficients of determination of post-season body composition components (Table 10) indicated that bodyweight was the best BMD predictor variable for the overall group $(\mathrm{F}(1,26)=46.434$, $\left.\mathrm{p}<.05, \mathrm{R}^{2}=0.641\right)$ and for the amenorrheic subgroup $\left(\mathrm{F}(1,9)=14.947, \mathrm{p}<.05, \mathrm{R}^{2}=\right.$ .624). $\mathrm{LT}$ was the best BMD predictor variable for the eumenorrhic subgroup $(\mathrm{F}(1,15)=$ 26.374, $\mathrm{p}<.05, \mathrm{R}^{2}=.637$ ). These findings agreed with the Framingham Study (Felson, et al., 1993) that investigated the effects of bodyweight and BMI on BMD of 693 females and 439 males (mean age $=76.0$ years old) and found that bodyweight and BMI was more strongly associated with women than men. The study concluded that predictor variables for BMD vary depending upon the population in question. Taking this into account, Reid, Planck, \& Evans (1992) found bodyweight was the best BMD predictor variable for premenopausal women (mean age $\pm \mathrm{SD}=33+8$ years), while Madsen, 
Adams, \& Van Loan (1998) found LT to be the best BMD predictor in eumenorrheic athletes (mean age $\pm \mathrm{SD}=20.8 \pm 2.5$ years).

\section{Incidence of Amenorrhea}

The incidence of amenorrhea that was reported in the current study supported the incidental rates from previous research. According to a study of two hundred twenty-six elite female athletes, Wolmann, et al. (1991), found that approximately $45 \%$ of collegiate runners were amenorrheic. Similarly, a study by Drinkwater et al. (1984) found that 25$40 \%$ of highly-trained adult, endurance runners suffered from amenorrhea. The postseason incidental rate of amenorrhea for the current study was reported as $39.2 \%$ (11 of 28). From personal discussions with many local high school cross-country coaches, these figures contradict their belief that, while athletic amenorrhea may be prevalent in collegiate runners, it is not as prevalent in adolescent runners. The fact of the matter is that athletic amenorrhea in adolescent athletes is difficult at best to visually discern. Many coaches conjure images of adolescents with eating disorders, such as anorexia, when they think of amenorrhea. They look at adolescent runners and see very few athletes with extremely low bodyweight and bodyfat and assume that athletic amenorrhea is not prevalent in adolescent runners. They never consider that adolescents that weigh 52 \pm 7 kilograms with $22 \pm 6 \%$ body fat could be amenorrheic. Consequently, the topic and its consequences are rarely discussed in team meetings by coaches, trainers, or team physicians.

It is important to note that the data relating to performance, training volume, menstrual dysfunction, menarchal age, nutritional supplementation, and injury were self- 
reported by the subjects. The validity of this study is dependent upon the accurate reporting of this information.

\subsection{Recommendations for Future Research}

The current study expanded the knowledge base by investigating the relationship of athletic amenorrhea to bone mineral density within the subpopulation of adolescent cross-country runners. After reviewing the findings of the current study, further quantitative investigation is recommended to determine if additional findings can assist in the improvement of the short- and long-term health benefits of female, adolescent athletes.

The scope of the present study provided findings related to bone response during the competitive high-school cross-country season. In order to fully understand bone response in the female, adolescent athlete, investigations must also include bone response during the non-competitive season. By extending the research to include a full cycle of growth, more meaningful findings and a better understanding of bone response as related to female, adolescent athletes can be obtained.

Furthermore, investigation of off-season training behavior is as important as studying the training behavior during the competitive season. The argument could be made that it is more important to study off-season training regimens because of the variability of the subjects' training behavior. While the training regimen for cross-country athletes during the competitive season was relatively constant, the training regimens for the individual athletes during the off-season was not. During this period, training volumes varied widely from more demanding volumes to none at all, depending upon the athlete 
and her commitment to the sport. By incorporating off-season findings with competitive season findings, a full cycle of information would be available for study. It is only by examining the full cycle of data that a thorough understanding of the relationship of athletic amenorrhea and bone mineral density in adolescent, cross-country runners can occur.

Previous research indicated that low levels of bone mineral density were associated with increased levels of stress fractures (Johnson, Weiss \& Wheeler, 1994; Loucks, 1985; Modelesky \& Lewis, 2002; Torstveit \& Sundgot-Borgen, 2005; Warren, 1983). The findings of the current study did not support the research. After reviewing the current findings, a question arises as to whether adolescent cross-country runners who are undergoing rapid bone growth are less at risk of stress fractures than adult athletes, or whether further consideration of the complex nature of stress fractures with its 10 risk factors is required. An increased level of stress fractures is a key element regarding the short-term effects of low levels of bone mineral density and further research is necessary to address this issue with respect to adolescent athletes. Training volume, intensity, and recuperation during and after the season should also be included in the investigation. Additionally, previous research concluded that calcium supplementation can assist women in maintaining proper bone health when the conditions conducive to amenorrhea were present (Lloyd, et al., 1993). The findings of the current study did not support the research. While some of the subjects did report nutritional supplementation, the levels of calcium that they ingested were insufficient to support or refute the research. Verification that calcium supplementation could assist in maintaining proper bone health as related to female, adolescent cross-country runners is important because it could 
reduce the problems associated with the short-term effects of low levels of bone mineral density. Further research is also recommended to address this issue.

The unanswered issues that relate to the short- and long-term health in adolescent athletes can only be addressed by continued research.

\subsection{Implications}

After reviewing the current study, it is important to consider the subjects as well as the findings. The subjects are adolescent athletes and the long-term implication of the results is the increased risk of osteoporosis later in life. In many, if not most, cases the adolescent athlete is more concerned with performance than with the increased risk of osteoporosis years later. The fact of the matter is that improved performance and longterm bone health is not mutually exclusive. Not only is it necessary to caution the athlete of the repercussions of unhealthy training behavior, it is extremely important to promote, educate, and encourage the adolescent athlete to utilize proper training methods so that the healthful benefits of physical activity as well as improved performance are obtained .

\subsection{Summary}

The current study investigated the relationship of athletic amenorrhea and bone mineral density and added to the empirical knowledge base regarding how the relationship relates to adolescent cross-country runners. The sample for this study consisted of 28 female, adolescent, cross-country runners. Data consisted of body composition measurements and self-reported information concerning performance, training volume, menstrual dysfunction, menarchal age, nutritional supplementation, and 
injury. Using statistical and inferential analyses, the current study documented that: lower levels of bone mineral density are associated with athletic amenorrhea in adolescent, cross-country runners; lower levels of bodyweight, body fat, and bone mineral content are also associated with athletic amenorrhea in adolescent cross-country runners; crosscountry running positively enhances bone mineral density in female adolescents; and bodyweight is the best predictor variable for bone mineral density.

This study suggests the need for future research that includes quantitative investigation relating to athletic amenorrhea in adolescent cross-country runners. The study needs to consider the implications of the increased long-term risk of osteoporosis in adolescent cross-country runners and to address the misconception that athletic amenorrhea is not an adolescent problem.

Another area that suggests further examination is the investigation of stress fractures in adolescent athletes. The current study did not reflect an association with lower levels of BMD and stress fractures as previous studies had in adult athletes (Johnson, Weiss \& Wheeler, 1994; Loucks, 1985; Modelesky \& Lewis, 2002; Torstveit \& Sundgot-Borgen, 2005; Warren, 1983). A question arises as to whether adolescent athletes are less at risk of stress fractures than adult athletes or whether further consideration of the complex nature of stress fractures is required. 


\section{References}

Almarwaey, O, Jones, A., and Tolfrey, K. (2003). Physiological correlates with endurance running performance in trained adolescents. Medicine and Science in Sports and Medicine, 35 (3), 480-487.

Barbeau, P., Gutin, B., and Litaker, M. (1999). Physical activity impacts body composition in children. American Journal of Clinical Nutrition, 69, 705-711.

Barrow, G., and Saha, S. (1988). Menstrual irregularity and stress fractures in collegiate female distance runners. American Journal of Sports Medicine, 16, 209-216.

Bayer, M., and Bayley, N. (1976). Growth Diagnosis. In E. Bay, L. Coggeshall, L. Dragstedt, P. De Bruyn, T. Park, and W. Taliaferro (eds): Selected Methods for Interpreting and Predicting Physical Development from One Year to Maturity, Chicago: The University of Chicago Press, pp 217-225.

Beck, B., and Snow, C. (2003). Bone health across the lifespan - exercising our options. Exercise and Sport Sciences Reviews, 31 (3), 117-122.

Bennell, K., Malcolm, S., Thomas, S., Wark, J., and Brukner, P. (1996). The incidence and distribution of stress fractures in competitive track and field athletes: a twelve month prospective study. American Journal of Sports Medicine, 24(2). 211-217.

Beunen, G., Malina, R., Lefevre, J., Claessens, A., Renson, R., and Vanreusel, B. (1994). Adiposity and biological maturity in girls 6-16 years of age. International Journal of Obesity and Related Metabolic Disorders, 18, 542-546.

Block, J., Friedlander, A., Brooks, G., Steiger, P., Stubbs, H., \& Genant, H. (1989). Determinants of bone density among athletes engaged in weight-bearing and non-weight-bearing activity. Journal of Applied Physiology, 67(3), 11001105.

Botwinick, M., Hoy, K., Aulet, M., Gutin, B., Wang, J., and Pierson, R. (1989). Total and regional bone density in female runners. Medicine and Science in Sports and Exercise, 21, S111.

Bullen, B., Skrinar, I., Beitins, G., VonMering, B., Turnball, B., and McArthur, J. (1985). Induction of menstrual disorders by strenuous exercise in untrained women. New England Journal of Medicine, 312, 1349-1353.

Bungum, T., and Vincent, M. (1997). Determinants of physical activity among female adolescents. American Journal of Preventive Medicine, 13, 115-122. 
Cobb, K., Bachrach, L., Greendale, G., Marcus, R., Neer, R., Nieves, J., et al., (2003). Disordered eating, menstrual irregularity, and bone mineral density in females runners. Journal of Medicine and Science in Sports and Exercise, 35 (5), 711-719.

Conroy, B.P. and R.W. Earle. (1994). Bone, muscle and connective tissue adaptations to physical activity. In T.R. Baechle (Ed.), Essentials of Strength Training and Conditioning (pp. 51-66). Champaign: Human Kinetics.

Conroy, B.P., W.J. Kraemer, C.M. Maresh, and G.P. Dalsky. (1992). Adaptive responses of bone to physical activity. Medicine Exercise Nutrition Health, 1, 6474.

Cullen, D., Smith, R., and Akhter, M. (2000). Time course for bone formation with long-term mechanical loading. Journal of Applied Physiology, 88, 19431948 .

DeSouza, M., Maguire, M., Rubin, K. and Maresh, C. (1990). Effects of menstrual phase and amenorrhea on exercise performance in runners. Medicine and Science in Sports and Exercise, 22 (5), 575-580.

Dhuper, S., Warren, M., Brooks-Gunn, W., and Fox, R. (1990). Effects of hormonal status on bone density in adolescent girls. Journal of Clinical Endocrinology and Metabolism, 71 (5) 1083-1088.

Drinkwater, B. (1984). Bone mineral content of amenorrheic and eumenorrheic athletes. New England Journal of Medicine. 311, 277-281.

Drinkwater, B. (1992). Body weight and osteoporosis. In Eating, body weight, and performance in athletes. Disorders of Modern Society. K. Brownell, J. Rodin, and J. Wilmore (Eds.). Philadelphia: Lea \& Febiger.

Drinkwater, B., Bruemner, B., and Chestnut, C. (1990). Menstrual history as a determinant of current bone density in young athletes. Journal of the American Medical Association, 263, 545-548.

Drinkwater, B., Nelson, K., Chestnut, C., Bruemner, W., and Shainholtz, S. (1984). Bone mineral content of amenorrheic and eumenorrheic athletes. New England Journal of Medicine, 311, 277-281.

Drinkwater, B., Nelson, K., Ott, S., and Chestnut, C. (1986). Bone mineral density after resumption of menses in amenorrheic athletes. Journal of Americam Medical Association, 256, 380-382. 
Dueck, C., Matt, K., Manore, M., and Skinner, J. (1996). Treatment of athletic amenorrhea with a diet and training intervention program. International Journal of Sport Nutrition 6, 24-40.

Duncan, C., Blimkie, C., Kemp, A., Higgs, W., Cowell, C., Woodhead, H., et al. (2002). Mid-femur geometry and biomechanical properties in 15- to 18-yr-old female athletes. Medicine and Science in Sports and Exercise, 34 (4), 673-681.

Felson, D., Zhang, Y., Hannan, M., and Anderson, J (1993). Effects of weight and body mass index on bone mineral density in men and women: The Framingham Study. Journal of Bone and Mineral Research, 8 (5), 567-573.

Frisch, R., Gotz-Wilbergen, A., McArthur, J., Albright, T., Witsch, J., and Bullen, B., et al. (1981). Delayed menarche and amenorrhea of college athletes in relation to age of onset of training. Journal of the American Medical Association, 246, 1559-1563.

Fuchs, R., Bauer, J., and Snow, C. (2001). Jumping improves hip and lumbar spine bone mass in prepubescent children: a randomized controlled trial. Journal of Bone Mineral Research, 16, 148-156.

Gordon, K., Perl, M., and Levy, C., (1989). Structural alterations and breaking strength of mouse femora exposed to three activity regimens. Bone, 10, 303-312.

Gutin, B., and Kasper, M. (1992). Can vigorous exercise play a role in osteoporosis prevention. Osteoporosis International, 2, 55-69.

Hallberg, I. (2004). Health-related quality of life after osteoporotic fractures. Osteoporosis International, 15, 834-841.

Hawkins, S., Schroeder, E., Dreyer, H., Underwood, S., and Wiswell, R. (2003). Five-year maintenance of bone mineral density in women master runners. Medicine and Science in Sports and Exercise, 35 (1), 137-144.

Highet, R. (1989). Athletic amenorrhea: an update on etiology, complications, and management. Sports Medicine, 7, 82-108.

Hotta, M., Shibasaki, T., Sato, K., and Demura, H. (1998). The importance of body weight history in the occurrence and recovery of osteoporosis in patients with anorexia nervosa: evaluation by dual X-ray absorptiometry and bone metabolic markers. European Journal of Endocrinology, 139, 276-283.

Janz, K., Burns, T., Torner, J., Levy, R., Willing, M., and Warren, J. (2001). Physical activity and bone measures in young children: The Iowa Bone Development Study. Pediatrics, 107 (6), 1387-1393. 
Johnson, A., Weiss, C., and Wheeler, D. (1994). Stress fractures of the femoral shaft in athletes. American Journal of Sports Medicine, 22, 248-256.

Jones, D., Judd, J., Taylor, P., Campbell, W., and Nair, P. (1987). Influence of dietary fat on menstrual cycle and menses length. Journal of Human Nutrition and Clinical Nutrition, 41C, 341-345.

Kanalay, J., Boileau, R., Bahr, J., Misner, J., and Nelson, R. (1992). Cortisol levels during prolonged exercise: the influence of menstrual phase and menstrual status. International Journal of Sports Medicine, 13 (4), 332-336.

Kannus, P., Haapasalo, H., Sankelo, M., Sievanen, Pasanen, M., Heinonen, A., Oja, P., and Vuori, I. (1995). Effect of starting age of physical activity on bone mass in the dominant arm of tennis and squash players. Annals of Internal Medicine, 123, 27-31.

Karlsson, M., Linden, C., Karlsson, C., Johnell, O., Obrant, K., and Seeman, E. (2000). Exercise during growth and BMD and fractures in old age. Lancet, 355, 469-470.

Kennedy, C. (1999). Childhood Nutrition. Annual Review of Nursing Research, $136-138$.

Khan, K., McKay, H., Haapasalo, H., Bennell, K., Forwood, M., Kannus, P., and Wark, J. (2000). Does childhood and adolescence provide a unique opportunity for exercise to strengthen the skeleton? Journal of Science and Medicine in Sports, 3, 150-164.

Kirchner, E., Lewis, R., and O'Connor, P. (1996). Effect of past gymnastics on adult bone mass. Journal of Applied Physiology, 80, 226-232.

Krowchuk, D., Kreiter, S., and Woods, C., (1998). Problem dieting behaviors among young adolescents. Archives of Pediatric Medicine, 152, 884-888.

Layne, J., and Nelson M. (1999). The effects of progressive resistance training on bone density: a review. Medicine and Science in Sports and Exercise. 31 (1), 2530 .

Lee, K. and Lanyon, L. (2004). Mechanical loading influences bone mass through estrogen receptor $\alpha$. Exercise and Sport Sciences Review, 32 (2), 64-68.

Leighton, G., and Clark, M., (1929). Milk consumption and growth of school children: secondary preliminary report on tests to Scottish Board of Health. Lancet, 1, 40-43. 
Lloyd, T., Andon, M., Rollings, N., Martel, J., Landis, J., Demers, L., et al. (1993). Calcium supplementation and bone mineral density in adolescent girls. The Journal of the American Medical Association, 270 (7), 841-845.

Loucks, A. (1985). Athletic amenorrhea: a review. Medicine and Science in Sports and Exercise. 17, 56-72.

Loucks, A. and Horvath, S. (1984). Exercise-induced stress responses in amenorrheic and eumenorrheic athletes. Journal of Clinical Endocrinological Metablism, 59, 1109-1120.

Loucks, A., Mortola, J., Girton, L., and Yen, S. (1989). Alterations in the hypothalamic-pituitary-ovarian and the hypothalamic-pituitary-adrenal axes in athletic women. Journal of Clinical Endocrinological Metablism, 68, 402-411.

Loucks, A., and Verdun, M. (1998). Slow restoration of LH pulsatility by refeeding in energetically disrupted women. American Journal of Physiology, 44, R1218-R1226.

Loucks, A., Verdun, M., and Heath, E. (1998). Low energy availability, not stress of exercise, alters LH pulsatility in exercising women. Journal of Applied Physiology 84(1), 37-46.

Lutz, J., (1986). Bone mineral, serum calcium, and dietary intakes of mother/daughter pairs. American Journal of Clinical Nutrition, 44, 99-106.

Macleod, M., Houston, A., Sanders, L., and Anagnostopoulos, C. (1999). Incidence of trauma related stress fractures and shin splints in male and female amy recruits: retrospective case study. British Medical Journal, 318, 29.

Madsen, K., Adams, W., and Van Loan, M. (1998). Effects of physical activity, body weight and composition, and muscular strength on bone density in young women. Medicine and Science in Sports and Exercise, 30 (1), 114-120.

Malina, R. (1985). Menarche in athletes: a synthesis and hypothesis. Annals of Human Biology, 10 (1), 1-24.

Malina, R. (1978). Adolescent growth and maturation: selected aspects of current research. Yearbook of Physical Anthropology, 21, 63-94.

Margulies, J., Simkin, A., and Leichter, I., (1986). Effect of intense physical activity on the bone-mineral content in the lower limbs of young adults. Journal of Bone Joint Surgery, 68A, 1090-1093. 
Marieb, E. (1998). Human anatomy \& physiology (4 ${ }^{\text {th }}$ ed., pp.168-184). Menlo Park, CA: Longman.

Maughan, R., Abel, R., Watson, J., and Weir, J., (1986). Forearm composition and muscle function in trained and untrained limbs. Clinical Physiology, 6, 389396.

Matkovic, C., Fontant, D., Tominic, D., Goal, P., and Chestnut, C. (1990). Factors that influence bone mass formation. American Journal of Clinical Nutrition, 52, 878-888.

Matkovic, V., Kostial, K., Simonovic, I., Bradarec, A., and Nordin., B. (1977). Influence of calcium intake, age and sex on bone. Calciferous Tissue Research, 22 (suppl), 393-396.

Mazes, R. (1990). Dual energy x-ray absorptiometry for total-body regional bonemineral and soft-tissue computation. American Journal of Clinical Nutrition, 51, 1106.

McLean, J., Barr, S., and Prior, J. (2001). Dietary restraint, exercise, and bone density in young women: are they related? Medicine and Science in Sports and Exercise, $33(8), 1292-1296$.

McMurray, R., Proctor, C., and Wilson, W. (1991). Effect of caloric deficit and dietary manipulation on aerobic and anaerobic exercise. International Journal of Sports Medicine, 12, 167-172.

Merzenich, H., Boeing, H., and Wahendorf, J. (1993). Dietary fat and sports activityas determinants for age at menarche. American Journal of Epidemiology, $138,217-224$.

Meyer, N., Shaw, J., Manore, M., Dolan, S., Subudhi, A., Schultz, B., and Walker, J. (2004). Bone mineral density of Olympic-level female winter sport athletes, Medicine and Science in Sports and Exercise, 36 (9), 1594-1601.

Modlesky, C., and Lewis, R. (2002). Does exercise during growth have a longterm effect on bone health? Exercise and Sports Sciences Reviews, 30 (4) 171176.

Morrow, J., and Freedman, P. (1994). Relationship between habitual physical activity and aerobic fitness in adolescents. Pediatric Exercise Science, 6, 315-329.

Nattiv, A., Agostini, A., Drinkwater, B., and Yeager, K. (1994). The female athlete triad. Journal of Clinical Sports Medicine, 13, 405-418. 
Nattiv, A., Casper, J., Abdelkerim, A., Dorey, F., Hecht, S., and Puffer, J. (2002). Female track athletes are at greater risk for stress fractures. Medicine \& Science in Sports \& Exercise, 34(5), S157.

Nelson, M., Fisher, E., Dilmanian, F., Dallal, G., and Evans, W. (1991). A one year walking program and increased dietary calcium in postmenopausal women: effects on bone. American Journal of Clinical Nutrition, 53, 1303-1311.

Nevill, A., Burrows, M., Holder, R., Bird, S., and Simpson, D. (2003). Does lower-body BMD develop at the expense of upper-body BMD in female runners? Medicine and Science in Sports and Exercise, 35 (10), 1733-1739.

Newton-John, H., and Morgan, B. (1970). The loss of bone with age: osteoporosis and fractures. Journal of Clinical Orthopedics. 71, 229-232.

Orr, J., (1928). Milk consumption and the growth of school children. Lancet, 1, 202-203.

Peck, W., Riggs, L., and Bell, N. (2004). Physician's Resource Manual on Osteoporosis. Washington, DC. National Osteoporosis Foundation.

Pocock, N., Eisman, J., Hopper, J., Yeates, M., Sambrook, P., and Eberl, S., (1987). Genetic determinants of bone mass in adults: a twin study. Journal of Clinical Investigations, 80, 706-710.

Procter,K., Adams, W., Shafffrath, J., and Van Loan, M. (2002). Upper-limb bone mineral density of female collegiate gymnasts versus controls. Medicine and Science in Sports and Exercise, 34 (11), 1830-1835.

Reid, I., Plank, L., and Evans, M. (1992). Fat mass is an important determinant of whole body bone mineral density in premenopausal women but not in men. Journal of Clinical Endocrinology and Metabolism, 75, 779-782.

Rencken, M., Chestnut, C., and Drinkwater, B., (1996). Bone density at multiple skeletal sites in amenorrheic athletes. Journal of the American Medical Association, 276, 238-240.

Risser, W., Lee, E., and Leblanc, A., (1990). Bone density in eumenorrheic female college athletes. Medicine and Science in Sports and Exercise, 22, 570574.

Sidhu, L., and Grewal, R. (1980). Age of menarche in various categories of Indian sportswomen. British Journal of Sports Medicine, 14, 199-203. 
Smith, D., Nancy, W., Won Kang, K., Christian, J., and Johnston, C., (1973). Genetic factors in determining bone mass. Journal of Clinical Investigations, 52, 2800-2808.

Sothern, M., Loftin, M., Suskind, R., Udall, J., and Blecker, U. (1999). The health benefits of physical activity in children and adolescents: Implications for chronic disease prevention. European Journal of Pediatrics, 158 (4), 271-274.

Stark, O., Peckham, C., and Maynihan, C. (1989). Weight and age at menarche. American Journal of Human Biology, 64, 282-288.

Suominen, H. (1993). Bone mineral density and long term exercise. Sports Medicine, 16, 316-330.

Torstveit, M., and Sundgot-Borgen, J. (2005). The female athlete triad: Are elite athletes at increased risk? Medicine and Science in Sports and Exercise, 37 (2), 184-193.

Turner, C. and Robling, A. (2003). Designing regimens to increase bone strength. Exercise and Sport Sciences Review, 31 (1), 45-50.

Vainionpaa, A. (2004). Effects of high-impact exercise on bone mineral density: a randomized controlled trial of premenopausal women. Osteoporosis International, 15, 767-778.

Vicente-Rodriguez, G., Ara, I., Perez-Gomez, J., Serrano-Sanchez, J., Dorado, C., and Calbet, J. (2004). High femoral bone mineral density accretion in prepubertal soccer players, Medicine and Science in Sports and Exercise, 36 (10), 1789-1795.

Warren, M. (1983). Effects of undernutrition on reproductive function in the human. Endocrinological Review, 4, 363-377.

Warren, M., Brooks-Gunn, J., Hamilton, L., Warren, L., and Hamilton, W., (1986). Scoliosis and fractures in young dancers. New England Journal of Medicine, 314, 1348-1353.

Wells, Christine. (1991). Women, sport and performance. Human Kinetics. p 367.

Whalen, R., and Carter, D. (1988). Influence of physical activity on the regulation of bone density. Journal of Biomechanics, 21, 825-837.

Whitaker, R., Pepe, M., Wright, J., Seidel, K., and Dietz, W. (1998). Early adiposity rebound and the risk of adult obesity. Journal of Pediatrics, 101, 5. 
Williams, N., Young, J., McArthur, J., Bullen, B., Skrinar, G., and Turnbull, J. (1995). Strenuous exercise with caloric restriction: effect on leutinizing hormone secretion. Medicine and Science in Sports and Exercise 27 (10), 1390-1398.

Wolinsky, I. (1994). Nutrition in exercise and sport. CRC press, 508

Wolman, R., Faulmann, L., Clark, P., Hesp, R., and Harries, M. (1991). Different training patterns and bone mineral density of the femoral shaft in elite, female athletes. Annual of Rheumatoid Disorders, 50, 487-489.

Zacharias, L., Rand, W., and Wurtman, R. (1976). A prospective study of sexual development and growth in American girls: the statistics of menarche. Journal of Obstetrics and Gynecology, 31, 325-334.

Zanker, C., Cooke, C., Truscott, J., Oldroyd, B., and Jacobs, H. (2004). Annual changes of bone density over 12 years in an amenorrheic athlete. Medicine and Science in Sports and Exercise, 36 (1), 137-142. 
APPENDIX A - Data Questionnaire 


\section{APPENDIX A}

\section{Data Questionnaire}

(To be completed by participant in study)

Name:

First

Middle

Last

Address:

\section{City}

State

Zip Code

Telephone Number: )-(

Date of Birth:

$$
\overline{\text { Month - Day }}-\text { Year }
$$

Grade in School (Circle one): $9^{\text {th }} \quad 10^{\text {th }} \quad 11^{\text {th }} \quad 12^{\text {th }}$

Height of biological mother: ___ feet ___ inches

Height of biological father: ___ feet __ inches

Do you take the following nutritional supplements?:

Calcium Yes No

if yes, how many milligrams? mg How often? Daily Weekly

Vitamin D Yes No

if yes, how many milligrams? mg How often? Daily Weekly

At what age did you have your first period (menstrual cycle)? years old I have not had my first period

(If you have not had your first period (menstrual cycle), answer the next question "NA")

In the past year, how many periods (menstrual cycles) have you missed?

What is your personal best for the two-mile run? mins secs

During the last season, how many miles/week did you run? miles

Have you been diagnosed with a stress fracture in the last 12 months? 
APPENDIX B - Raw Data 


\section{APPENDIX B}

\section{RAW DATA KEY}

A - prewgt Preseason weight in kilograms

B - prehgt Preseason height in kilograms

C - prebmd Preseason bone mineral density (BMD) in $\mathrm{g} / \mathrm{c}^{2}$

D - bfpc Preseason fat tissue percentage

E - prebf

F - 1tpc

G - prelt

$\mathrm{H}-$ bmcpc

I - bmckg

$\mathrm{J}-$ calgms

$\mathrm{K}-$ prez

L - ageyr

Preseason fat tissue in kilograms

Preseason lean tissue percentage

Preseason lean tissue in kilograms

Preseason bone mineral content percentage

$\mathrm{M}$ - agemos

$\mathrm{N}$ - head

O - arms

$\mathrm{P}-$ legs

Preseason bone mineral content in kilograms

Preseason bone calcium in grams

Q - trunk

$\mathrm{R}$ - ribs

$\mathrm{S}$ - pelvis

Preseason BMD z-scores

Preseason age in years

Preseason age in months

Preseason head BMD

Preseason arm BMD

$\mathrm{T}$ - spine

U - ma

Preseason leg BMD

$\mathrm{V}-\mathrm{cal}$

Preseason trunk BMD

Preseason rib BMD

Preseason pelvic BMD

Preseason spinal BMD

W - vitd

Menarchal age in years

$\mathrm{X}-\mathrm{sm}$

Calcium supplementation ingestion $(0=$ no; $1=$ yes $)$

$\mathrm{Y}$ - groups

Vitamin D or multiple vitamin ingestion $(0=$ no; $1=$ yes $)$

Z - postwgt

Skeletal maturation (\% of adult growth)

AA -posthgt

Eumenorrheic athletes $=1$; amenorrheic athletes $=2$

$\mathrm{AB}$ - postbmd

Post season weight in kilograms

$\mathrm{AC}-$ postbf

Post season height in kilograms

$\mathrm{AD}$ - postlt

Post season BMD in $\mathrm{g} / \mathrm{c}^{2}$

$\mathrm{AE}-$ bmckg2

Post season fat tissue in kilograms

$\mathrm{AF}$ - calgms 2

Post season lean tissue in kilograms

AG - postz

Post season bone mineral content in kilograms

AH - head2

Post season bone calcium in grams

$\mathrm{AI}$ - arms 2

Post season BMD z-scores

AJ - legs 2

Post season head BMD

AK - trunk2

Post season arm BMD

$\mathrm{AL}$ - ribs 2

Post season leg BMD

AM - pelvis 2

Post season trunk BMD

AN - spine2

Post season rib BMD

AO - bfpc 2

Post season pelvic BMD

AP - perf2mi

Post season spinal BMD

AQ - prebmi

Post season fat tissue percentage

AR - postbmi

2-mile personal best performance in minutes

AS - misperi

Preseason body mass index (BMI)

AT - kmpw

Post season body mass index (BMI)

\# of menstrual periods missed in the 12 months preceding post analysis

$\mathrm{AU}-\mathrm{inj}$

Kilometers run per week (training volume)

Diagnosed with stress fractures in the last 12 months, No $=1$, Yes $=2$ 


\section{RAW DATA}

\begin{tabular}{l|cccccccccc|}
\multicolumn{1}{l}{ Sub } & $\mathrm{A}$ & $\mathrm{B}$ & $\mathrm{C}$ & $\mathrm{D}$ & $\mathrm{E}$ & $\mathrm{F}$ & $\mathrm{G}$ & $\mathrm{H}$ & $\mathrm{I}$ & $\mathrm{J}$ \\
\cline { 2 - 10 } 1 & 60.9 & 160.0 & 1.210 & 23.6 & 14.20 & 71.1 & 43.30 & 4.5 & 2.75 & 1044 \\
2 & 54.6 & 159.8 & 1.100 & 23.6 & 12.70 & 71.2 & 38.90 & 4.2 & 2.30 & 879 \\
3 & 51.7 & 152.0 & 1.148 & 17.7 & 8.89 & 75.6 & 39.10 & 4.5 & 2.34 & 890 \\
4 & 50.5 & 158.0 & 1.060 & 27.2 & 13.50 & 67.5 & 34.10 & 4.0 & 2.04 & 773 \\
5 & 61.3 & 161.0 & 1.142 & 33.6 & 20.30 & 61.5 & 37.70 & 4.0 & 2.45 & 931 \\
6 & 65.0 & 170.0 & 1.199 & 26.3 & 17.04 & 68.8 & 44.70 & 4.6 & 3.00 & 1139 \\
7 & 42.6 & 153.5 & 1.055 & 21.1 & 8.82 & 73.2 & 31.20 & 4.3 & 1.84 & 700 \\
8 & 53.6 & 159.5 & 1.079 & 25.7 & 13.60 & 69.2 & 37.10 & 3.9 & 2.10 & 799 \\
9 & 45.2 & 159.5 & 1.060 & 19.2 & 8.57 & 75.0 & 33.90 & 4.6 & 2.06 & 781 \\
10 & 52.3 & 167.8 & 1.038 & 18.4 & 9.55 & 76.5 & 40.00 & 4.3 & 2.25 & 853 \\
11 & 60.8 & 154.5 & 1.184 & 33.0 & 19.80 & 61.8 & 37.60 & 4.4 & 2.69 & 1022 \\
12 & 50.3 & 161.0 & 1.173 & 18.6 & 9.10 & 74.8 & 37.60 & 4.7 & 2.36 & 895 \\
13 & 64.4 & 159.5 & 1.245 & 32.0 & 20.30 & 62.6 & 40.30 & 4.5 & 2.90 & 1117 \\
14 & 61.9 & 159.5 & 1.134 & 33.3 & 20.30 & 61.4 & 38.00 & 4.2 & 2.63 & 998 \\
15 & 59.1 & 161.0 & 1.129 & 31.6 & 18.60 & 64.0 & 37.80 & 4.0 & 2.39 & 908 \\
16 & 52.2 & 161.5 & 1.089 & 25.5 & 13.16 & 69.5 & 36.27 & 4.0 & 2.11 & 800 \\
17 & 45.0 & 154.0 & .937 & 19.8 & 8.79 & 75.1 & 33.79 & 3.8 & 1.73 & 657 \\
18 & 37.3 & 144.0 & 935 & 12.2 & 4.53 & 83.3 & 31.08 & 4.0 & 1.50 & 569 \\
19 & 54.1 & 172.0 & 1.161 & 18.6 & 10.11 & 76.7 & 41.50 & 4.9 & 2.66 & 1009 \\
20 & 54.1 & 171.0 & 1.104 & 20.3 & 10.90 & 74.3 & 40.20 & 4.6 & 2.50 & 946 \\
21 & 61.4 & 154.5 & 1.266 & 29.8 & 18.00 & 64.5 & 39.63 & 4.6 & 2.82 & 1072 \\
22 & 56.5 & 162.5 & 1.250 & 18.3 & 10.16 & 75.4 & 42.60 & 5.0 & 2.80 & 1064 \\
23 & 39.3 & 159.5 & 1.026 & 15.3 & 5.84 & 77.9 & 30.63 & 4.4 & 1.74 & 659 \\
24 & 55.6 & 162.0 & 1.170 & 25.0 & 13.73 & 69.5 & 38.65 & 4.7 & 2.59 & 985 \\
25 & 52.2 & 159.8 & 1.140 & 20.6 & 10.69 & 74.3 & 38.78 & 4.6 & 2.40 & 912 \\
26 & 53.8 & 159.5 & 1.059 & 26.0 & 13.86 & 69.3 & 37.30 & 3.9 & 2.10 & 797 \\
27 & 62.3 & 165.4 & 1.210 & 20.0 & 12.30 & 74.6 & 46.48 & 4.6 & 2.86 & 1085 \\
28 & 55.3 & 161.5 & 1.161 & 27.5 & 15.16 & 67.8 & 37.48 & 4.5 & 2.48 & 941 \\
\hline
\end{tabular}




\section{RAW DATA}

\begin{tabular}{l|llllllllll|}
\multicolumn{1}{l}{ Sub } & \multicolumn{1}{c}{$\mathrm{K}$} & $\mathrm{L}$ & $\mathrm{M}$ & $\mathrm{N}$ & $\mathrm{O}$ & $\mathrm{P}$ & $\mathrm{Q}$ & $\mathrm{R}$ & $\mathrm{S}$ & $\mathrm{T}$ \\
\cline { 2 - 10 } 1 & 1.1 & 18 & 216 & 2.204 & .999 & 1.293 & .973 & .726 & 1.164 & 1.216 \\
2 & .7 & 14 & 177 & 1.941 & .798 & 1.235 & .904 & .678 & 1.116 & 1.158 \\
3 & 1.3 & 14 & 176 & 2.113 & .811 & 1.198 & .950 & .696 & 1.123 & 1.293 \\
4 & -.8 & 16 & 192 & 1.962 & .783 & 1.068 & .896 & .669 & 1.117 & .992 \\
5 & .7 & 15 & 182 & 2.117 & .808 & 1.210 & .949 & .683 & 1.301 & 1.131 \\
6 & .9 & 16 & 201 & 2.080 & .830 & 1.271 & 1.071 & .783 & 1.425 & 1.225 \\
7 & -.9 & 17 & 208 & 1.983 & .775 & 1.083 & .833 & .610 & 1.035 & .949 \\
8 & .4 & 14 & 176 & 1.832 & .739 & 1.218 & .882 & .631 & 1.141 & 1.011 \\
9 & .7 & 13 & 160 & 1.947 & .753 & 1.100 & .874 & .629 & 1.082 & 1.005 \\
10 & -.1 & 14 & 172 & 1.841 & .761 & 1.042 & .926 & .670 & 1.132 & 1.196 \\
11 & 1.7 & 14 & 171 & 2.130 & .830 & 1.254 & 1.022 & .771 & 1.298 & 1.259 \\
12 & 2.1 & 13 & 158 & 2.074 & .797 & 1.244 & .980 & .689 & 1.192 & 1.182 \\
13 & 2.4 & 13 & 157 & 2.219 & .936 & 1.263 & 1.140 & .887 & 1.406 & 1.368 \\
14 & .1 & 17 & 210 & 2.260 & .781 & 1.239 & .944 & .733 & 1.091 & 1.195 \\
15 & 1.1 & 14 & 179 & 1.883 & .794 & 1.209 & .969 & .734 & 1.276 & 1.055 \\
16 & .1 & 15 & 185 & 2.086 & .773 & 1.164 & .881 & .664 & 1.080 & 1.048 \\
17 & -.8 & 13 & 168 & 1.585 & .656 & 1.006 & .783 & .586 & 1.039 & .854 \\
18 & -.9 & 13 & 167 & 1.761 & .728 & .891 & .761 & .607 & .846 & .879 \\
19 & .4 & 17 & 205 & 2.031 & .972 & 1.241 & .953 & .705 & 1.143 & 1.243 \\
20 & .7 & 14 & 168 & 1.803 & .806 & 1.167 & .980 & .715 & 1.139 & 1.326 \\
21 & 1.8 & 16 & 199 & 2.186 & .879 & 1.448 & 1.064 & .776 & 1.306 & 1.395 \\
22 & 1.6 & 17 & 204 & 1.938 & .876 & 1.384 & 1.086 & .769 & 1.409 & 1.224 \\
23 & .3 & 13 & 165 & 1.747 & .690 & 1.110 & .818 & .568 & 1.034 & .953 \\
24 & 1.6 & 14 & 177 & 2.266 & .860 & 1.165 & 1.021 & .755 & 1.245 & 1.274 \\
25 & .2 & 16 & 196 & 2.060 & .742 & 1.271 & .920 & .698 & 1.177 & 1.057 \\
26 & .2 & 14 & 175 & 2.095 & .795 & 1.089 & .847 & .656 & 1.063 & .972 \\
27 & 1.1 & 16 & 202 & 2.055 & .884 & 1.286 & 1.070 & .796 & 1.309 & 1.284 \\
28 & .4 & 17 & 211 & 2.293 & .779 & 1.176 & .997 & .713 & 1.263 & 1.192 \\
\hline
\end{tabular}




\section{RAW DATA}

\begin{tabular}{l|cccccccccc}
\multicolumn{1}{l}{ Sub } & $\mathrm{U}$ & $\mathrm{V}$ & $\mathrm{W}$ & $\mathrm{X}$ & $\mathrm{Y}$ & $\mathrm{Z}$ & $\mathrm{AA}$ & $\mathrm{AB}$ & $\mathrm{AC}$ & $\mathrm{AD}$ \\
\cline { 2 - 10 } 1 & 10 & 0 & 0 & .9958 & 1 & 62.7 & 159.5 & 1.239 & 17.41 & 42.18 \\
2 & 14 & 0 & 0 & .9876 & 1 & 56.4 & 160.0 & 1.169 & 15.64 & 38.62 \\
3 & 13 & 0 & 0 & .9663 & 2 & 54.0 & 152.7 & 1.225 & 13.82 & 38.23 \\
4 & 12 & 0 & 0 & .9934 & 1 & 52.3 & 158.5 & 1.076 & 15.92 & 33.07 \\
5 & 13 & 0 & 0 & .9904 & 1 & 65.0 & 162.0 & 1.187 & 23.50 & 37.90 \\
6 & 14 & 0 & 0 & .9936 & 1 & 68.2 & 170.7 & 1.205 & 19.66 & 44.52 \\
7 & 12 & 0 & 0 & .9922 & 1 & 44.7 & 153.5 & 1.068 & 10.39 & 31.69 \\
8 & 14 & 0 & 0 & .9805 & 2 & 53.5 & 161.5 & 1.106 & 13.14 & 37.44 \\
9 & 12 & 1 & 1 & .9564 & 1 & 48.0 & 163.0 & 1.095 & 8.97 & 36.91 \\
10 & 14 & 0 & 0 & .9749 & 2 & 54.5 & 169.0 & 1.070 & 9.23 & 41.53 \\
11 & 12 & 0 & 0 & .9815 & 1 & 60.5 & 156.0 & 1.172 & 18.31 & 38.27 \\
12 & 12 & 1 & 1 & .9630 & 1 & 51.4 & 161.0 & 1.189 & 11.35 & 37.33 \\
13 & 12 & 0 & 0 & .9806 & 1 & 65.9 & 160.0 & 1.263 & 21.12 & 40.74 \\
14 & 14 & 0 & 0 & .9923 & 2 & 63.6 & 161.5 & 1.150 & 20.79 & 38.52 \\
15 & 13 & 0 & 0 & .9778 & 2 & 57.2 & 162.0 & 1.128 & 16.91 & 38.29 \\
16 & 13 & 0 & 0 & .9888 & 1 & 51.8 & 163.5 & 1.107 & 13.09 & 35.97 \\
17 & 13 & 0 & 0 & .9534 & 2 & 47.7 & 158.0 & .984 & 8.24 & 36.26 \\
18 & 12 & 0 & 0 & .9386 & 2 & 37.7 & 144.0 & .938 & 5.20 & 30.56 \\
19 & 14 & 0 & 0 & .9960 & 2 & 55.5 & 172.7 & 1.155 & 11.39 & 42.08 \\
20 & 10 & 0 & 0 & .9712 & 2 & 55.3 & 171.5 & 1.099 & 12.91 & 39.48 \\
21 & 13 & 0 & 0 & .9989 & 1 & 58.6 & 154.6 & 1.254 & 16.33 & 38.95 \\
22 & 14 & 0 & 0 & .9945 & 1 & 60.5 & 162.3 & 1.273 & 13.90 & 43.40 \\
23 & 13 & 0 & 0 & .9516 & 2 & 42.3 & 162.5 & 1.024 & 7.45 & 32.26 \\
24 & 12 & 0 & 0 & .9847 & 1 & 55.5 & 162.5 & 1.200 & 13.31 & 38.06 \\
25 & 14 & 1 & 1 & .9930 & 2 & 52.3 & 159.7 & 1.121 & 11.40 & 38.12 \\
26 & 12 & 0 & 0 & .9719 & 1 & 53.6 & 159.5 & 1.089 & 14.61 & 35.97 \\
27 & 13 & 1 & 1 & .9936 & 1 & 60.0 & 165.4 & 1.213 & 11.26 & 45.38 \\
28 & 12 & 1 & 1 & .9948 & 1 & 58.6 & 160.0 & 1.160 & 17.46 & 37.77 \\
\hline
\end{tabular}


RAW DATA

\begin{tabular}{l|llllllllll|} 
Sub & AE & AF & AG & AH & AI & AJ & AK & AL & AM & AN \\
\cline { 2 - 9 } 1 & 3.01 & 1143 & 1.4 & 2.476 & .887 & 1.359 & 1.026 & .780 & 1.261 & 1.255 \\
2 & 2.49 & 946 & 1.1 & 2.079 & .823 & 1.337 & .956 & .717 & 1.207 & 1.182 \\
3 & 2.61 & 991 & 1.7 & 2.285 & .851 & 1.280 & 1.030 & .746 & 1.204 & 1.335 \\
4 & 2.17 & 823 & -.6 & 2.074 & .793 & 1.067 & .918 & .682 & 1.112 & 1.174 \\
5 & 2.68 & 1018 & 1.3 & 2.283 & .815 & 1.229 & 1.018 & .759 & 1.235 & 1.261 \\
6 & 3.16 & 1199 & 1.0 & 2.109 & .843 & 1.244 & 1.111 & .807 & 1.346 & 1.363 \\
7 & 1.89 & 718 & -.7 & 2.071 & .778 & 1.066 & .872 & .651 & 1.067 & 1.038 \\
8 & 2.18 & 828 & .3 & 1.845 & .771 & 1.237 & .910 & .662 & 1.218 & 1.006 \\
9 & 2.19 & 830 & 1.1 & 2.060 & .744 & 1.130 & .926 & .638 & 1.109 & 1.197 \\
10 & 2.35 & 894 & .3 & 1.883 & .766 & 1.093 & .956 & .714 & 1.110 & 1.153 \\
11 & 2.71 & 1028 & 1.6 & 2.166 & .833 & 1.233 & .994 & .749 & 1.283 & 1.168 \\
12 & 2.41 & 917 & 2.3 & 2.133 & .789 & 1.252 & 1.003 & .685 & 1.270 & 1.185 \\
13 & 3.01 & 1141 & 2.6 & 2.240 & .959 & 1.268 & 1.159 & .907 & 1.409 & 1.473 \\
14 & 2.62 & 997 & .3 & 2.207 & .800 & 1.233 & .955 & .733 & 1.168 & 1.163 \\
15 & 2.44 & 926 & .5 & 1.923 & .775 & 1.221 & .963 & .716 & 1.187 & 1.112 \\
16 & 2.24 & 850 & .3 & 2.087 & .813 & 1.194 & .895 & .670 & 1.091 & 1.107 \\
17 & 1.91 & 727 & -.8 & 1.614 & .680 & 1.086 & .818 & .619 & 1.077 & .853 \\
18 & 1.53 & 582 & -1.3 & 1.816 & .672 & .883 & .779 & .607 & .866 & .918 \\
19 & 2.69 & 1020 & .4 & 2.130 & .826 & 1.244 & .973 & .721 & 1.160 & 1.200 \\
20 & 2.45 & 932 & .7 & 1.859 & .788 & 1.147 & .981 & .736 & 1.113 & 1.200 \\
21 & 2.77 & 1052 & 1.6 & 2.180 & .889 & 1.380 & 1.063 & .771 & 1.312 & 1.286 \\
22 & 2.90 & 1100 & 1.9 & 2.052 & .876 & 1.385 & 1.121 & .785 & 1.412 & 1.379 \\
23 & 1.83 & 696 & -.3 & 1.792 & .710 & 1.075 & .850 & .594 & 1.078 & 1.028 \\
24 & 2.72 & 1033 & 1.4 & 2.281 & .872 & 1.178 & 1.064 & .795 & 1.320 & 1.267 \\
25 & 2.43 & 925 & -.1 & 2.166 & .737 & 1.247 & .893 & .678 & 1.174 & 1.013 \\
26 & 2.16 & 820 & .0 & 2.090 & .813 & 1.115 & .882 & .669 & 1.137 & 1.013 \\
27 & 2.85 & 1082 & 1.1 & 2.063 & .890 & 1.303 & 1.056 & .769 & 1.242 & 1.373 \\
28 & 2.58 & 981 & .4 & 2.322 & .790 & 1.155 & 1.008 & .741 & 1.204 & 1.252 \\
& & & & & & & & & & \\
\hline
\end{tabular}




\section{RAW DATA}

\begin{tabular}{|c|c|c|c|c|c|c|c|}
\hline Sub & $\mathrm{AO}$ & AP & $\mathrm{AQ}$ & $\mathrm{AR}$ & $\mathrm{AS}$ & AT & $\mathrm{AU}$ \\
\hline 1 & 27.8 & 14.12 & 23.79 & 24.65 & 1 & 64.4 & 1 \\
\hline 2 & 27.6 & 14.50 & 21.38 & 22.01 & 0 & 48.3 & 1 \\
\hline 3 & 25.3 & 14.02 & 22.38 & 23.16 & 4 & 48.3 & 1 \\
\hline 4 & 31.1 & 16.18 & 20.23 & 20.82 & 0 & 32.2 & 2 \\
\hline 5 & 36.7 & 18.00 & 23.65 & 24.77 & 0 & 32.2 & 1 \\
\hline 6 & 29.2 & 13.33 & 22.49 & 23.40 & 1 & 64.4 & 1 \\
\hline 7 & 23.6 & 17.00 & 18.08 & 18.97 & 0 & 48.3 & 1 \\
\hline 8 & 24.9 & 15.52 & 21.07 & 20.49 & 5 & 32.2 & 1 \\
\hline 9 & 18.7 & 14.12 & 17.77 & 18.07 & 0 & 32.2 & 1 \\
\hline 10 & 17.4 & 14.50 & 18.57 & 19.10 & 6 & 32.2 & 1 \\
\hline 11 & 30.9 & 15.32 & 25.47 & 24.84 & 0 & 32.2 & 1 \\
\hline 12 & 22.2 & 15.30 & 19.41 & 19.81 & 2 & 16.1 & 1 \\
\hline 13 & 32.6 & 18.87 & 25.31 & 25.74 & 1 & 16.1 & 1 \\
\hline 14 & 33.6 & 15.33 & 24.33 & 24.40 & 4 & 48.3 & 1 \\
\hline 15 & 29.3 & 16.97 & 22.80 & 21.79 & 4 & 32.2 & 1 \\
\hline 16 & 25.5 & 13.08 & 20.01 & 19.38 & 0 & 48.3 & 1 \\
\hline 17 & 17.8 & 13.42 & 18.97 & 19.12 & 12 & 48.3 & 1 \\
\hline 18 & 13.9 & 17.00 & 17.99 & 18.19 & 6 & 16.1 & 1 \\
\hline 19 & 20.3 & 13.78 & 18.29 & 18.62 & 4 & 64.4 & 1 \\
\hline 20 & 23.5 & 14.23 & 18.50 & 18.79 & 4 & 32.2 & 2 \\
\hline 21 & 28.1 & 15.60 & 25.72 & 24.53 & 1 & 48.3 & 2 \\
\hline 22 & 23.1 & 12.57 & 21.40 & 22.95 & 0 & 64.4 & 1 \\
\hline 23 & 17.9 & 13.92 & 15.45 & 16.01 & 7 & 32.2 & 1 \\
\hline 24 & 24.6 & 17.83 & 21.19 & 21.00 & 2 & 32.2 & 1 \\
\hline 25 & 21.9 & 16.60 & 20.44 & 20.49 & 12 & 32.2 & 1 \\
\hline 26 & 27.7 & 19.08 & 21.15 & 21.08 & 0 & 32.2 & 1 \\
\hline 27 & 18.9 & 13.67 & 22.77 & 21.93 & 1 & 64.4 & 1 \\
\hline 28 & 30.2 & 12.50 & 21.20 & 22.90 & 0 & 64.4 & 1 \\
\hline
\end{tabular}


APPENDIX C - Detailed Results of Paired t-tests 
Paired t-tests were used to determine significant seasonal changes of variables overall and by subgroup. Tables 12 and 13 provide overall and by subgroup the preseason and post-season mean values of the body composition components, respectively; and notes by asterisk in the post-season columns what variables had significant seasonal changes. Table 14 provides the paired t-test results of the body composition variables.

Table 12

Overall Seasonal Changes of Body Composition Components

Physical Characteristics

Subjects $(\mathrm{n}=28)$

$\underline{\text { Variables }}$

Weight $(\mathrm{kg})$

Height $(\mathrm{cm})$

Lean Tissue $(\mathrm{kg})$

Body Fat $(\mathrm{kg})$

Body Fat Percentage (\%)

Bone Mineral Content $(\mathrm{kg})$

BMD $\left(\mathrm{gm} / \mathrm{cm}^{2}\right)$

$\mathrm{BMD}_{\text {spine }}\left(\mathrm{gm} / \mathrm{cm}^{2}\right)$

$\mathrm{BMD}_{\text {pelvis }}\left(\mathrm{gm} / \mathrm{cm}^{2}\right)$

BMDlegs $\left(\mathrm{gm} / \mathrm{cm}^{2}\right)$

BMI $\left(\mathrm{kg} / \mathrm{m}^{2}\right)$

Calcium (gm)

BMD z-score

$$
\text { Preseason (mean }+ \text { SD) } \quad \text { Post-season (mean }+ \text { SD) }
$$

$$
\begin{gathered}
54.1 \pm 7.3 \\
160.1 \pm 5.9 \\
38.1 \pm 3.9 \\
12.9 \pm 4.5 \\
23.7 \pm 5.8 \\
2.4 \pm .4 \\
1.12 \pm .08 \\
1.14 \pm .15 \\
1.17 \pm .13 \\
1.19 \pm .12 \\
21.1+2.6 \\
900.1 \pm 148.4 \\
.65 \pm .9
\end{gathered}
$$

$55.3 \pm 7.1^{*}$

$161.0 \pm 5.9 *$

$38.2 \pm 3.6$

$14.1+4.4$ *

$25.2 \pm 5.6$

$2.5 \pm .4^{*}$

$1.14 \pm .08^{*}$

$1.18 \pm .15^{*}$

$1.19+.12$

$1.20 \pm .11$

$21.3+2.5$

$935.7 \pm 147.7^{*}$

$.70 \pm 1.0$

* - Denotes significant seasonal increase using paired t-tests, $\mathrm{P}<0.05$ 
Table 13

Seasonal Changes of Body Composition Components by Subgroup

\begin{tabular}{|c|c|c|c|c|}
\hline \multirow[b]{3}{*}{$\underline{\text { Variables }}$} & \multicolumn{4}{|c|}{ Physical Characteristics } \\
\hline & \multicolumn{2}{|c|}{$\begin{array}{l}\text { Eumenorrheic Subgroup } \\
\qquad(\mathrm{n}=17)\end{array}$} & \multicolumn{2}{|c|}{$\begin{array}{l}\text { Amenorrheic Subgroup } \\
\qquad(\mathrm{n}=11)\end{array}$} \\
\hline & $\begin{array}{c}\text { Preseason (mean } \\
+\mathrm{SD})\end{array}$ & $\begin{array}{l}\text { Post-season } \\
(\text { mean + SD) }\end{array}$ & $\begin{array}{c}\text { Preseason } \\
(\text { mean }+ \text { SD) }\end{array}$ & $\begin{array}{l}\text { Post-season } \\
(\text { mean }+ \text { SD) }\end{array}$ \\
\hline Weight (kg) & $56.0+6.5$ & $57.3+6.5^{*}$ & $51.0+7.6$ & $52.2+7.2 *$ \\
\hline Height $(\mathrm{cm})$ & $160.2+4.0$ & $160 . \overline{7}+4.1$ & $160.0 \pm 8.3$ & $161.4 \pm 8.3^{*}$ \\
\hline LT (kg) & $38.7 \pm 4.0$ & $38.6 \pm 3.7$ & $37.1 \pm 3.7$ & $37.5 \pm 3.5$ \\
\hline BF (kg) & $14.2 \pm 3.9$ & $15.4 \pm 3.9^{*}$ & $11.1 \pm 4.8$ & $11.9 \pm 4.4$ \\
\hline BF Percentage $(\%)$ & $25.3 \pm 4.9$ & $26.9 \pm 4.8$ & $21.2 \pm 6.5$ & $22.3 \pm 5.8$ \\
\hline $\mathrm{BMC}(\mathrm{kg})$ & $2.5 \pm .36$ & $2.6 \pm .36^{*}$ & $2.2+.39$ & $2.3 \pm .37 *$ \\
\hline $\mathrm{BMD}\left(\mathrm{gm} / \mathrm{cm}^{2}\right)$ & $1.15+.07$ & $1.17 \pm .07 *$ & $1.08+.08$ & $1.09+.06$ \\
\hline BMDspine $\left(\mathrm{gm} / \mathrm{cm}^{2}\right)$ & $1.17 \pm .14$ & $1.23 \pm .12 *$ & $1.10 \pm .16$ & $1.09 \pm .14$ \\
\hline $\begin{array}{l}\text { BMDpelvis } \\
\left(\mathrm{gm} / \mathrm{cm}^{2}\right)\end{array}$ & $1.22 \pm .13$ & $1.24 \pm .11$ & $1.10 \pm .11$ & $1.12 \pm .10$ \\
\hline BMDlegs $\left(\mathrm{gm} / \mathrm{cm}^{2}\right)$ & $1.22 \pm .11$ & $1.23 \pm .10$ & $1.14 \pm .12$ & $1.16 \pm .12$ \\
\hline BMI $\left(\mathrm{kg} / \mathrm{m}^{2}\right)$ & $21.8 \pm 2.4$ & $22.2 \pm 2.3$ & $19.9 \pm 2.6$ & $20.0 \pm 2.4$ \\
\hline Calcium (gm) & $942.7 \pm 137.1$ & $981.2 \pm 137.0^{*}$ & $836.4 \pm 147.8$ & $865.3 \pm 141.1 *$ \\
\hline BMD z-score & $.91 \pm .93$ & $1.05 \pm .92 *$ & $.25 \pm .68$ & $.16 \pm .79$ \\
\hline
\end{tabular}

\footnotetext{
* Denotes significant seasonal increase using paired t-tests, $\mathrm{P}<0.05$
} 
Table 14

Paired t-test Results of Variables, Overall and by Subgroup

\begin{tabular}{|c|c|c|c|c|c|c|}
\hline \multirow[b]{3}{*}{$\underline{\text { Variables }}$} & \multicolumn{4}{|c|}{$\underline{\text { Paired t-test Results }}$} & & \\
\hline & \multicolumn{2}{|c|}{$\begin{array}{l}\text { Subject Group } \\
\quad(\mathrm{n}=28)\end{array}$} & \multicolumn{2}{|c|}{$\begin{array}{l}\text { Eumenorrheic Subgroup } \\
\qquad(\mathrm{n}=17)\end{array}$} & \multicolumn{2}{|c|}{$\begin{array}{l}\text { Amenorrheic Subgroup } \\
\qquad(\mathrm{n}=11)\end{array}$} \\
\hline & $\underline{\mathrm{t} \text {-value }}$ & $\underline{\text { Sig }}$ & $\underline{\mathrm{t} \text {-value }}$ & $\underline{\text { Sig }}$ & $\underline{\text { t-value }}$ & $\underline{\text { Sig }}$ \\
\hline Weight & -3.61 & $.001 *$ & -2.54 & $.022 *$ & -2.67 & $.023^{*}$ \\
\hline Height & -3.59 & $.001 *$ & -1.84 & .085 & -3.55 & $.005^{*}$ \\
\hline BMD & -4.01 & $.000^{*}$ & -3.90 & $.001^{*}$ & -1.80 & .102 \\
\hline Body Fat & -3.29 & $.003^{*}$ & -2.96 & $.009 *$ & -1.50 & .165 \\
\hline Lean Tissue & -0.67 & .508 & 0.23 & .818 & -1.32 & .217 \\
\hline $\mathrm{BMC}$ & -5.85 & $.000^{*}$ & -5.30 & $.000^{*}$ & -2.79 & $.019 *$ \\
\hline Calcium & -5.87 & $.000^{*}$ & -5.18 & $.000 *$ & -2.92 & $.015^{*}$ \\
\hline BMDspine & -2.32 & $.028 *$ & -3.12 & $.007 *$ & 0.42 & .685 \\
\hline BMDpelvis & -1.45 & .159 & -0.87 & .399 & -1.23 & .246 \\
\hline BMDlegs & -1.56 & .131 & -1.03 & .317 & -1.15 & .278 \\
\hline BMD zscore & -0.88 & .389 & -2.51 & $.023 *$ & 0.85 & .414 \\
\hline
\end{tabular}


APPENDIX D - Detailed Results of Multivariate Analyses 


\section{APPENDIX D}

\section{Multivariate Analyses}

Four one-way multivariate analyses of variance (MANOVA) were used to investigate subgroup differences in regard to various dependent variables. First, a oneway MANOVA was conducted to determine subgroup differences between skeletal maturity, age of menarche, age, and performance. The variables of the remaining three MANOVAs consisted of BMD and other body composition components. The remaining three MANOVAs were conducted also yielded significant subgroup differences (Table 15). Analyses of variance (ANOVAs) investigating other dependent variables revealed significant subgroup differences (Table 15) with respect to BMD (Eumenorrheic BMD = $1.17 \pm .07 \mathrm{~g} / \mathrm{cm}^{2}$, Amenorrheic BMD $=1.09 \pm .06 \mathrm{~g} / \mathrm{cm}^{2}, \mathrm{~F}(1,54)=16.22, \mathrm{p}<.05$, partial $\left.\eta^{2}=.231\right), \mathrm{BMD}_{\text {spine }}\left(\right.$ Eumenorrheic $\mathrm{BMD}_{\text {spine }}=1.23 \pm .12 \mathrm{~g} / \mathrm{cm}^{2}$, Amenorrheic BMD spine $=1.09 \pm .14 \mathrm{~g} / \mathrm{cm}^{2}, \mathrm{~F}(1,54)=8.22, \mathrm{p}<.05$, partial $\left.\eta^{2}=.132\right), \mathrm{BMD}_{\text {pelvis }}($ Eumenorrheic $\mathrm{BMD}_{\text {pelvis }}=1.24 \pm .11 \mathrm{~g} / \mathrm{cm}^{2}$, Amenorrheic $\mathrm{BMD}_{\text {pelvis }}=1.12 \pm .10 \mathrm{~g} / \mathrm{cm}^{2}, \mathrm{~F}(1,54)=$ 14.83, $\mathrm{p}<.05$, partial $\eta^{2}=.215$ ), bodyweight (Eumenorrheic $\mathrm{BW}=57.3 \pm 6.5 \mathrm{~kg}$, Amenorrheic $\mathrm{BW}=52.2 \pm 7.2 \mathrm{~kg}, \mathrm{~F}(1,54)=7.65, \mathrm{p}<.05$, partial $\left.\eta^{2}=.124\right), \mathrm{BF}$ $($ Eumenorrheic BF $=15.4 \pm 3.9 \mathrm{~kg}$, Amenorrheic BF $=11.9 \pm 4.4 \mathrm{~kg}, \mathrm{~F}(1,54)=8.56$, $\mathrm{p}<.05$, partial $\left.\eta^{2}=.137\right)$, calcium $($ Eumenorrheic Calcium $=981.2 \pm 137.0 \mathrm{~g}$, Amenorrheic Calcium $=865.3 \pm 141.1 \mathrm{~g}, \mathrm{~F}(1,54)=8.60, \mathrm{p}<.05$, partial $\left.\eta^{2}=.137\right)$, BMI $\left(\right.$ Eumenorrheic BMI $=22.2 \pm 2.3 \mathrm{~kg} / \mathrm{m}^{2}$, Amenorrheic BMI $=20.0 \pm 2.4 \mathrm{~kg} / \mathrm{m}^{2}, \mathrm{~F}(1,54)=$ 9.93, $\mathrm{p}<.05$, partial $\left.\eta^{2}=.155\right)$, and BMC $($ Eumenorrheic $\mathrm{BMC}=2.6 \pm .36 \mathrm{~kg}$, Amenorrheic $\mathrm{BMC}=2.3 \pm .37 \mathrm{~kg}, \mathrm{~F}(1,54)=8.52, \mathrm{p}<.05$, partial $\left.\eta^{2}=.136\right)$. There were no significant subgroup differences with respect to BMDlegs height, and LT. Table 16 
notes the ANOVA results of the various dependent variables from the four MANOVAs that were conducted.

Table 15

MANOVA Results

\begin{tabular}{|c|c|c|c|c|c|}
\hline \multicolumn{6}{|c|}{$\underline{\text { MANOVA Results }}$} \\
\hline MANOVA & $\underline{\text { Wilk's } \lambda}$ & $\underline{F}$ & $\underline{p}$ & $\underline{\eta}^{2}$ & Power \\
\hline 1 & .628 & $(4,51)=5.26$ & $.000 *$ & .372 & .994 \\
\hline 2 & .643 & $(4,51)=7.08$ & $.000 *$ & .357 & .991 \\
\hline 3 & .818 & $(4,51)=2.86$ & $.001 *$ & .182 & .732 \\
\hline 4 & .715 & $(4,51)=5.09$ & $.003 *$ & .285 & .950 \\
\hline
\end{tabular}

$\mathrm{P}<.05 ; *$ - Significant 
Table 16

ANOVA Results

$\underline{\text { ANOVA Results - Group Differences }}$

\begin{tabular}{lccccc}
\multicolumn{1}{r}{ Variable } & Wilk's $\lambda$ & $\underline{\mathrm{F}(1,54)}$ & $\underline{\mathrm{p}}$ & $\underline{\text { Partial } \eta^{2}}$ & $\underline{\text { Power }}$ \\
\cline { 2 - 6 } SM & .628 & 11.68 & $.001^{*}$ & .178 & .919 \\
MA & .628 & 4.46 & $.039^{*}$ & .076 & .545 \\
Age & .628 & 1.86 & .178 & .033 & .268 \\
Performance & .628 & .427 & .516 & .008 & .098 \\
BMD & .643 & 16.22 & $.000^{*}$ & .231 & .977 \\
BMDlegs & .643 & 2.36 & .130 & .042 & .327 \\
BMD spine & .643 & 8.22 & $.006^{*}$ & .132 & .804 \\
BMD pelvis & .643 & 14.83 & $.000^{*}$ & .215 & .966 \\
Weight & .818 & 7.65 & $.008^{*}$ & .124 & .776 \\
Height & .818 & .020 & .888 & .000 & .052 \\
BF & .818 & 8.56 & $.005^{*}$ & .137 & .819 \\
LT & .818 & 1.82 & .183 & .033 & .263 \\
Calcium & .715 & 8.60 & $.005^{*}$ & .137 & .821 \\
BMI & .715 & 9.93 & $.003^{*}$ & .155 & .872 \\
BMC & .715 & 8.52 & $.005^{*}$ & .136 & .818
\end{tabular}

SM - Skeletal Maturity

MA - Menarchal Age

$\mathrm{P}<.05$

* - Significant 
Four multivariate analyses of covariance (MANCOVA) were conducted to determine the effect of skeletal maturity on the eumenorrheic and amenorrheic categories as measured by the dependent variables used in the MANOVA analyses. Table 17 shows three $\left(1^{\text {st }}, 2^{\text {nd }}\right.$, and $\left.4^{\text {th }}\right)$ of the four MANCOVA results yielded significant differences between the two categories, $1^{\text {st }}-\left(\right.$ Wilk's $\lambda=.764, F(3,51)=5.26, \mathrm{p}<.05$, partial $\eta^{2}=$ $.236), 2^{\text {nd }}-\left(\right.$ Wilk's $\lambda=.771, F(4,50)=7.08, p<.05$, partial $\left.\eta^{2}=.229\right)$, and $4^{\text {th }}-($ Wilk's $\lambda$ $=.827, \mathrm{~F}(4,50)=5.09, \mathrm{p}<.05$, partial $\left.\eta^{2}=.173\right)$, respectively. In addition, Table 16 shows the covariate, skeletal maturity, also significantly influenced the combined dependent variable for the three $\left(1^{\text {st }}, 2^{\text {nd }}\right.$, and $\left.4^{\text {th }}\right)$ of the four MANCOVAs, $1^{\text {st }}-($ Wilk's $\lambda=.311$, $\mathrm{F}(3,51)=37.67, \mathrm{p}<.05$, partial $\left.\eta^{2}=.689\right), 2^{\text {nd }}-($ Wilk’s $\lambda=.652, F(4,50)=6.67, p<.05$, partial $\left.\eta^{2}=.348\right)$, and $4^{\text {th }}-\left(\right.$ Wilk's $\lambda=.614, F(4,50)=7.86, p<.05$, partial $\left.\eta^{2}=.386\right)$, respectively. Analyses of covariance (ANCOVA) were conducted on each dependent variable as a follow-up test to the MANCOVAs. Table 18 shows significant category differences were noted for menarchal age (Eumenorrheic MA $=12.5 \pm 1.0 \mathrm{yrs,}$ Amenorrheic MA $=13.1 \pm 1.2$ yrs, $\mathrm{F}(1,53)=10.59, \mathrm{p}<.05$, partial $\left.\eta^{2}=.167\right), \mathrm{BMD}$ (Eumenorrheic $\mathrm{BMD}=1.17 \pm .07 \mathrm{~g} / \mathrm{cm}^{2}$, Amenorrheic BMD $=1.09 \pm .06 \mathrm{~g} / \mathrm{cm}^{2}, \mathrm{~F}(1,53)$ $=5.17, \mathrm{p}<.05$, partial $\left.\eta^{2}=.089\right)$ and $\mathrm{BMD}_{\text {pelvis }}\left(\right.$ Eumenorrheic $\mathrm{BMD}_{\text {pelvis }}=1.24 \pm .11$ $\mathrm{g} / \mathrm{cm}^{2}$, Amenorrheic $\mathrm{BMD}_{\text {pelvis }}=1.12 \pm .10 \mathrm{~g} / \mathrm{cm}^{2}, \mathrm{~F}(1,53)=5.24, \mathrm{p}<.05$, partial $\eta^{2}=$ $.090)$. 
Table 17

MANCOVA Results with SM as Covariate

\begin{tabular}{|c|c|c|c|c|c|}
\hline \multicolumn{6}{|c|}{ MANCOVA Results } \\
\hline \multicolumn{6}{|c|}{$\begin{array}{c}\text { Controlled } \\
\text { for } \\
\text { Skeletal Maturity (SM) } \\
\end{array}$} \\
\hline MANCOVA & $\underline{\text { Wilk's } \lambda}$ & $\underline{F}$ & $\mathrm{p}$ & $\underline{\eta}^{2}$ & Power \\
\hline \#1 - Group & .764 & $(3,51)=5.26$ & $.003 *$ & .236 & .909 \\
\hline Covariate & .311 & $(3,51)=37.67$ & $.000 *$ & .689 & 1.00 \\
\hline \#2 - Group & .771 & $(4,50)=7.08$ & $.010^{*}$ & .229 & .852 \\
\hline Covariate & .652 & $(4,50)=6.67$ & $.000 *$ & .348 & .987 \\
\hline \#3 - Group & .906 & $(4,50)=2.86$ & .286 & .094 & .374 \\
\hline \#4 - Group & .827 & $(4,50)=5.09$ & $.046^{*}$ & .173 & .691 \\
\hline Covariate & .614 & $(4,50)=7.86$ & .000 & .386 & .996 \\
\hline
\end{tabular}


Table 18

ANCOVA Results with SM as Covariate

\begin{tabular}{|c|c|c|c|c|c|c|}
\hline \multicolumn{7}{|c|}{ ANCOVA Results - Group Differences } \\
\hline \multicolumn{7}{|c|}{ Follow-up Tests from MANCOVA } \\
\hline \multicolumn{7}{|c|}{$\begin{array}{l}\text { Controlled } \\
\text { for } \\
\text { Skeletal Maturity }\end{array}$} \\
\hline MANCOVA & $\begin{array}{l}\text { Dependent } \\
\text { Variables }\end{array}$ & Wilk's $\lambda$ & $\underline{F(1,53)}$ & $\underline{p}$ & $\underline{\text { Partial } \eta^{2}}$ & $\underline{\text { Power }}$ \\
\hline$\# 1$ & MA & .764 & 10.59 & $.002 *$ & .167 & .891 \\
\hline$\# 1$ & Age & .764 & 3.86 & .055 & .068 & .487 \\
\hline$\# 1$ & Performance & .764 & .917 & .343 & .017 & .156 \\
\hline$\# 2$ & BMD & .771 & 5.17 & $.027 *$ & .089 & .607 \\
\hline \#2 & BMDlegs & .771 & .005 & .943 & .000 & .051 \\
\hline$\# 2$ & BMD spine & .771 & 2.14 & .149 & .039 & .301 \\
\hline$\# 2$ & $\mathrm{BMD}_{\text {pelvis }}$ & .771 & 5.24 & $.026^{*}$ & .090 & .613 \\
\hline$\# 4$ & Calcium & .827 & .925 & .340 & .017 & .157 \\
\hline$\# 4$ & BMI & .827 & 2.53 & .118 & .046 & .345 \\
\hline$\# 4$ & $\mathrm{BMC}$ & .827 & .889 & .350 & .016 & .153 \\
\hline
\end{tabular}

MA - Menarchal Age

$\mathrm{P}<.05$

* - Significant

Additionally, four multivariate analyses of covariance (MANCOVA) were

conducted to investigate subgroup differences using skeletal maturity and menarchal age as covariates. Table 19 shows only one group $\left(2^{\text {nd }}\right)$ of the four MANCOVA results yielded significant differences between the eumenorrheic and amenorrheic categories, $2^{\text {nd }}$ $-\left(\right.$ Wilk's $\lambda=.789, F(4,49)=3.28, p<.05$, partial $\left.\eta^{2}=.211\right)$. The covariate, skeletal 
maturity, also significantly influenced the combined dependent variable for the second MANCOVA, $2^{\text {nd }}-\left(\right.$ Wilk's $\lambda=.675, F(4,49)=5.89, p<.05$, partial $\left.\eta^{2}=.325\right)$. The other covariate, menarchal age, did not significantly influence the combined dependent variable. Analyses of covariance (ANCOVA) were conducted on each dependent variable of the second MANCOVA as a follow-up test. Table 20 shows significant category differences were found for $\mathrm{BMD}_{\text {pelvis }}\left(\right.$ Eumenorrheic $\mathrm{BMD}_{\text {pelvis }}=1.24 \pm .11 \mathrm{~g} / \mathrm{cm}^{2}$, Amenorrheic $\mathrm{BMD}_{\text {pelvis }}=1.12 \pm .10 \mathrm{~g} / \mathrm{cm}^{2}, \mathrm{~F}(1,52)=6.76, \mathrm{p}<.05$, partial $\left.\eta^{2}=.115\right)$.

Table 19

MANCOVA Results with SM \& MA as Covariates

\section{MANCOVA Results}

Controlled

for

$\underline{\text { Skeletal Maturity (SM) \& Menarchal Age (MA) }}$

\begin{tabular}{|c|c|c|c|c|c|}
\hline MANCOVA & $\underline{\text { Wilk's } \lambda}$ & $\underline{F}$ & $\mathrm{p}$ & $\underline{\eta^{2}}$ & Power \\
\hline \#1 - Group & .916 & $(2,51)=2.33$ & .108 & .084 & .450 \\
\hline \#2 - Group & .789 & $(4,49)=3.28$ & $.019 *$ & .211 & .799 \\
\hline Covariate - SM & .675 & $(4,49)=5.89$ & $.001 *$ & .325 & .974 \\
\hline Covariate - MA & .886 & $(4,49)=1.58$ & .196 & .114 & .450 \\
\hline \#3 - Group & .926 & $(4,49)=.980$ & .427 & .074 & .287 \\
\hline \#4 - Group & .835 & $(4,49)=.061$ & .061 & .165 & .651 \\
\hline
\end{tabular}


Table 20

ANCOVA Results with SM \& MA as Covariates

\begin{tabular}{|c|c|c|c|c|c|c|}
\hline \multicolumn{7}{|c|}{ ANCOVA Results - Group Differences } \\
\hline \multicolumn{7}{|c|}{ Follow-up Tests from MANCOVA } \\
\hline \multicolumn{7}{|c|}{$\begin{array}{c}\text { Controlled } \\
\text { for } \\
\text { Skeletal Maturity \& Menarchal Age } \\
\end{array}$} \\
\hline MANCOVA & $\begin{array}{c}\text { Dependent } \\
\text { Variables }\end{array}$ & $\begin{array}{c}\text { Wilk's } \\
\underline{\lambda}\end{array}$ & $\underline{\mathrm{F}(1,52)}$ & $\underline{p}$ & $\underline{\text { Partial } \eta^{2}}$ & Power \\
\hline$\# 2$ & BMD & .789 & 4.01 & .051 & .072 & .502 \\
\hline$\# 2$ & BMDlegs & .789 & .028 & .867 & .001 & .053 \\
\hline$\# 2$ & $\mathrm{BMD}_{\text {spine }}$ & .789 & 1.03 & .315 & .019 & .169 \\
\hline$\# 2$ & BMD pelvis & .789 & 6.76 & $.012 *$ & .115 & .723 \\
\hline
\end{tabular}


APPENDIX E - Human Subjects Approval 


\section{APPENDIX E}

\section{University Committee for the Protection of Human Subjects in Research University of New Orleans}

\section{Form Number: $06 \mathrm{dec} 03$}

(please refer to this number in all future correspondence concerning this protocol)

Principal Investigator: J. Mark Loftin

Title: Professor

Department: HPHP College: Education

Project Title: A comparison of bone minetal density of adolescent female high school cross-country runners before and after a competitive season

Dates of Proposed Project Period From

$9 / 1 / 05$

to

$8 / 30 / 06$

Approval Status:

\section{$\square$ Full Board Review}

$\square$ Expedite

$\square$ Exempt

\section{(40) Approved Date: 8/11/05}

Deferred Date:

Disapproved Date:

Project requires review more than annually. Review every months.

*approval is for 1 year from approval date only and may be renewed yearly.

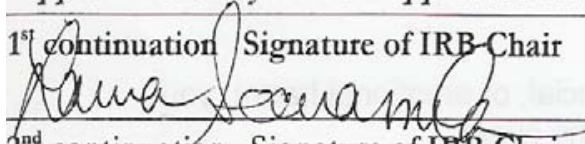

$2^{\text {nd }}$ continuation Signature of IRB Chair

Date:

$2^{\text {nd }}$ continuation Signature of IRB Chair

$3^{\text {rd }}$ continuation Signature of IRB Chair

Date:

$4^{\text {th }}$ continuation Signature of IRB Chair

Date:

Committee Signatures:

Laura Scaramella, Ph.D. (Chair)

Pamela Jenkins, Ph.D.

Anthony Kontos, Ph.D. (Associate chair)

Richard B. Speaker, Ph.D.

Gary Talarchek, Ph.D.

Kari Walsh

Kathleen Whalen, LSW

L. Allen Witt, Ph.D. 
APPENDIX F - Informed Consent Form 


\section{APPENDIX F}

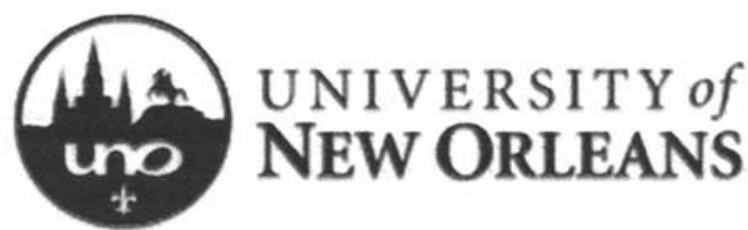

\section{Informed Consent}

1. Title of the Research Study:

Body Composition Changes in Adolescent Female High School Cross-Country Runners Before and After a Competitive Season

\section{Director of the Project:}

Marc Bonis, (985) 649-0111 or mbonis@uno.edu, is presently a doctoral student at the University of New Orleans, in the Curriculum and Instruction Program. The research being conducted in this study is being completed in partial fulfillment of doctoral program requirements under the supervision of Dr. J. Mark Loftin - Chair, Human Performance and Health Promotion Department, University of New Orleans, New Orleans, Louisiana 70148. Phone: (504) 2806417. E-mail jloftin@uno.edu.

\section{Purpose of This Research Study:}

The study is to compare the bone mineral density (BMD) of adolescent female high school cross-country runners before and after a competitive season from an elite female cross-country high school program in New Orleans. While in training, female athletes can stress their body to such an extent that their menstrual cycle can be disrupted or cease to function. This can result in the reduction or cessation in the production of estrogen, an important hormone for bone growth. Females, who are experiencing this condition and undergoing rapid bone growth, may suffer from insufficient levels of bone mineral density attained during the adolescent period of growth. This may cause stress fractures in the short-term and increase the risk of osteoporosis later in life.

\section{4. $\quad$ Procedures for the Research Study}

As a participant in the study your daughter will be asked to do the following: 
A. Have her height and weight measured prior to the DXA scan during and after the season.

B. Have her body composition measured during and after the season

using a device called a DXA (Dual energy X-ray Absorptiometry) whole body densitometer. This device measures your daughter's percent body fat, lean tissue mass, bone mineral content, and bone mineral density. The DXA requires your daughter to lay on her back on the scan table while the DXA scans your daughter's entire body. The DXA procedure lasts approximately 15-20 minutes, depending upon the subject's height and weight. Your daughter should wear gym shorts and t-shirt or other casual or sports clothing. All scans and analyses will be performed by the program director, Marc Bonis, under the supervision of Dr. J. Mark Loftin - Chair, Human Performance and Health Promotion Department.

C. While the risk of harm from radiation with the DXA procedure is extremely small, the long-term effects of exposure to a fetus is not known. Therefore, as a purely precautionary measure, your daughter will be screened for the presence of human chorionic gonadotropin (HCG) using a standard urine-based pregnancy kit. She will be asked to provide a urine sample. If she tests "positive" for HCG, she will not be scanned.

D. Respond to questions about her training regimen, performance, injuries, nutritional supplements ingested, and maturational status.

Height, weight, and DXA measurements will be conducted on the UNO campus at the Department of Human Performance and Health Promotion at the student/athlete's convenience after school or on weekends. Both of the research study visits to UNO should last approximately 45 minutes to an hour.

\section{5. $\quad$ Potential Risks or Discomforts}

The risks involved in this study include few discomforts and an extremely small level of radiation exposure from the DXA machine. The actual amount of radiation emitted from a total body scan is $0.2 \mathrm{uSv}$, which in practical terms is much less than the amount received during a cross-country airplane trip. While the risk of harm from radiation with the DXA procedure is extremely small, the long-term effects of exposure to a fetus is not known. Therefore, as a purely precautionary measure, your daughter will be screened for the presence of human chorionic gonadotropin (HCG) using a standard urine-based pregnancy kit. She will be asked to provide a urine sample. If she tests "positive" for HCG, she will 
not be scanned and will be counseled to inform her physician that she has tested positive for HCG.

If your daughter is scanned and the DXA results indicate a bone mineral density less than the acceptable range for subjects in her age group, she will be counseled to inform her physician regarding her bone mineral density.

Should you have questions or concerns, or wish to discuss possible risks or discomforts, please contact Marc Bonis, project director, at (985) 649-0111 or mbonis@uno.edu; or Mark Loftin, faculty supervisor, at (504) 280-6417 or jloftin@uno.edu. If you have any questions about your rights as a research participant, please contact the University Of New Orleans Institutional Review Board at (504) 280-6420.

If you do not have questions now, you may ask questions later. During the study you may have questions that could affect whether you want your daughter to stay in the study. If so contact Marc Bonis, project director, at (985) 649-0111 or mbonis@uno.edu; or Mark Loftin, faculty supervisor, at (504) 280-6417 or jloftin@uno.edu. If you have any questions about your rights as a research participant, please contact the University Of New Orleans Institutional Review Board at (504) 280-6420.

\section{6. $\quad$ Potential Benefits to You or Others}

The results of the investigation will advance our knowledge of the effect of crosscountry programs on bone mineral density of female adolescent athletes. In appreciation of your daughter's participation, she will receive the results of her body composition measurement that if done in a clinical environment would cost $\$ 300$ - \$500, depending upon the facility.

\section{Alternative Procedures:}

There are no alternative procedures for this research. Participation in this study is completely voluntary, and you may withdraw consent and terminate participation at any time without consequence. Your daughter may choose not to participate in any individual measurement activity or to withdraw from the entire study at any time, for whatever reason. If you decide to withdraw your daughter from the study, the information and data collected will be kept in a confidential manner. Your decision on whether to let your daughter participate will not jeopardize your future relations with Mount Carmel High School or the University of New Orleans. 


\section{8. $\quad$ Protection and Confidentiality}

All data collected during this study, including your address and phone number will be strictly confidential. School personnel (principal, administrators, teachers, etc.) will not have access to any information pertaining directly to your daughter. Data will be stored in locked file cabinets and protected computer files at the University of New Orleans. Participants will never be identified in any reports, papers, or publications from this study. A subject identification number will be assigned to each participant at the beginning of the study and this number will be used for record keeping and data analysis.

\section{9. $\quad$ Signatures and Consent to Participate}

I have been fully informed of the above described research procedures with the possible benefits and risks, and I have given my permission for my daughter to participate in this study.

Signature of Parent or Guardian

Signature of Project Director $\overline{\text { Name of Parent or Guardian (PRINT) }} \quad \overline{\text { Date }}$

Name of Project Director (PRINT)
Date 
APPENDIX G - Child's Assent Form 


\section{APPENDIX G}

\section{CHILD'S ASSENT FORM}

\section{Body Composition Changes in Adolescent Female High School Cross-Country Runners Before and After a Competitive Season}

My parent or guardian has said it is okay for me to participate in this project. This project will study the bone mineral density changes before and after the cross-country season. I understand that if I agree to participate in this project, I will be asked to do the following procedures:

1. Have your height and weight measured during and after the cross-country season.

2. Have your body composition measured during and after the season using a device called a DXA (Dual energy X-ray Absorptiometry)whole body densitometer. This device measures your percent body fat, lean tissue mass, bone mineral content, and bone mineral density. The DXA procedure lasts approximately 15-20 minutes, depending upon your height and weight. You should wear gym shorts and t-shirt or other casual or sports clothing. All scans and analyses will be performed by the program director, Marc Bonis, under the supervision of Dr. J. Mark Loftin - Chair, Human Performance and Health Promotion Department.

3. As a precautionary measure for the DXA scan, be screened for human chorionic gonadotropin (HCG) using a standard urine-based pregnancy kit. You will be asked to provide a urine sample. If you test "positive", you will not be allowed to participate in the study.

4. Respond to questions about my training regimen, other physical activities, injuries, medication, nutritional supplements ingested, and maturational status.

Height, weight, and DXA measurements will be conducted on the UNO campus at the Department of Human Performance and Health Promotion at the student/athlete's convenience after school or on weekends. Each visit should last approximately 45 minutes to an hour.

Being in this project is up to me. I can choose to quit or ask to stop at any time. Also, if I do not like any of the questions, I do not have to answer them. Only the university people working on this project will see my data. No one will be upset if I don't want to be in the 
project, it will not affect my position on the team, my grades or what my teachers or coaches think of me.

Should you have questions or concerns, or wish to discuss possible risks or discomforts, please contact Marc Bonis, project director, at (985) 649-0111 or mbonis@uno.edu; or Mark Loftin, faculty supervisor, at (504) 280-6417 or jloftin@uno.edu. If you have any questions about your rights as a research participant, please contact the University Of New Orleans Institutional Review Board at (504) 280-6420.

If you do not have questions now, you may ask questions later. During the study you may have questions that could affect whether you want your daughter to stay in the study. If so contact Marc Bonis, project director, at (985) 649-0111 or mbonis@uno.edu; or Mark Loftin, faculty supervisor, at (504) 280-6417 or jloftin@uno.edu. If you have any questions about your rights as a research participant, please contact the University Of New Orleans Institutional Review Board at (504) 280-6420.

Please mark one of the choices below to tell us what you want to do: Yes, I want to be in this project. No, I don't want to be in this project.

By signing my name below, I agree to be in this project.

Signature of Participant

Signature of Project Director
Name of Participant (PRINT)

Name of Project Director (PRINT)
Date

Date 


\section{Vita}

Marc Bonis was born in New Orleans on December 16, 1946. He graduated from Jesuit High School of New Orleans in 1964. He received his Bachelor of Science degree in physics from Loyola University of New Orleans in 1968. In 1980, he received his Master of Business Administration degree with a concentration in organizational behavior from Tulane University. He received his Master of Arts degree in human performance and health promotion with a concentration in exercise physiology from the University of New Orleans in 2002. 